\title{
Gastrointestinale Tumore - interdisziplinäre Diskussion neuer Daten
}

\author{
Teilnehmer des XI. Interdisziplinären Workshops «Gastrointestinale Tumore»: \\ Dirk Arnold $^{\mathrm{a}}$ Rainer Fietkau ${ }^{\mathrm{b}}$ Susanna Hegewisch-Becker ${ }^{\mathrm{c}}$ Thomas Höhler $^{\mathrm{d}}$ \\ Wolfram Trudo Knoefe ${ }^{\mathrm{e}}$ Stefan Kubicka ${ }^{f}$ Hauke Lang $^{g}$ Torsten Liersch $^{\mathrm{h}}$ Markus Luster \\ Helmut Oettle ${ }^{k}$ Anke Reinacher-Schick' Karsten Ridwelskim Hanno Riess ${ }^{n} \quad$ Claus Rödel $^{\circ}$ \\ Josef Rüschoff ${ }^{p}$ Wolff Schmiegel' Hans-Joachim Schmoll ${ }^{q}$ Udo Vanhoefer ${ }^{r}$
}

${ }^{a}$ Universitäres Cancer Center Hamburg, Universitätsklinikum Hamburg-Eppendorf,

${ }^{\mathrm{b}}$ Klinik für Strahlentherapie, Universitätsklinik Erlangen,

c Onkologische Schwerpunktpraxis, Hamburg-Eppendorf,

${ }^{d}$ Medizinische Klinik I, Prosper-Hospital, Recklinghausen,

${ }^{\text {e }}$ Klinik für Allgemein- und Viszeralchirurgie, Universitätsklinikum Düsseldorf,

f Abteilung Gastroenterologie, Hepatologie und Endokrinologie, Medizinische Hochschule Hannover,

${ }^{9}$ Klinik für Allgemein- und Abdominalchirurgie, Universitätsmedizin Mainz,

${ }^{\text {h }}$ Klinik für Allgemein- und Viszeralchirurgie, Klinische Forschergruppe 179, Universitätsmedizin Göttingen,

' Klinik für Nuklearmedizin, Universität Ulm,

${ }^{k}$ Charité Zentrum für Tumormedizin, Berlin und Onkologische Schwerpunktpraxis, Friedrichshafen,

' Medizinische Universitätsklinik, Knappschaftskrankenhaus, Ruhr-Universität Bochum,

${ }^{m}$ Klinik für Allgemein- und Viszeralchirurgie, Klinikum Magdeburg,

${ }^{n}$ Universitätsklinik Charité, Virchow Klinikum, Charité Centrum für Tumormedizin, Hämatologie/Hämostaseologie/Onkologie, Universitätsmedizin Berlin,

${ }^{\circ}$ Klinik für Strahlentherapie und Onkologie, Universität Frankfurt am Main,

${ }^{\mathrm{P}}$ Institut für Pathologie Nordhessen und Targos Molecular Pathology GmbH, Kassel,

a Klinik für Innere Med. IV, Onkologie/ Hämatologie, Universitätsklinikum Halle (Saale),

r Zentrum Innere Medizin, Kath. Marienkrankenhaus, Hamburg, Germany

\section{Einleitung}

Der XI. Interdisziplinäre Expertenworkshop «Gastrointestinale Tumore», an dem 19 Vertreter der Fachbereiche internistische Onkologie, Gastroenterologie, Strahlentherapie, Chirurgie, Nuklearmedizin und Pathologie teilnahmen, bot einen Überblick über den aktuellen Stand der Wissenschaft im Bereich der gastrointestinalen Karzinome, wobei der Schwerpunkt auf dem Kolon-/Rektum- und Magenkarzinom lag, da in diesen Bereichen die meisten neuen Entwicklungen zu verzeichnen waren.

Der Workshop versteht sich als ein interaktives Diskussionsforum zur aktuellen Standortbestimmung von Diagnostik und Therapie sowie zur Thesengenerierung für neue wissenschaftliche und therapeutische Ansätze.

Schwerpunkte der diesjährigen Veranstaltung waren zum einen die adjuvante Therapie des Kolonkarzinoms und die
First-Line-Therapie des metastasierten kolorektalen Karzinoms, denn in diesen Indikationen haben neue Studiendaten jetzt eine weitere Klärung des Therapiealgorithmus herbeigeführt. Darüber hinaus war die perioperative Therapie bei Lebermetastasen ein wichtiges Thema, zu dem aktuelle Studienkonzepte vorgestellt wurden. Des Weiteren wurde die HER2Diagnostik beim Magenkarzinom intensiv diskutiert, denn diese unterscheidet sich deutlich von der beim Mammakarzinom. Bei korrekter Diagnostik ist das HER2-positive Magenkarzinom offenbar deutlich weiter verbreitet als bisher angenommen. Viel Beachtung fanden auch die Ergebnisse von 2 aktuellen Phase-III-Studien beim Pankreaskarzinom, die das therapeutische Vorgehen verändern werden und erstmals seit langem einen Fortschritt bei diesem schwer therapierbaren Tumor bedeuten dürften.

Die wichtigsten Ergebnisse der 2-tägigen Diskussionsrunde sind im vorliegenden Supplement zusammengefasst.

\section{KARGER}

Fax +49 7614520714

Information@Karger.de

www.karger.com
(C) 2011 S. Karger GmbH, Freiburg

0378-584X/11/3415-0001\$38.00/0

Accessible online at:

www.karger.com/onk 


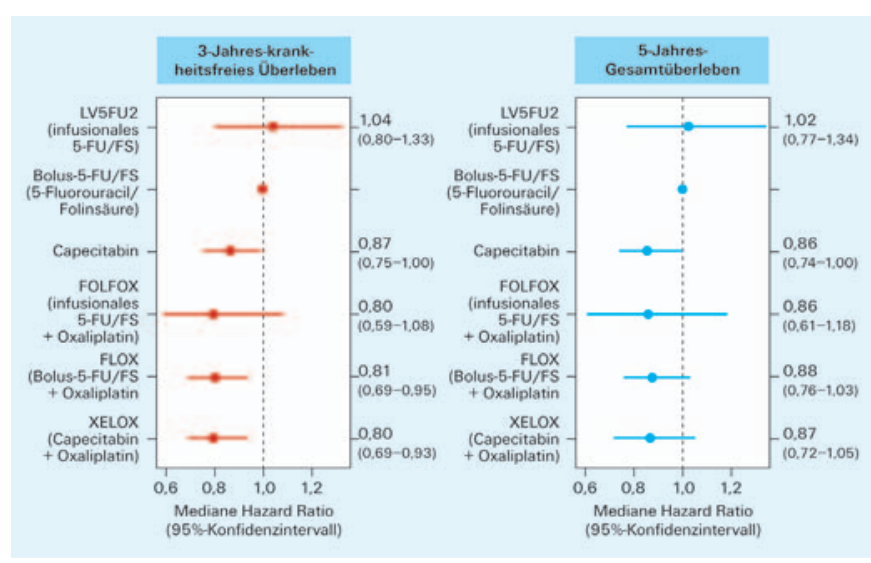

Abb. 1. Netzwerk-Metaanalyse: relative Wirksamkeit der verschiedenen Regime in der adjuvanten Therapie des Kolonkarzinoms versus Bolus5-FU/FS als Referenzpunkt (modifiziert nach [7]).

Der Text erhebt keinen Anspruch auf Vollständigkeit hinsichtlich der vielfältigen, teils kontroversen Diskussionen und ist auch nicht als umfassende Übersichtsarbeit zum Thema gastrointestinale Tumoren gedacht. Angesichts des rasanten Fortschritts im Bereich der Onkologie fällt es aber schwer, die neuen Erkenntnisse immer zeitnah in LeitlinienGremien zu diskutieren und in Leitlinien-Updates umzusetzen. Deshalb ist es sinnvoll und notwendig, interdisziplinäre Treffen durchzuführen, bei denen neue Studienergebnisse diskutiert und hinsichtlich ihrer klinischen Relevanz beurteilt werden.

Wir hoffen, dass das vorliegende Supplement Ärzten aller onkologischen Fachdisziplinen eine Hilfe sein kann, die aktuellen Entwicklungen in der Onkologie zeitnah in ihre therapeutischen Entscheidungen mit einzubeziehen.

\section{Adjuvante Therapie des Kolonkarzinoms - State of the Art Verantwortlicher Autor: Udo Vanhoefer, Hamburg}

In den letzten Monaten wurden neue Studienergebnisse zur adjuvanten Therapie des Kolonkarzinoms vorgestellt, die einerseits zu einer Bestätigung und Konsolidierung der bisherigen Erkenntnisse geführt haben und andererseits die Rolle der Biologika klären konnten. Folgende Statements lassen sich aus den neuen Daten ableiten:

1) Die beiden Therapieregime FOLFOX (infusionales 5-Fluorouracil (5-FU)/Folinsäure (FS) plus Oxaliplatin) und XELOX (das orale Fluoropyrimidin Capecitabin plus Oxaliplatin) sind äquivalent wirksam bei Patienten mit einem R0-resezierten Kolonkarzinom im Stadium III und gelten hier als Standard.

2) Stadium-II-Hochrisikopatienten können ebenfalls mit einem Oxaliplatin-haltigen Regime behandelt werden; hier ist die Datenlage zugunsten von Oxaliplatin aber weniger eindeutig.
3) Eine alternative Strategie ist die Gabe von Capecitabin als Monotherapie. Dies gilt insbesondere bei Kontraindikationen gegen Oxaliplatin und für Patienten im Stadium II.

4) Ein negativer Effekt bezüglich der Wirksamkeit bei älteren Patienten ist für XELOX und für Capecitabin als Monotherapie nicht nachgewiesen; im Gegenteil bleibt - im Gegensatz zu FOLFOX - die Wirksamkeit von XELOX versus Bolus-5-FU/FS auch bei über 70-Jährigen erhalten.

5) Es gibt keinen Stellenwert für eine Irinotecan-basierte Therapie in der Adjuvanz.

6) Auch Cetuximab hat keinen Stellenwert in der adjuvanten Therapie. Die Studiendaten zeigen ein tendenziell schlechteres krankheitsfreies Überleben (DFS) und, auch bei Patienten mit einem KRAS-Wildtyp-Tumor, einen Trend zu einem schlechteren Gesamtüberleben (OS), wenn mit Cetuximab/FOLFOX behandelt wurde.

7) Bevacizumab spielt in der adjuvanten Situation ebenfalls keine Rolle. Die beiden adjuvanten Phase-III-Studien NSABP-C08 und AVANT zeigen keine signifikante Verbesserung des DFS für die Kombination FOLFOX/Bevacizumab oder XELOX/Bevacizumab.

8) Ein möglichst frühzeitiger Beginn der adjuvanten Therapie ist offenbar von Bedeutung.

\section{Ad 1-3) FOLFOX und XELOX sind äquivalent,}

\section{Capecitabin-Monotherapie als Alternative}

Eine kürzlich vorgestellte Netzwerk-Metaanalyse überprüfte anhand der Daten von 5 großen randomisierten adjuvanten Studien (MOSAIC [1], NSABP-C07 [2], NO16968 [3], X-ACT [4] und C-96-I [5]) mit insgesamt mehr als 9000 Patienten die Wirksamkeit der verschiedenen verfügbaren Therapieregime beim Kolonkarzinom im Stadium UICC II und III (UICC = Union internationale contre le cancer). Die NetzwerkMetaanalyse ist eine statistische Methode, mit der bei Fehlen eines direkten Vergleichs die relative Wirksamkeit von 2 verschiedenen Therapieregimen miteinander verglichen werden kann [6]. In Abbildung 1 ist die relative Wirksamkeit der verschiedenen Therapieregime versus Bolus-5-FU/FS graphisch dargestellt. Abbildung 2 gibt die Hazard-Ratio (HR) des jeweiligen Vergleichs für das DFS nach 3 Jahren an [7].

Es zeigt sich zweierlei: Zum einen ist XELOX (Capecitabin plus Oxaliplatin) dem infusionalen Schema FOLFOX äquivalent $(\mathrm{HR}=1,00)$. Zum anderen ist die Capecitabin-Monotherapie offenbar wirksamer als die 5-FU/FS-Bolus-Gabe (HR $=0,87 ; 95 \%$-Konfidenzintervall $(\mathrm{CI}): 0,75-1,00)$ und nur geringfügig weniger wirksam als die Oxaliplatin-haltigen Kombinationen. Basierend auf diesen Daten sollte eine adjuvante Monotherapie mit Capecitabin als eine Alternative für Patienten erwogen werden, die aufgrund des Nebenwirkungsspektrums von Oxaliplatin nicht mit einer Kombinationstherapie behandelt werden können.

Angesichts der vergleichbaren Wirksamkeit von XELOX und FOLFOX erscheint es sinnvoll, so die Expertenrunde, die Auswahl des Kombinationsregimes von zusätzlichen Fakto- 


\begin{tabular}{|c|c|c|c|c|c|c|}
\hline \multicolumn{7}{|c|}{ 3.Jahres krankheitsfreies Öberleben [Mediane Hazard Ratio (9596-Konfidenzintervall)] } \\
\hline Therapie & Bolus-5-FU/FS & FLOX & LV5FU2 & FOLFOX & XELOX & Capecitabin \\
\hline Bolus-5-FU/FS & - & $\begin{array}{c}1.23 \\
(1.06-1.44)\end{array}$ & $\begin{array}{c}0.96 \\
(0.75-1.24)\end{array}$ & $\begin{array}{c}1,25 \\
(0.93-1.71)\end{array}$ & $\begin{array}{c}1.25 \\
(1.08-1.45)\end{array}$ & $\begin{array}{c}1.15 \\
(1.00-1.33)\end{array}$ \\
\hline FLOX & $\begin{array}{c}0.81 \\
(0.69-0.95)\end{array}$ & - & $\begin{array}{c}0.78 \\
(0.58-1.05)\end{array}$ & $\begin{array}{c}1.01 \\
(0.73-1.43)\end{array}$ & $\begin{array}{c}1.01 \\
(0.82-1.26)\end{array}$ & $\begin{array}{c}0.93 \\
(0,75-1,15)\end{array}$ \\
\hline LV5FU2 & $\begin{array}{c}1.04 \\
(0,80-1,33)\end{array}$ & $\begin{array}{c}1.28 \\
(0.95-1,72)\end{array}$ & - & $\begin{array}{c}1.30 \\
(1,10-1,53)\end{array}$ & $\begin{array}{c}1.30 \\
(0,97-1,74)\end{array}$ & $\begin{array}{c}1.19 \\
(0,89-1,59)\end{array}$ \\
\hline FOLFOX & $\begin{array}{c}0.80 \\
(0.59-1.08)\end{array}$ & $\begin{array}{c}0.99 \\
(0.70-1.38)\end{array}$ & $\begin{array}{c}0.77 \\
(0.65-0.91)\end{array}$ & - & $\begin{array}{c}1.00 \\
(0.71-1.40)\end{array}$ & $\begin{array}{c}0.92 \\
(0.66-1,28)\end{array}$ \\
\hline XELOX & $\begin{array}{c}0.80 \\
(0,69-0,93)\end{array}$ & $\begin{array}{c}0.99 \\
(0,80-1,22)\end{array}$ & $\begin{array}{c}0,77 \\
(0,58-1,03)\end{array}$ & $\begin{array}{c}1.00 \\
(0,71-1,41)\end{array}$ & - & $\begin{array}{c}0.92 \\
(0,75-1,13)\end{array}$ \\
\hline Capecitabin & $\begin{array}{c}0.87 \\
(0.75-1.00)\end{array}$ & $\begin{array}{c}1.07 \\
(0.87-1.33)\end{array}$ & $\begin{array}{c}0.84 \\
(0.63-1,12)\end{array}$ & $\begin{array}{c}1.09 \\
(0.78-1.52)\end{array}$ & $\begin{array}{c}1.09 \\
(0.88-1.34)\end{array}$ & - \\
\hline
\end{tabular}

Abb. 2. Netzwerk-Metaanalyse: paarweiser Vergleich der verschiedenen Regime in der adjuvanten Therapie des Kolonkarzinoms. Angegeben ist für jeden Paarvergleich die HR für das DFS nach 3 Jahren (modifiziert nach [18]).

ren abhängig zu machen, wie z.B. vom Nebenwirkungsprofil, von den Kosten und von den Vorteilen für die Patienten. Es ist bekannt [8], dass die Kombination von Oxaliplatin mit dem oralen Capecitabin gut verträglich und kosteneffektiv ist. Außerdem kann bei Gabe von Capecitabin auf die intravenöse Dauerinfusion von 5-FU verzichtet werden. Die Summe der Argumente spricht für die Gabe von XELOX in der adjuvanten Situation.

\section{Ad 4) Kein negativer Effekt für XELOX oder Capecitabin bei älteren Patienten}

Ursprünglich hatte die deutsche S3-Leitlinie ausdrücklich vermerkt, dass für die Durchführung einer adjuvanten Chemotherapie keine Altersbeschränkung existiert [9]. Dieses Statement wurde Ende des Jahres 2009 relativiert, d.h. die S3-Leitlinie wurde per Konsensus dahingehend modifiziert, dass nur noch für die unter 70-jährigen Patienten eine klare Empfehlung für Oxaliplatin-haltige Protokolle formuliert wurde. Für Patienten über 70 Jahre wurde eine zurückhaltende Indikationsstellung für die Oxaliplatin-Kombinationstherapie angeraten. Unstrittig wurde bei Patienten über 70 Jahre aber eine Fluoropyrimidin-Monotherapie empfohlen [10].

Ausgangspunkt der damaligen Diskussion und des S3-Leitlinien-Amendments war vor allem eine Analyse der «ACCENT Collaborative Group», die auf dem American Society of Clinical Oncology (ASCO)-Meeting 2009 vorgestellt wurde [11] und die auf eine geringere Effektivität von «neueren» adjuvanten Protokollen bei Älteren hinwies. In dieser Hypothesen generierenden Analyse sollte der Einfluss des Lebensalters auf die Wirksamkeit der «neueren Therapien» untersucht werden. Die Datenbasis waren 6 aktuellere Phase-III-Studien [1, 2, 4, 12-16], die alle «neueren Therapien» einschließlich der oralen Fluoropyrimidine, Oxaliplatin und Irinotecan untersucht hatten. Insgesamt wurden 12669 Patienten analysiert, wovon der Anteil der über 70-Jährigen 17\% ( $\mathrm{n}=2170)$ betrug. Das Gesamtergebnis zeigte einen signifikanten Nutzen im Hinblick auf das DFS (HR 0,85; CI 0,80-0,91) und das
OS (HR 0,86; CI 0,79-0,92) für die unter 70-Jährigen, aber keinen Nutzen für die über 70-Jährigen (DFS: HR 1,11; CI 0,97-1,27; OS: HR 1,14; CI 0,98-1,32). Die Interaktion zwischen Alter und Nutzen der Chemotherapie hinsichtlich des DFS war mit $\mathrm{p}=0,005$ signifikant.

Aufgrund des weiten Einschlusskriteriums «neuere Therapien» und der Heterogenität hinsichtlich der Substanzen und des statistischen Studiendesigns (teils mit Nicht-Unterlegenheits-, teils mit Überlegensheitshypothesen) interessierten vor allem die beiden Studien mit der Oxaliplatin-haltigen Kombinationstherapie, MOSAIC und NSABP-C07 [1, 2, 12]. 5-FU war in diesen Studien als Infusion (MOSAIC) bzw. als Bolus (NSABP-C07) gegeben worden. Auch in diesen Studien konnte ein signifikanter Nutzen hinsichtlich des DFS und des OS bei Patienten im Stadium III nur für die unter 70-Jährigen ( $\mathrm{n}=3,977)$, nicht aber für die über 70-Jährigen $(\mathrm{n}=703)$ dokumentiert werden (DFS: HR 0,77 (CI 0,68-0,86) bzw. 1,04 (CI 0,80-1,35); OS: HR 0,81 (CI 0,71-0,93) bzw. 1,19 (CI 0,901,57); Test auf Interaktion: $\mathrm{p}=0,016$ bzw. 0,037).

Auf dem ASCO Gastrointestinal Cancers Symposium (ASCO GI) im Januar 2010 und im Januar 2011 wurden dann aber Subgruppen-Analysen der oben erwähnten Studien NO16968 [3] und X-ACT [4] vorgestellt, die den Nutzen der Kombination Capecitabin/Oxaliplatin sowie der CapecitabinMonotherapie unabhängig vom Alter - und explizit auch bei den über 70-jährigen Patienten - zeigen [17, 18] (Abb. 3).

Beide Studien, X-ACT und NO16968, wurden bei Patienten mit einem Kolonkarzinom im Stadium III durchgeführt. Die Patienten erhielten postoperativ randomisiert entweder Capecitabin mono versus Bolus-5-FU (X-ACT-Studie) oder die Kombination Capecitabin/Oxaliplatin (= XELOX) versus Bolus-5-FU (Studie NO16968).

Bei den über 70-Jährigen in der X-ACT-Studie betrug das 5-Jahres-DFS 58,8\% versus 55,8\% zugunsten von Capecitabin, das 5-Jahres-OS 68,8\% versus 65,8\% zugunsten von Capecitabin. Damit ist Capecitabin auch bei älteren Patienten hinsichtlich DFS und OS mindestens ebenso wirksam wie, wenn nicht wirksamer als Bolus-5-FU.

In der Studie NO16968 war die Kombination XELOX signifikant besser wirksam als die 5-FU/FS-Bolusgabe. Die Wirksamkeitsvorteile finden sich auch bei den über 70-jährigen Patienten (3-Jahres-DFS 66\% vs. $60 \%$; HR =0,87). Dieses Ergebnis steht in Gegensatz zu den Ergebnissen der ACCENT-Database und der MOSAIC-Studie, die für das Therapieregime FOLFOX in der adjuvanten Situation keinen Nutzen bei älteren Patienten zeigen konnten.

Für die Praxis bedeutet dies, dass die Wirksamkeit von sowohl Capecitabin als auch XELOX bei Älteren nachweislich erhalten bleibt. Somit besteht die Option, auch bei älteren Patienten eine Oxaliplatin-basierte adjuvante Therapie durchzuführen.

Vor diesem Hintergrund empfahl die Expertenrunde, die Entscheidung, ob man einen über 70-jährigen Patienten nur mit einem oralen Fluoropyrimidin oder mit XELOX behan- 


\section{Studie N016968}

\begin{tabular}{|c|c|c|c|}
\hline \multirow[t]{2}{*}{ Altersgruppe } & \multicolumn{2}{|c|}{$\begin{array}{c}\text { 3-Jahres- } \\
\text { krankheitsfreies } \\
\text { Überleben }(\%)\end{array}$} & \multirow[t]{2}{*}{$\begin{array}{c}\text { Hazard Ratio } \\
\text { (95\%-Konfidenz- } \\
\text { intervall) }\end{array}$} \\
\hline & XELOX & 5-FU/FS & \\
\hline \multicolumn{4}{|c|}{$<65$ versus $\geq 65$ Jahre } \\
\hline$<65$ Jahre, $n=1.142$ & 72,0 & 69,0 & $0,80(0,65-0,98)$ \\
\hline$\geq 65$ Jahre, $n=744$ & 68.0 & 62,0 & $0,81(0,64-1,03)$ \\
\hline \multicolumn{4}{|l|}{$<70$ versus $\geq 70$ Jahre } \\
\hline$<70$ Jahre, $n=1.477$ & 72,0 & 69.0 & $0,79(0,66-0,94)$ \\
\hline$\geq 70$ Jahre, $n=409$ & 66.0 & 60,0 & $0,87(0,63-1,18)$ \\
\hline \multicolumn{3}{|c|}{ Interaktion der Therapie mit dem Alter* } & $p=0,6222$ \\
\hline
\end{tabular}

\section{b X-ACT-Studie}

\begin{tabular}{|c|c|c|c|}
\hline Altersgruppe & \multicolumn{2}{|c|}{ 5-Jahres-Rate (\%) } & $\begin{array}{c}\text { Hazard Ratio } \\
\text { (95\%-Konfidenz- } \\
\text { intervall) }\end{array}$ \\
\hline \multicolumn{4}{|c|}{ Capecitabin 5-FU/FS } \\
\hline \multicolumn{4}{|c|}{ Krankheitsfreies Überleben } \\
\hline$<70$ Jahre, $n=1.589$ & 59,0 & 54,0 & $0.87(0.75-1,00)$ \\
\hline$\geq 70$ Jahre, $n=396$ & 58,8 & 55,8 & $0,97(0,72-1,31)$ \\
\hline \multicolumn{3}{|c|}{ Interaktion der Therapie mit dem Alter } & $p=0,05$ \\
\hline \multicolumn{4}{|c|}{ Gesamtüberleben } \\
\hline$<70$ Jahre, $n=1.589$ & 71,0 & 68,0 & $0,86(0,72-1,02)$ \\
\hline$\geq 70$ Jahre, $n=396$ & 68,8 & 65,8 & $0,91(0,65-1,26)$ \\
\hline \multicolumn{3}{|c|}{ Interaktion der Therapie mit dem Alter } & $p=0,08$ \\
\hline
\end{tabular}

Abb. 3. Subgruppen-Analysen der Adjuvanz-Studien NO16968 (a) und X-ACT (b) zum Nutzen der Kombination XELOX (Capecitabin/Oxaliplatin) sowie der Capecitabin-Monotherapie unabhängig vom Alter (modifiziert nach [18])

delt, vor allem am biologischen Alter sowie den Komorbiditäten des Patienten festzumachen. Das FOLFOX-Regime sollte bei älteren Patienten nicht zur Anwendung kommen.

Liegt eine Kontraindikation gegen Oxaliplatin vor, ist eine Fluoropyrimidin-Monotherapie indiziert. Dabei werden orale Fluoropyrimidine den infusionalen Schemata vorgezogen. Der Einsatz von 5-FU-Bolus-Regimen gilt als obsolet [9]. Diese Empfehlung der S3-Leitlinie basiert im Wesentlichen auf den Ergebnissen der X-ACT-Studie, die zeigen konnte, dass eine Capecitabin-Monotherapie hinsichtlich des DFS (primärer Endpunkt) einem 5-FU-Bolus-Schema nicht unterlegen ist $[4,16]$.

Ad 5, 6) Kein Stellenwert für eine Irinotecan-basierte Therapie in der Adjuvanz; kein Stellenwert für Cetuximab

Irinotecan-haltige Schemata sind in der adjuvanten Therapie des Kolonkarzinoms nicht von Nutzen, wie die Studien CALGB 89803, PETACC-3 und ACCORD gezeigt haben $[13,14,19]$.
Die Ergebnisse der ersten Phase-III-Studie zum adjuvanten Einsatz des epidermalen Wachstumsfaktorrezeptor (EGFR)-Antikörpers Cetuximab wurden großteils auf dem letztjährigen ASCO-Meeting vorgestellt [20, 21]. Die große Intergroup-Studie NCCTG-N0147 war ursprünglich 6-armig gestartet. In 2 Therapiearmen wurde FOLFIRI (infusionales 5-FU, FS, Irinotecan) mit oder ohne Cetuximab gegeben. In weiteren Therapiearmen wurde mFOLFOX6 (infusionales 5-FU, FS, Oxaliplatin) mit oder ohne Cetuximab verabreicht. Nachdem 3 Studien [13, 14, 19] aber gezeigt hatten, dass Irinotecan in der adjuvanten Therapie nicht indiziert ist, hatte man die beiden FOLFIRI-haltigen Arme von NCCTGN0147 geschlossen. Die mFOLFOX6-haltigen Arme von NCCTG-N0147, die im letzten Jahr präsentiert wurden, zeigten, dass Cetuximab in der adjuvanten Situation unabhängig vom KRAS-Status nicht eingesetzt werden sollte. So betrug das 3-Jahres-DFS bei Patienten mit KRAS-Wildtyp-Tumoren $74,1 \%$ für FOLFOX versus $73,3 \%$ für FOLFOX/Cetuximab $(H R=1,18 ; p=0,33)$. Das 3-Jahres-OS lag bei 87,3\% für FOLFOX versus 82,1\% für FOLFOX/Cetuximab. In keiner Subgruppe konnte ein Benefit für Cetuximab gezeigt werden. Die Toxizität im Cetuximab-Arm war signifikant erhöht und führte häufiger zu einem vorzeitigen Therapieabbruch [20]. Bei den Patienten mit KRAS-mutierten Tumoren war FOLFOX signifikant besser wirksam, der Einsatz von Cetuximab unterlegen (3-Jahres-DFS 70,3\% für FOLFOX vs. 62,3\% für FOLFOX/Cetuximab (HR = 1,48; $\mathrm{p}=0,02$ zuungunsten von Cetuximab); 3-Jahres-OS 86,1\% unter FOLFOX vs. 79,1\% unter FOLFOX/Cetuximab $(\mathrm{p}=0,07))[21]$.

Auf dem diesjährigen ASCO GI wurden die Ergebnisse der beiden abgebrochenen FOLFIRI-haltigen Arme präsentiert (insgesamt 146 Patienten). Die Hinzugabe von Cetuximab verbesserte das DFS und das OS im Gesamtkollektiv und in der Subgruppe der Patienten mit KRAS-WildtypTumor. Tendenziell profitierten auch die Patienten mit einem KRAS-mutierten Tumor. Allerdings war das 3-Jahres-DFS für FOLFIRI mit nur 66,7\% deutlich schlechter als das für die Oxalinplatin-basierte Therapie. Das DFS unter FOLFIRI/Cetuximab lag im Gesamtkollektiv bei $86,6 \%$, in der KRASWildtyp-Gruppe sogar bei 92,3\%. (Zum Vergleich: Das 3-Jahres-DFS betrug 78,2\% in der MOSAIC-Studie unter alleiniger FOLFOX-Therapie.) Nichthämatologische Nebenwirkungen Grad $\geq 3$ waren unter Cetuximab signifikant häufiger ( $68 \%$ vs. $46 \%, p=0,02)$ [22].

Angesichts der kleinen Patientenzahl der abgebrochenen Studie sollten die Ergebnisse für die Kombination FOLFIRI/ Cetuximab mit Vorsicht interpretiert werden. In der Expertenrunde wurde die weitere Evaluation der Kombination FOLFIRI/Cetuximab in der adjuvanten Situation an einem größeren Patientenkollektiv als durchaus interessant bezeichnet. Als Vergleichsarm sollte dann aber der aktuelle Standard FOLFOX bzw. XELOX dienen. 


\section{Ad 7) Bevacizumab in der Adjuvanz ohne Bedeutung}

Die im Jahr 2009 vorgestellte Phase-III-Studie NSABP-C08 prüfte die Gabe von Bevacizumab in Kombination mit einem modifizierten FOLFOX6-Regime [23]. Der primäre Endpunkt (DFS nach 3 Jahren) zeigte keinen signifikanten Unterschied, sodass die Studie negativ ist.

Auf dem diesjährigen ASCO GI wurden jetzt die Ergebnisse der zweiten Phase-III-Studie zum Einsatz des vaskulären endothelialen Wachstumsfaktor (VEGF)-Antikörpers Bevacizumab in der Adjuvanz vorgestellt, die AVANT-Studie [24]. Im Rahmen der 3-armigen multinationalen Studie erhielten insgesamt 3451 Patienten mit einem Kolonkarzinom im Stadium III oder Hochrisiko-Stadium II postoperativ randomisiert eine der folgenden Therapien: Arm A: FOLFOX4 über 24 Wochen; Arm B: FOLFOX4 plus Bevacizumab über 24 Wochen, gefolgt von Bevacizumab allein über weitere 24 Wochen; Arm C: XELOX plus Bevacizumab über 24 Wochen, gefolgt von Bevacizumab allein über weitere 24 Wochen. Die mediane Beobachtungszeit betrug 48 Monate.

Präsentiert wurde die Intention-to-treat (ITT)-Analyse der Patienten im Stadium UICC III: Die Hinzugabe von Bevacizumab verlängerte weder das DFS noch das OS. So betrug das 3-Jahres-DFS 76\% im FOLFOX-Arm versus 73\% im FOLFOX/Bevacizumab-Arm versus 75\% im XELOX/Bevacizumab-Arm. Der Unterschied war nicht signifikant. Tendenziell wiesen die beiden Bevacizumab-Arme numerisch mehr Rezidive auf als der FOLFOX-Kontrollarm.

Damit ist Bevacizumab nach Irinotecan und Cetuximab die dritte Substanz, die trotz nachgewiesener Wirksamkeit beim metastasierten kolorektalen Karzinom in der Adjuvanz keinen Nutzen zeigt.

\section{Ad 8) Frühzeitiger Beginn der adjuvanten Therapie ist \\ bedeutsam}

Insgesamt 9 adjuvante Studien mit mehr als 14000 Patienten wurden daraufhin untersucht, ob das Überleben der Patienten mit der Zeit zusammenhängt, die zwischen Operation und Beginn der adjuvanten Therapie verstreicht. Eine systematische Metaanalyse zeigt, dass eine Verzögerung der adjuvanten Therapie um nur 4 Wochen mit einer signifikanten Reduktion von DFS und OS assoziiert ist. Jeder 4-Wochen-Zeitraum erhöhte das Rezidivrisiko signifikant um $15 \%$ und das Sterberisiko um $12 \%$ [25].

Dieses Ergebnis zeigt zwar keine Kausalität auf, so die Diskussion in der Expertenrunde, denn theoretisch wäre es möglich, dass die Patienten mit guter Prognose einfach früher mit der Therapie begonnen haben. Dennoch könnte dieses Ergebnis ein Argument für den frühen Beginn mit einer adjuvanten Therapie (z.B. ab der 2. postoperativen Woche) mit Capecitabin sein - da eine Fluoropyrimidin-Monotherapie eine geringere Toxizität aufweist als eine Oxaliplatin-basierte Kombination - gefolgt von einer späteren Aufstockung mit Oxalipatin (XELOX).

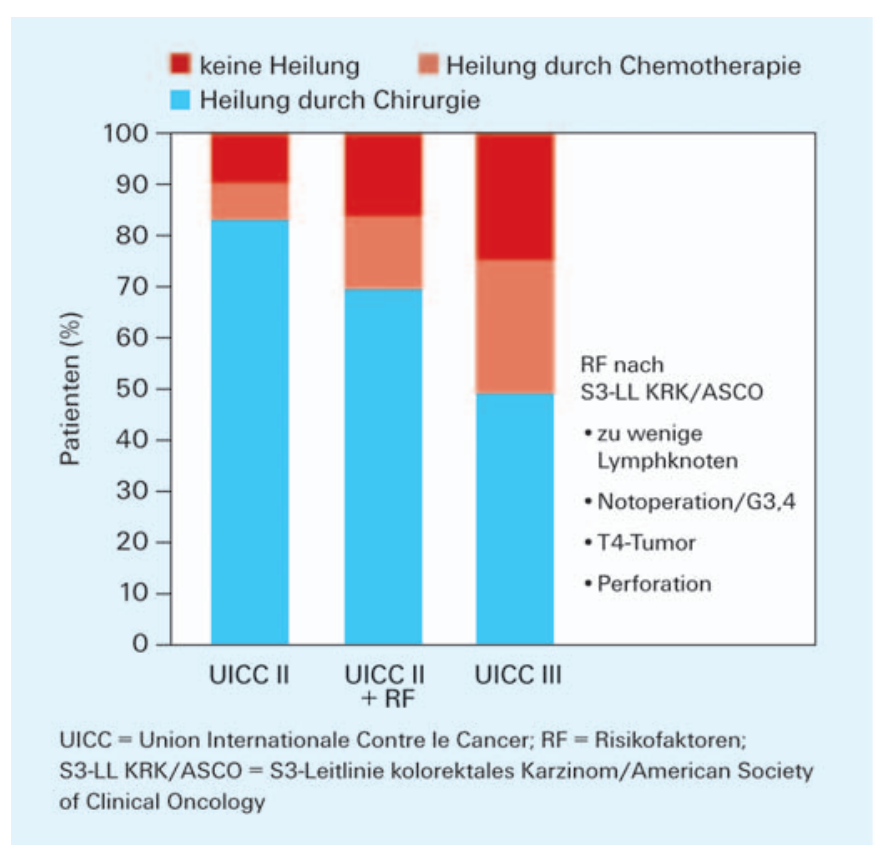

Abb. 4. Kolonkarzinom - relativer Nutzen der adjuvanten Chemotherapie in Abhängigkeit vom Tumorstadium.

\section{Kolonkarzinom im Stadium II: prognostische und prädiktive Marker \\ Verantwortliche Autorin: Anke Reinacher-Schick, Bochum}

Aus klinischen Studien ist bekannt, dass Patienten mit einem Kolonkarzinom im Stadium II in etwa $70-80 \%$ der Fälle durch die Operation geheilt werden (abhängig vom Vorhandensein bestimmter Risikofaktoren). Die übrigen werden, meist innerhalb der ersten 2 Jahre, rezidivieren - vor allem in Form von Fernmetastasen - und in der Folge an der Erkrankung versterben. Eine adjuvante Therapie kann bei einem Teil der Patienten die Heilung verbessern (Abb. 4).

Nach molekularen Markern zur Identifikation dieser rezidivgefährdeten Subgruppe wird nach wie vor intensiv gesucht. Hilfreich wären prognostische Marker, anhand derer sich ablesen lässt, bei welchen Patienten disseminierte Tumorzellen vorliegen (denn nur diese Patienten bräuchten eine Chemotherapie) - und prädiktive Marker, die vorab aussagen, wer von welcher Therapie profitieren wird.

\section{Klassische Risikofaktoren}

Etabliert (laut S3-Leitlinie und ASCO Foundation) sind bislang nur bestimmte klinische und histopathologische Risikofaktoren, die helfen sollen, Patienten mit einer besonders ungünstigen Prognose im Stadium II zu identifizieren. Zu diesen Risikofaktoren gehören: ein T4-Tumor, zu wenig untersuchte Lymphknoten, Notoperation (Ileus, Perforation), Grading G3/4. Diese Hochrisikopatienten sollten, so die Empfehlung der S3-Leitlinie, adjuvant chemotherapeutisch behandelt werden. 


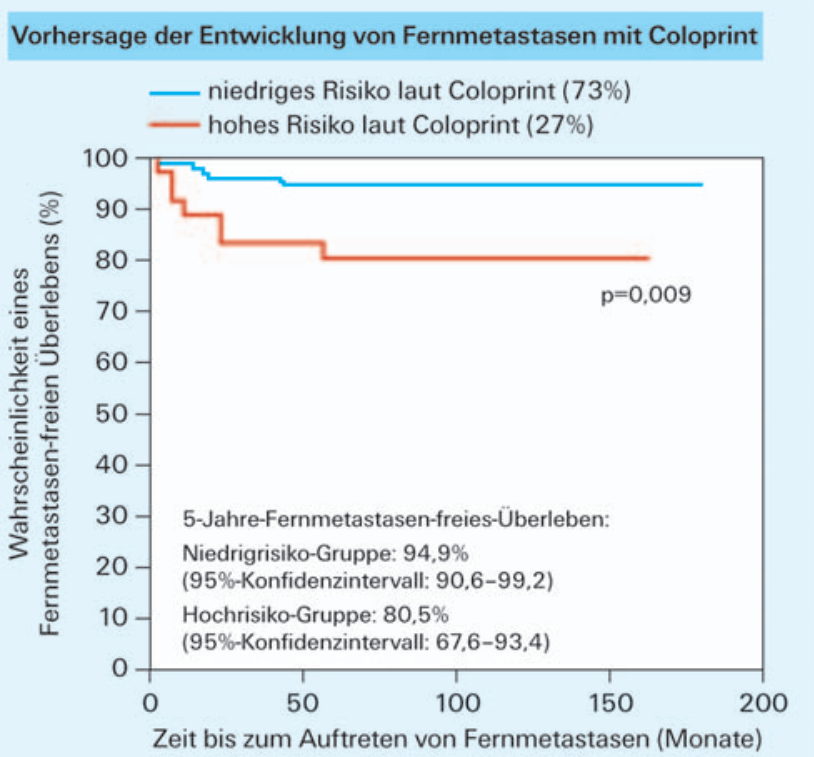

Abb. 5. 18-Gen-Signatur als prognostischer Marker im Stadium II klinische Validierung des Coloprint-Verfahrens (modifiziert nach [27]).

\section{Gensignaturen als prognostische Marker}

$\mathrm{Neu}$ ist der sogenannte ColoPrint-Test, ein diagnostisches Verfahren, das auf einer 18-Gen-Signatur beruht und die Prognose von Patienten mit Kolonkarzinom im Stadium II abschätzen soll. Die unabhängige Validierung dieses Tests wurde kürzlich publiziert [26, 27]. Aber auch der Coloprint-Test bietet nur ein prognostisches Expressionsprofil von Stadium-II-Patienten, kein prädiktives. In der univariaten Analyse war ColoPrint der einzige signifikante Parameter, mit dem sich die Entwicklung distaler Metastasen vorhersagen ließ $(\mathrm{HR}=4,1 ; 95 \%$-CI 1,31-13,01; $\mathrm{p}=0,009)$ (Abb. 5). Dagegen ermöglichten die oben genannten etablierten klinischen Risikofaktoren bei dem untersuchten Patientengut keine klare Identifikation der Hochrisikogruppe $(\mathrm{HR}=2,3 ; 95 \%$-CI $0,68-7,53 ; \mathrm{p}=0,18)$ und verbesserten die prognostische Aussagekraft der ColoPrint-Klassifikation nicht.

In einer anderen, methodisch ebenfalls sehr aufwendigen Arbeit gelang die Identifizierung eines 12-Gen-Rezidiv-Scores für Patienten im Stadium II, validiert anhand der QUASAR-Studie [28]. (An der britischen QUASARStudie hatten 3239 Patienten teilgenommen, davon 91\% «low-risk»-Stadium-II-Patienten. Sie erhielten randomisiert entweder 6 Zyklen einer 5-FU-haltigen adjuvanten Chemotherapie oder wurden nur nachbeobachtet. Nach einer medianen Beobachtungszeit von 5,5 Jahren zeigte sich ein absoluter Überlebensvorteil von 3,6\% durch die adjuvante, 5-FU-basierte Therapie, was einem relativen Überlebensvorteil von $18 \%$ entsprach $(\mathrm{p}=0,008)$. Dieser relative Überlebensvorteil von $18 \%$ konnte in allen Risikogruppen

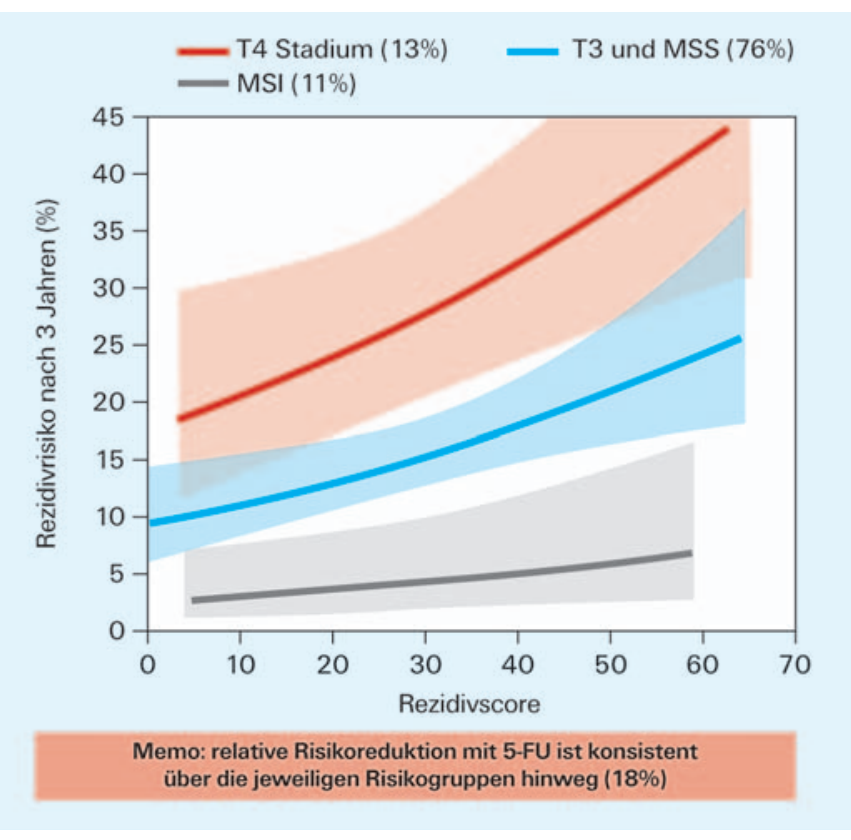

Abb. 6. 12-Gen-Rezidiv-Score für Kolonkarzinom-Patienten im Stadium II - kontinuierliche Skala in allen Risikogruppen (T4-Stadium; T3 und MSS; MSI) (modifiziert nach [28]).

dokumentiert werden [29]). Auch der 12-Gen-RezidivScore erwies sich in allen für diese Studie definierten Risikogruppen als valide, d.h. er konnte das Rezidivrisiko sowohl bei Patienten mit T4-Tumoren als auch bei Patienten mit T3-Tumoren und Mikrosatelliten-Stabilität (MSS) sowie bei Patienten mit Mikrosatelliten-Instabilität (MSI) vorhersagen (Abb. 6).

\section{MSI und MSS}

Die Risikogruppen-Einteilung nach dem Vorhandensein einer MSI der Stadium-II-Patienten entspricht Erkenntnissen aus der PETACC-3-Studie, wonach die MSI neben der T-Kategorie der stärkste Prognosemarker ist [30, 31]. Die MSI resultiert aus einer defekten DNA-«Mismatch»-Reparatur (dMMR), und es war schon früher bekannt, dass Patienten mit Tumoren, die eine hochgradige MSI (MSI-H) aufweisen, eine bessere Prognose haben als Patienten, die keinen Mismatch-Reparatur-Defekt haben (MSS) [32]. Laut PETACC-3 ist der prognostische Wert von MSI gerade bei Patienten mit einem Kolonkarzinom im Stadium II hoch signifikant.

\section{KRAS- und BRAF-Mutationen}

KRAS- und BRAF-Mutationen sind bei Stadium-II-Patienten offenbar ebenfalls von prognostischer Bedeutung. So zeigte eine weitere Analyse der QUASAR-Daten das signifikant erhöhte Rezidivrisiko von Stadium-II-Patienten mi KRAS-mutierten Tumoren (relatives Risiko $(\mathrm{RR})=2,32 ; \mathrm{p}<0,00001$ ). Und den Daten der PETACC-3-Studie ist zu entnehmen, dass Patienten mit MSI und BRAF-mutierten Tumoren eine sehr 
gute Prognose haben, etwa vergleichbar mit der Prognose von Patienten mit BRAF-Wildtyp-Tumoren. Die Prognose von Patienten mit MSS und BRAF-mutierten Tumoren ist dagegen deutlich schlechter.

\section{Erwartetes lebensqualitätsadjustiertes Überleben}

(Markov-Analyse)

Ein weiterer neuer Ansatz, Patienten für eine adjuvante Therapie auszuwählen, basiert ebenfalls auf einem MultigenRezidiv-Score (Onkotype DX), bezieht aber anhand eines mathematischen Modells (Markov-Modell) auch die Auswirkungen einer adjuvanten Therapie auf das lebensqualitätsadjustierte Überleben und die volkswirtschaftlichen Kosten ein [33]. Das Ziel besteht darin, mit diesem Modell die qualitätsadjustierte Lebenserwartung zu steigern und Kosten einzusparen. Von der Expertenrunde wird dieses Vorgehen aber eher kritisch gesehen, da die Erfahrung zeigt, dass viele Patienten vorübergehend deutliche Lebensqualitätseinschränkungen hinzunehmen bereit sind, wenn dadurch die Chance auf Heilung verbessert wird.

\section{Fazit}

Es gibt inzwischen mehrere prognostische Gensignaturen, anhand derer sich das Rezidivrisiko für Patienten mit einem Kolonkarzinom im Stadium II berechnen lässt. Neben der Gensignatur spielen der Mikrosatelliten-Status (MSI vs. MSS), die klassischen klinischen Risikofaktoren (T4-Status usw.), der KRAS- und BRAF-Status sowie nicht zuletzt auch das biologische Alter und klinische Komorbiditäten eine Rolle für die Prognose. Damit liegen jetzt 5 verschiedene Prognoseparameter vor, deren jeweiliger Einfluss noch nicht definitiv geklärt ist und für deren Berücksichtigung bei der Therapieentscheidung es derzeit keinen anerkannten Algorithmus gibt - außer der bekannten Empfehlung der S3-Leitlinie, wonach Stadium-II-Patienten mit klinischen Risikofaktoren (vor allem T4) eine adjuvante Therapie erhalten sollten und Stadium-II-Patienten ohne klinische Risikofaktoren eine adjuvante Therapie erhalten können.

Eine prädiktive Gensignatur konnte bislang nicht identifiziert werden. Das heißt, dass nach wie vor auch mittels Gensignaturen nicht vorhergesagt werden kann, wem eine konkrete Therapie nützen wird. Somit kann man sich derzeit nur die Frage stellen und beantworten, ob man Patienten mit einem niedrigen Rezidivrisiko behandeln will oder nicht. Die Antwort wird individuell unterschiedlich ausfallen. Für die Beantwortung könnten die Ergebnisse der QUASAR-Studie eine Rolle spielen, wonach 5-FU bei klinischen «low-risk»-Patienten in allen untersuchten Subgruppen (also auch bei Patienten mit MSI, die nachweislich eine gute Prognose haben) einen relativen Überlebensvorteil von $18 \%$ bietet.

Damit kann auch die vor 2 Jahren an dieser Stelle ausgesprochene Empfehlung, Patienten im Stadium II routinemäßig auf MSI zu testen, bevor mit einer Fluoropyrimidin-
Monotherapie begonnen wird, so nicht aufrechterhalten werden. Damals war man davon ausgegangen, dass dem MSI-Status nicht nur eine prognostische, sondern auch eine prädiktive Bedeutung zukommt. Denn mehrere Studien hatten gezeigt, dass sich bei Stadium-II-Patienten mit MSI-HTumoren die 5-FU-Therapie signifikant negativ auf das OS auswirkt [32, 34-36]. Eine weitere Auswertung der PETACC-3-Daten, die MSI als starken prognostischen Faktor bestätigten, kam aber zu dem Ergebnis, dass der positive prognostische Effekt von MSI-H auch dann erhalten bleibt, wenn die Patienten mit 5-FU behandelt werden (Widerspruch zu [36]) [13, 37]. Aufgrund dieser widersprüchlichen Daten ist die Frage, ob MSI auch ein prädiktiver Marker ist, wieder offen. Ob man auf MSI testen sollte mit der Begründung, dann diejenigen Stadium-II-Patienten von der Therapie auszuschließen, die auch ohne Therapie eine exzellente Prognose haben, bleibt derzeit der Entscheidung des behandelnden Arztes überlassen.

Weitgehend geklärt scheint die Rolle von Oxaliplatin im Stadium II. Da die MOSAIC-Studie für den Einsatz von Oxaliplatin im «low-risk»-Stadium II keine überzeugenden Daten erbrachte [1, 12], empfiehlt die S3-Leitlinie hier, Fluoropyrimidine als Monotherapie einzusetzen, bevorzugt orale Fluoropyrimidine [9]. Zudem gibt es neue Daten aus der NSABPC07-Studie, wonach Lymphknoten-negative (und somit Stadium-II-) Patienten selbst bei prognostisch ungünstigem 33-Gen-Index von der zusätzlichen Oxaliplatin-Gabe nur einen marginalen Nutzen haben [38].

\section{Operationstechniken beim Kolonkarzinom Verantwortlicher Autor: Hauke Lang, Mainz}

Die totale mesorektale Exzision (TME) beim Rektumkarzinom ist heute Standard. Analog dazu wird beim Kolonkarzinom seit Jahren die CME - die komplette Mesokolon-Exzision mit zentraler Gefäßligatur (CVL) - gefordert [39]. Hierbei erfolgt eine scharfe Dissektion der viszeralen Faszie von der parietalen Faszie. Daraus resultiert eine komplette Mobilisation des gesamten Mesokolons, das eine intakte Umhüllung durch viszerales Peritoneum behält. Durch diese Technik konnte in Erlangen die 5-Jahres-Lokalrezidivrate beim Kolonkarzinom von 6,5 auf 3,6\% gesenkt werden. Gleichzeitig stieg das 5-Jahres-OS der kurativ operierten Patienten von 82,1 auf $89,1 \%$ an [39].

Wie ein Vergleich mit Standard-Resektaten aus Leeds, Großbritannien, zeigte, umfassten die Erlanger CME/CVLResektate mehr Gewebe, d.h. der Tumor wurde weiträumiger umschnitten und es wurden mehr Lymphknoten entfernt, was die besseren Langzeitergebnisse in Erlangen zum Teil erklären könnte [40, 41].

Angesichts dieser Daten ist die CME mit CVL beim Kolonkarzinom heute Standard bzw. sollte in allen Häusern Standard sein, betonte die Expertenrunde. 
First-Line-Therapie des metastasierten kolorektalen Karzinoms: aktuelle Standards

Verantwortlicher Autor: Stefan Kubicka, Hannover

\section{Kombinations-Chemotherapie oder eskalierende}

Sequenztherapie? Wann minimal intensive Therapie?

\section{Mitverantwortlich für dieses Kapitel: Hanno Riess, Berlin}

Die Studien CAIRO und FOCUS haben gezeigt, dass in der palliativen Situation eine eskalierende Sequenztherapie zu ähnlich guten Ergebnissen führen kann wie eine sofortige Kombinationschemotherapie [42, 43]. Kandidaten für eine Sequenztherapie - oder für eine minimal intensive Therapie - sind in erster Linie Patienten, bei denen das Rezidiv sehr spät aufgetreten ist, oder Patienten, die früh auf eine «eskalierende» Therapie ansprechen, und natürlich Patienten, bei denen eine intensivere Therapie kontraindiziert ist oder die ein intensiveres Regime ablehnen. Voraussetzung für die Sequenztherapie/minimal intensive Therapie ist aber die engmaschige Tumorkontrolle und eine gute Patientenführung, da bei einer Tumorprogression schnell reagiert werden muss, um den Patienten nicht durch einen raschen Progress zu verlieren.

Außerdem, so die Expertenrunde, muss gewährleistet sein, dass der Patient auch bei einer Sequenztherapie alle verfügbaren Therapien erhält, was jedoch in der Praxis oft nicht der Fall ist. Der Standard sollte deshalb primär die Kombination sein; eine Sequenztherapie sollte nur in begründeten Ausnahmefällen erfolgen.

Dass auch und gerade Patienten mit einem tumorbedingt schlechten Performance-Status ((PS)2) von einer modernen Kombinationschemotherapie profitieren, macht eine gepoolte Analyse deutlich, in die die Daten von 9 First-Line-Studien eingingen [44]. Die Kombinationschemotherapie hatte bei den PS0/1- und bei den PS2-Patienten eine vergleichbar günstige Auswirkung auf das OS, reduzierte aber beim PS2-Patientenkollektiv vor allem die Frühmortalität. Dennoch lag die Todesrate bei den PS2-Patienten innerhalb der ersten 60 Tage ab dem Zeitpunkt der Randomisierung bei $12 \%$, in mehr als der Hälfte der Fälle ging dem Todesfall ein Tumorprogress voraus. Das heißt, dass die Wirksamkeit der Kombinationschemotherapie noch weiter verbessert werden muss, um die hohe Krebsfrühmortalität weiter zu senken.

Ein Einsatz von Bevacizumab ist bei älteren Patienten und bei PS2-Patienten in der Regel problemlos möglich, wenn die entsprechenden kardiovaskulären Kontraindikationen beachtet werden, so die Diskussion in der Expertenrunde. Es sollte bei diesem Kollektiv aber grundsätzlich eine besonders sorgfältige Überwachung der Toxizität erfolgen.

First-Line-Therapie bei potenziell resektablen Lebermetastasen Besteht das primäre Therapieziel darin, eine möglichst hohe Ansprechrate zu erzielen, um die Lebermetastasenresektion zu ermöglichen, ist die Gabe der Dreifach-Chemotherapie

\section{Oxaliplatin

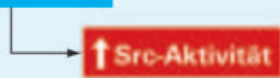

Eine Oxaliplatin/Src-

Kombinationstherapie ist in

vitro und in vivo synergistisch
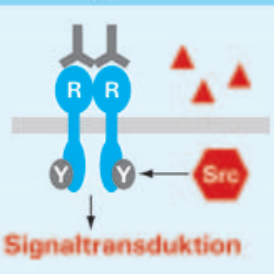

Die anti-EGFR-Resistenz in vitro wird über Src vermittelt

Abb. 7. Eine mögliche Ursache für negative Ergebnisse unter einer Oxaliplatin/Anti-EGFR-Therapie (modifiziert nach [53]).

FOLFOXIRI (infusionales 5-FU/FS/Oxaliplatin/Irinotecan) eine gute Option [45, 46]. Die Studie von Falcone et al. [46] konnte eine signifikante Verbesserung der Ansprechrate und eine damit verbundene Erhöhung der sekundären Resektionsrate zeigen. Auch die Vierfach-Therapie FOLFOXIRI/ Bevacizumab ist machbar und führte in einer Phase-II-Studie zu einer Ansprechrate von 80\% [47], was aber noch durch Phase-III-Studien bestätigt werden muss. Alternativ kommen - allerdings nur bei Patienten mit KRAS-Wildtyp-Tumoren Cetuximab-haltige Kombinationen infrage, da die Vorteile der EGFR-Inhibitoren vermutlich vor allem in einer Erhöhung der Remissionsrate liegen, was dann in einigen Fällen eine sekundäre Resektion ermöglicht [48-50].

In der Expertenrunde wurde darauf hingewiesen, dass, wenn man sich für Cetuximab oder einen anderen EGFRAntikörper entscheidet, man bevorzugt mit einer Irinotecanhaltigen Chemotherapie kombinieren sollte, denn die klinischen Studien haben gezeigt, dass unter dieser Kombination eine bessere Wirksamkeit erwartet werden kann [49]. Große Studien, die einen EGFR-Antikörper in Kombination mit Oxaliplatin prüften, waren überwiegend negativ [51, 52]. Als Ursache wird unter anderem vermutet, dass Oxaliplatin das intrazelluläre Molekül Src aktiviert, wodurch es zu einer Aktivierung des EGFR-Signalweges und zu einer Resistenz gegen den EGFR-Antikörper kommen kann [53] (Abb. 7).

\section{First-Line-Therapie in allen anderen Fällen}

Mehrere Phase-III-Studien haben Bevacizumab in der FirstLine-Therapie des metastasierten kolorektalen Karzinoms etabliert [54-63]. Danach ist Bevacizumab sowohl in Kombination mit einer Irinotecan-haltigen als auch in Kombination mit einer Oxaliplatin-haltigen Chemotherapie wirksam oder kann auch mit einer 5-FU- bzw. Capecitabin-Monotherapie kombiniert werden. Das mediane progressionsfreie Überleben (PFS) betrug in der Regel bei Hinzugabe von Bevaci- 
Abb. 8. Potenzieller Therapie-Algorithmus für die First-Line-Therapie des metastasierten kolorektalen Karzinoms.

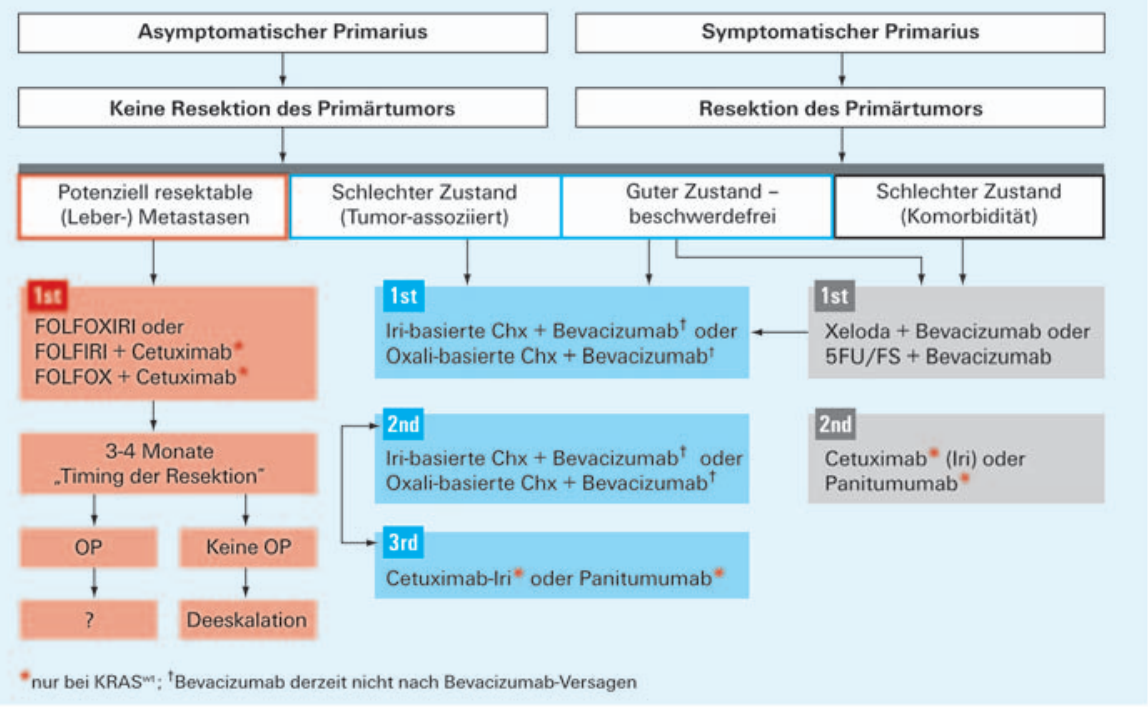

zumab zu einer Kombinationschemotherapie 10-11 Monate (10,6 Monate in der AVF2107-Studie mit Bevacizumab/ Irinotecan/5-FU; 11,2 Monate in der BICC-C-Studie mit Bevacizumab/FOLFIRI; 10,7 Monate in der PACCE-Studie mit Bevacizumab/Irinotecan-Kombination; 11,0 Monate in der PACCE-Studie mit Bevacizumab/Oxaliplatin-Kombination; 10,7 Monate in der CAIRO-2-Studie mit Bevacizumab/ Oxaliplatin/Capecitabin; 10,3 Monate in der HORIZON-IIIStudie mit Bevacizumab/FOLFOX; 9,4 Monate in der NO16966-Studie mit Bevacizumab/FOLFOX bzw. Bevacizumab/XELOX). Neben dieser konsistenten Wirksamkeit hat sich Bevacizumab im klinischen Alltag auch als gut verträglich erwiesen und verfügt damit über eine gute Wirkung/Nebenwirkung-Relation, was sich positiv auf die Lebensqualität der Patienten unter der Therapie auswirkt - ein in der FirstLine-Situation wichtiges Kriterium.

Cetuximab hingegen zeigt wenig Konsistenz hinsichtlich seiner Wirksamkeit in klinischen Studien [49-52] und erscheint außerdem für den generellen Einsatz in der FirstLine-Therapie als zu toxisch. Auch wenn in einer Studie mit Cetuximab das OS signifikant verbessert werden konnte, sind vor allem die grundsätzlich beobachteten Haut- und Nagelveränderungen durch EGFR-Inhibitoren für einige Patienten unter dem Gesichtspunkt einer rein palliativen Therapie problematisch.

Darüber hinaus sind EGFR-Antikörper in der Zweit- und Drittlinientherapie wirksam [64-67] und zugelassen, sodass die Option für den Einsatz von Cetuximab oder Panitumumab nach einer Bevacizumab-haltigen First-Line-Therapie immer noch offen ist und darüber hinaus auch die Akzeptanz der Haut- und Nageltoxizitäten in den späteren Therapielinien größer ist.

Aus dem Gesagten ergibt sich der in der Abbildung 8 dargestellte aktuelle Therapie-Algorithmus.

\section{Deeskalation, Stop-and-Go, Erhaltungstherapie Verantwortliche Autorin: Susanna Hegewisch-Becker, Hamburg}

Im letzten Jahr sind 3 Studien zu verschiedenen Varianten der Deeskalations- und Stop-and-Go-Strategie vorgestellt worden. Da sich die Studien sowohl bezüglich des Designs als auch bezüglich der Dauer der Induktionstherapie unterscheiden, sind die Ergebnisse nicht vergleichbar. In allen Studien wurde eine Oxaliplatin-basierte Chemotherapie eingesetzt, entweder in Kombination mit einem oralen oder mit einem infusionalen Fluoropyrimidin. In der MRC-COIN-Studie [51] wurde die durchgehend bis zur Progression applizierte Chemotherapie mit einer Stop-and-Go-Variante (12 Wochen Induktionsphase, dann Pause bis zum Progress) verglichen. Letztere zeigte ein geringfügig schlechteres OS (14,3 Monate vs. 15,6 Monate; HR 1,087 ), war aber deutlich besser verträglich (nur $5 \%$ Oxaliplatin-assoziierte Polyneuropathien des Grades $\geq 3$ vs. $18 \%$ unter der kontinuierlichen Gabe) [68]. In der 3-armigen NORDICVII-Studie [52] wurde im Stop-and-Go-Arm Cetuximab kontinuierlich bis zur Progression gegeben, während die Chemotherapie nach 16 Wochen gestoppt und erst im Falle der Progression wiederaufgenommen wurde. Im Vergleichsarm A wurde die Chemotherapie, in Arm B die Chemotherapie plus Cetuximab durchgängig bis zur Progression verabreicht. Auch hier waren PFS und OS unter der intermittierenden Chemotherapie nicht schlechter als bei kontinuierlicher Behandlung. Design und Ergebnisse beider Studien sind kontrovers diskutiert worden und erlauben keine definitiven Rückschlüsse auf die Wertigkeit verschiedener Deeskalationsstrategien.

Zur Frage einer Erhaltungstherapie mit Bevacizumab wurden auf dem letzten ASCO-Meeting die Ergebnisse der MACRO-Studie vorgestellt [69]. In dieser Phase-III-Studie erfolgte eine Randomisierung zwischen der als Standardthera- 
Abb. 9. Erhaltungstherapie beim kolorektalen Karzinom: Design der Studie KRK 0207 der AIO.

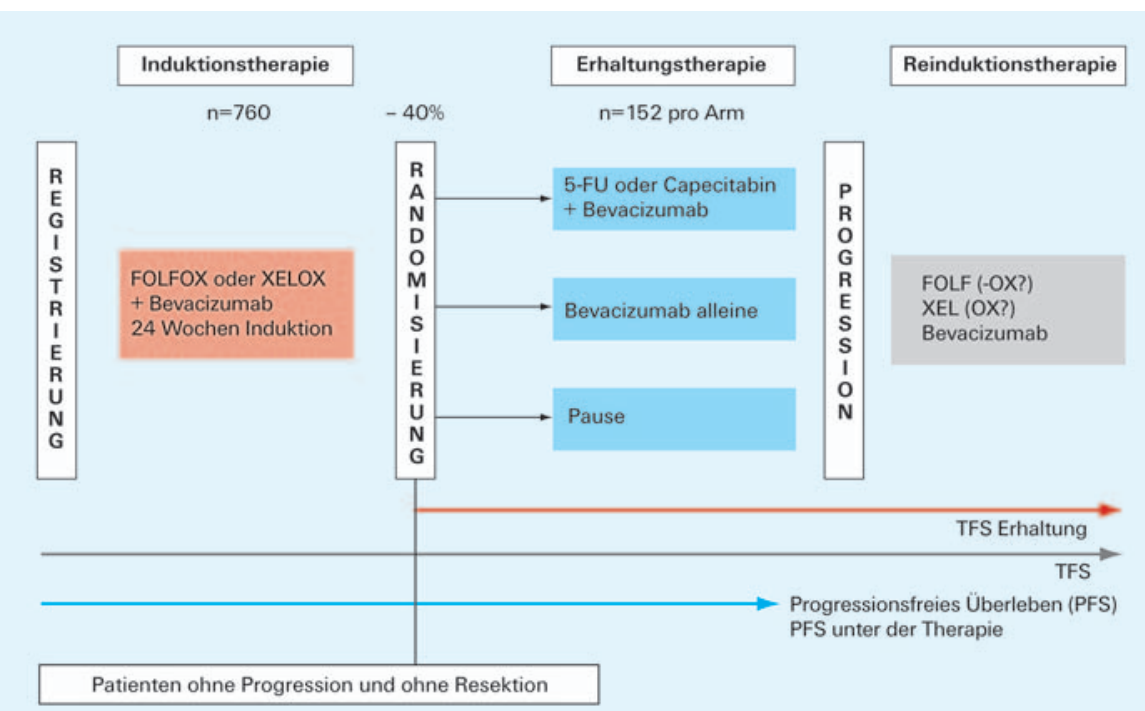

Primärer Endpunkt: TFS Erhaltung = Zeit bis zum Versagen der Erhaltungstherapie und der daran anschließenden Re-Induktion, gemessen ab dem Zeitpunkt der Randomisierung pie deklarierten durchgängigen Gabe von XELOX/Bevacizumab bis zur Progression oder einer Deeskalation auf Bevacizumab als Monotherapeutikum nach 6 Zyklen der Induktionstherapie. Unter der fortgesetzten XELOX/Bevacizumab-Kombinationstherapie lag das PFS bei 10,4 Monaten versus 9,7 Monaten unter der Bevacizumab-Mono-Erhaltungstherapie ( $\mathrm{HR}=1,1 ; 95 \%$-CI 0,89-1,37). Mit diesem CI verfehlte die Studie knapp ihr Ziel, die Nicht-Unterlegenheit der Bevacizumab-Mono-Erhaltungstherapie bezüglich des PFS zu beweisen (CI-Grenze vorab bei 1,32 festgelegt). Das OS lag bei 23,4 Monaten im Standardarm versus 21,7 Monaten im experimentellen Arm (HR = 1,04; 95\%-CI 0,81-1,32). Im experimentellen Arm wurde eine deutliche Reduktion der Oxaliplatin-assoziierten Polyneuropathie Grad $\geq 3$ gesehen (7,5\% versus $24,8 \%$ ).

Weitere Erkenntnisse zur Frage der Erhaltungstherapie dürfte die Studie KRK 0207 der Arbeitsgemeinschaft Internistische Onkologie (AIO) erbringen. In dieser Studie werden alle Patienten, die nach 24-wöchiger Induktion mit der Kombination XELOX/Bevacizumab oder FOLFOX/Bevacizumab weder progredient sind noch Lebermetastasen-reseziert werden können, randomisiert. Die Therapie wird dann mit 5-FU oder Capecitabin plus Bevacizumab (Arm A) weitergeführt bis zum Progress. Arm B erhält eine Bevacizumab-Monotherapie, Arm C pausiert. Zum Zeitpunkt der Progression erfolgt eine Reinduktion mit Chemotherapie plus Bevacizumab (Abb. 9).

Die Rekrutierung für diese Studie begann im September 2009. Bis zum Januar 2011 konnten 343 Patienten registriert werden. Insgesamt ist die Registrierung von 760 Patienten geplant.

\section{Diskussion}

Die Expertenrunde kam mehrheitlich zu dem Schluss, dass es bis zum Vorliegen weiterer Daten sinnvoll sein könnte, über
6 Monate mit einer Kombinationschemotherapie plus Bevacizumab zu behandeln, um danach zu deeskalieren und mit Capecitabin/Bevacizumab weiterzubehandeln bis zum Progress.

\section{Prognostische und prädiktive Marker im Stadium IV Verantwortliche Autorin: Anke Reinacher-Schick, Bochum}

Bezüglich prognostischer und prädiktiver Marker für das kolorektale Karzinom im Stadium IV gab es im letzten Jahr kaum neue Daten.

Eine Bestimmung von VEGF im Plasma/Serum erscheint nicht sinnvoll und ist außerdem sehr schwierig, da VEGF nicht stabil ist. Hohe VEGF-Spiegel haben keine prognostische Aussagekraft, zumindest nicht beim kolorektalen Karzinom. Beim nichtkleinzelligen Bronchialkarzinom gibt es Hinweise darauf, dass Patienten mit einem hohen VEGF-Spiegel eine schlechtere Prognose haben. Ein prädiktiver Nutzen von VEGF ist beim kolorektalen Karzinom ebenfalls nicht gegeben, möglicherweise aber beim Brustkrebs. Interessant ist, dass VEGF bei manchen Patienten unter der anti-angiogenen Therapie stark ansteigt, in diesen Fällen aber nicht vom Tumor, sondern vom Wirt, also vom Patienten selbst, verstärkt produziert wird und dann offenbar ein Ansprechen auf die Therapie anzeigt. Klinisch nutzbar ist dieses Phänomen bislang aber nicht [70].

Der derzeit vielversprechendste zirkulierende Biomarker, der in einigen Jahren klinisch relevant werden könnte, ist SDF (stromal-derived factor)- $1 \alpha$. Dieser Faktor fällt unter der Therapie ab und steigt vor dem Tumorprogress wieder an. Ebenfalls interessant ist der Entzündungsmarker Interleukin-6 (IL-6). Hohe IL-6-Spiegel scheinen darauf hinzuweisen, dass Patienten weniger von einer anti-angiogenen Therapie 
Tab. 1. Biomarker für die Anti-EGFRTherapie

\begin{tabular}{ll}
\hline Biomarker & Bedeutung für die Anti-EGFR-Therapie \\
\hline Hauttoxizität & prognostisch, aber nicht prädiktiv für das Ansprechen auf einen EGFR-Antikörper \\
KRAS & negativer Prädiktor \\
BRAF & prognostisch, aber wahrscheinlich nur von geringem prädiktivem Wert \\
PTEN & unklar infolge fehlender Standardisierung der immunhistochemischen Bewertung \\
PIK3CA & unklar, aber eine PI3K-Signalweg-Aktivierung durch PTEN-Verlust oder PIK3CA-Mutationen scheint \\
& ein negativer Prädiktor zu sein \\
\hline
\end{tabular}

\begin{tabular}{|c|c|c|}
\hline & Prognostisch & Prädiktiv \\
\hline VEGF-A & $?(+/-$ NSCLC, HCC $)$ & $\begin{array}{l}? \text { (Brust+, CRC-) } \\
\uparrow \text { unter Therapie }\end{array}$ \\
\hline PIGF & ass. mit PD & †unter Therapie, ggf.+ \\
\hline SDF- $1 \alpha /$ FGF & $\uparrow$ vor Progress & $\downarrow$ unter Therapie \\
\hline IL-6 & & $\uparrow$ prädiktiv \\
\hline CEC/CEPs & $\downarrow$ unter Therapie & $\begin{array}{l}\text { nicht signifikant } \\
\text { (Methodik?) }\end{array}$ \\
\hline \multicolumn{3}{|c|}{$\begin{array}{l}\text { CEC=zirkulierende Endothelzellen; CEPs=zirkulierende endotheliale } \\
\text { Progenitorzellen; } C R C=\text { kolorektales Karzinom; } F G F=\text { Fibroblasten-Wachs- } \\
\text { tumsfaktor; } \mathrm{HCC}=\text { Leberzellkarzinom; IL- } 6=\text { Interleukin- } 6 \text {; NSCLC=nicht- } \\
\text { kleinzelliges Bronchialkarzinom; PD=progrediente Tumorerkrankung; } \\
\text { PIGF=Plazenta-Wachstumsfaktor; SDF- } 1 \alpha=\text { stromal derived factor- } 1 \alpha \text {; } \\
\text { VEGF-A=vaskulärer endothelialer Wachstumsfaktor A }\end{array}$} \\
\hline
\end{tabular}

Abb. 10. Potenzielle zirkulierende Biomarker für die Anti-Angiogenesetherapie.

profitieren, weil bei ihnen die «alternativen Wege» stark ausgeprägt sind (Abb. 10).

Bildgebende Verfahren erscheinen vielversprechend, um ein frühes Ansprechen auf die Anti-VEGF-Therapie zu evaluieren. Allerdings ist aufgrund der eher «zytostatischen» Wirkung der anti-angiogenen Therapie eine Evaluierung nach RECIST (Response Evaluation Criteria in Solid Tumors), d.h. das Messen des Größenrückgangs von Tumor und Metastasen, zur Erfolgsbeurteilung wenig sinnvoll. Neu ist der Einsatz der dynamischen, kontrastverstärkten Magnetresonanztomographie (DCE-MRI), bei der eine Transferkonstante $\left(\mathrm{K}^{\text {trans }}\right)$ für das Kontrastmittel gemessen wird. Diese Transferkonstante ermöglicht eine Aussage über die Größe und Beschaffenheit der Endotheloberfläche und über die Gefäßpermeabilität und scheint tatsächlich prädiktiv zu sein für ein Ansprechen auf die anti-angiogenetische Therapie [71]. Fällt $\mathrm{K}^{\text {trans }}$ kurz nach Beginn einer Anti-VEGF-Therapie deutlich ab, so weist das auf ein gutes Ansprechen des Patienten auf die Therapie hin. Das Phänomen ist bereits 2 Tage nach Therapiebeginn zu beobachten. Für die Klinik ist dieses Verfahren noch nicht reif, aber es wird derzeit in klinischen Studien prospektiv untersucht.

Eine weitere vielversprechende neue Methode ist die Beurteilung des Ansprechens nach Computertomographie (CT)basierten morphologischen Kriterien [72]. Dagegen existieren
Biomarker im Gewebe für die anti-angiogene Therapie nicht. Weder die Mikrogefäßdichte noch die Proliferation von Endothelzellen oder die Expression des VEGF-Rezeptors Typ 2 sind von prognostischer oder prädiktiver Bedeutung.

\section{Fazit}

Derzeit stehen für die Anti-VEGF-Therapie (noch) keine prädiktiven Marker zur Verfügung. Abhängig von der Tumorentität gibt es jedoch einige vielversprechende Kandidaten. Hierzu gehören die Transferkonstante $\left(\mathrm{K}^{\text {trans }}\right)$ beim DCEMRI als dynamischer Biomarker und SDF-1 $\alpha$ als «Escape»Biomarker.

Auch bezüglich der Anti-EGFR-Marker gibt es wenig Neues zu berichten. KRAS ist als prädiktiver Marker etabliert. Die immunhistochemische EGFR-Bestimmung hat prognostischen Wert. BRAF wurde in der MRC-COIN-Studie als starker prognostischer Marker bestätigt [68], ist aber laut einer Analyse der CRYSTAL- und OPUS-Daten nicht von prädiktivem Wert für eine Cetuximab-Therapie [73], sodass lediglich überlegt wird, künftig in klinischen Studien auf BRAF zu stratifizieren (Tab. 1). Weitere klinische Konsequenzen stehen derzeit nicht an.

\section{Perioperative Therapie bei Lebermetastasen-Resektion Verantwortlicher Autor: Hans-Joachim Schmoll, Halle}

\section{Primär resektable Lebermetastasen}

In die Gruppe der Patienten mit metastasiertem kolorektalem Karzinom und «primär resektablen Lebermetastasen» fallen aus Sicht der deutschen S3-Leitlinie von 2008 [9] vor allem die in technischer Hinsicht resektablen Patienten; eine Unterscheidung bezüglich des «onkologischen» Risikoprofils der Patienten wird - im Gegensatz zu den Empfehlungen eines Europäischen Workshops [74] - nicht vorgenommen.

Bezüglich des Managements primär resektabler Lebermetastasen konkurrieren derzeit alleinige Operation, prä- und postoperative Chemotherapie und alleinige postoperative Chemotherapie miteinander. Die S3-Leitlinie sagt aus, dass eine prä- und postoperative Chemotherapie mit FOLFOX (infusionales 5-FU/FS/Oxaliplatin) bei Patienten mit primär resektablen Lebermetastasen nur «in begründeten Ausnahmefällen erwogen werden kann» [9]. Die alleinige postoperative Chemotherapie mit 5-FU/FS wird günstiger bewertet 
Tab. 2. Perioperative Chemotherapie mit FOLFOX bei resektablen Lebermetastasen (Studie EORTC 40983)

\begin{tabular}{|c|c|c|c|c|c|}
\hline & $\begin{array}{l}\text { Anzahl der Patienten mit } \\
\text { Chemotherapie }\end{array}$ & $\begin{array}{l}\text { Anzahl der Patienten } \\
\text { mit Chirurgie }\end{array}$ & $\begin{array}{l}\text { Absoluter Unterschied im } \\
\text { 3-Jahres-PFS, \% }\end{array}$ & HR (95\%-CI) & p-Wert \\
\hline Alle Patienten & 182 & 182 & $\begin{array}{l}+7,3 \% \text { (Steigerung von } \\
28,1 \% \text { auf } 35,4 \% \text { ) }\end{array}$ & $0,79(0,62-1,02)$ & 0,058 \\
\hline $\begin{array}{l}\text { Alle auswertbaren } \\
\text { Patienten }\end{array}$ & 171 & 171 & $\begin{array}{l}+8,1 \% \text { (Steigerung von } \\
28,1 \% \text { auf } 36,2 \% \text { ) }\end{array}$ & $0,77(0,60-1,00)$ & 0,041 \\
\hline $\begin{array}{l}\text { Alle resezierten } \\
\text { Patienten }\end{array}$ & 151 & 152 & $\begin{array}{l}+9,2 \% \text { (Steigerung von } \\
33,2 \% \text { auf } 42,4 \%\end{array}$ & $0,73(0,55-0,97)$ & 0,025 \\
\hline
\end{tabular}

Modifiziert nach [76].

(«...kann erwogen werden»). Damit gibt die S3-Leitlinie die bei vielen chirurgisch tätigen Ärzten vorherrschende Meinung wieder, wonach eine R0-Resektion, wenn sie möglich ist, ohne Verzögerung erfolgen sollte; Patienten mit «ungünstigen onkologischen Kriterien» wie z.B. hohem Fong-Score [75] könnten dann im Anschluss an die Operation chemotherapeutisch behandelt werden.

Aus internistischer Sicht stehen die genannten Abschnitte der S3-Leitlinie nicht in Einklang mit der publizierten Evidenz, die mehr für die prä- und postoperative Chemotherapie spricht. Kernstück der Argumentation für die prä- und postoperative Chemotherapie ist die EORTC-Studie 40983 [76]. An dieser internationalen, multizentrischen, randomisierten, kontrollierten Studie nahmen insgesamt 368 Patienten teil, von denen mehr als 50\% höchstens 1 isolierte Metastase und $78 \%$ höchstens 2 Lebermetastasen aufwiesen. Die Studie kam zu dem Ergebnis, dass die perioperative Chemotherapie mit FOLFOX4 (je 3 Monate prä- und postoperativ verabreicht) bei diesen Patienten das relative Rezidivrisiko verglichen mit der alleinigen Operation um etwa $20 \%$ reduziert. Das 3-Jahres-PFS konnte im Vergleich zu den nur resezieren Patienten um absolut 7,3\% (von 28,1 auf 35,4\%; ITT-Analyse) angehoben werden - dies bei einer Patientengruppe, die aufgrund ihrer Metastasierungscharakteristika «ideale» Kandidaten für eine primäre Resektion gewesen wären. Der Unterschied von 7,3\% verfehlte in der ITT-Analyse, der primären Kohorte für die Studienauswertung, zwar knapp das statistische Signifikanzniveau ( $\mathrm{p}=0,058)$. In der Analyse der «eligible patients» und der «resected patients», also der auswertbaren Patienten und derjenigen, die tatsächlich reseziert wurden, wurde das Signifikanzniveau aber erreicht $(\mathrm{p}=0,041$ bzw. 0,025) (Tab. 2).

Aus diesem Grund wird die prä- und postoperative Chemotherapie mit FOLFOX bei Patienten mit resektablen Lebermetastasen jetzt europaweit - mit Ausnahme von den meisten Chirurgen in Deutschland - als der neue Standard angesehen [74]. Auch die European Society for Medical Oncology (ESMO)-Konsensuskonferenz 2010 formuliert: «... is the current standard for all patients with resectable metastases suitable for upfront chemotherapy.»
Für die alleinige postoperative Chemotherapie, die in den deutschen Leitlinien bevorzugt wird, sprechen 2 wegen unzureichender Rekrutierung vorzeitig abgebrochene Studien, in denen ein (heute nicht mehr zeitgemäßes, weil weniger effektives) 5-FU-Bolus-Regime eingesetzt wurde [77, 78]. Die «gepoolte» Analyse der Daten beider abgebrochener Studien (278 Patienten) konnte weder eine signifikante Verlängerung des PFS $(p=0,058)$ noch eine signifikante Verlängerung des OS ( $p=0,095)$ zeigen, wenngleich der Kurvenverlauf einen Nutzen der adjuvanten Therapie vermuten lässt [79]. Die ESMO-Konsensuskonferenz 2010 formuliert hierzu: «If no preoperative chemotherapy is given, at least postoperative adjuvant chemotherapy with single agent 5-FU/FS or FOLFOX should be considered.»

\section{Fazit}

Die «optimale» Behandlungsstrategie für Patienten mit resektablen Lebermetastasen wird in Deutschland nach wie vor kontrovers diskutiert. Aus Sicht der internistischen Onkologen spricht die Evidenz eindeutig (Level II) für die prä- und postoperative Chemotherapie (mit oder ohne zusätzlicher Antikörper-Gabe), die Toxizität nicht maßgeblich dagegen. Aus Sicht der chirurgischen Onkologen wird die primäre Resektion und gegebenenfalls die adjuvante Chemotherapie favorisiert, insbesondere aufgrund der erhöhten Morbidität bei ausgedehnter Leberresektion nach neoadjuvanter Therapie. Von beiden Seiten wird die Durchführung weiterer Studien befürwortet.

\section{AIO/CAO-Joint-Studie und Panter-Studie}

Vor diesem Hintergrund startete im Dezember 2010 unter der Leitung von Prof. Schlitt (Chirurgische Arbeitsgemeinschaft für Onkologie (CAO)) und Prof. Schmoll (AIO) eine explorative randomisierte Phase-II-Studie. Insgesamt sollen 120 Patienten mit R0-resektablen Lebermetastasen für die AIO/ CAO-Joint-Studie rekrutiert werden. Sie erhalten randomisiert entweder keine präoperative Therapie und werden nur postoperativ über 6 Monate mit FOLFOX plus Bevacizumab behandelt. Oder sie erhalten präoperativ für 3 Monate die maximal intensive Therapie FOLFOXIRI plus Bevacizumab und postoperativ ebenfalls für 3 Monate FOLFOXIRI plus 


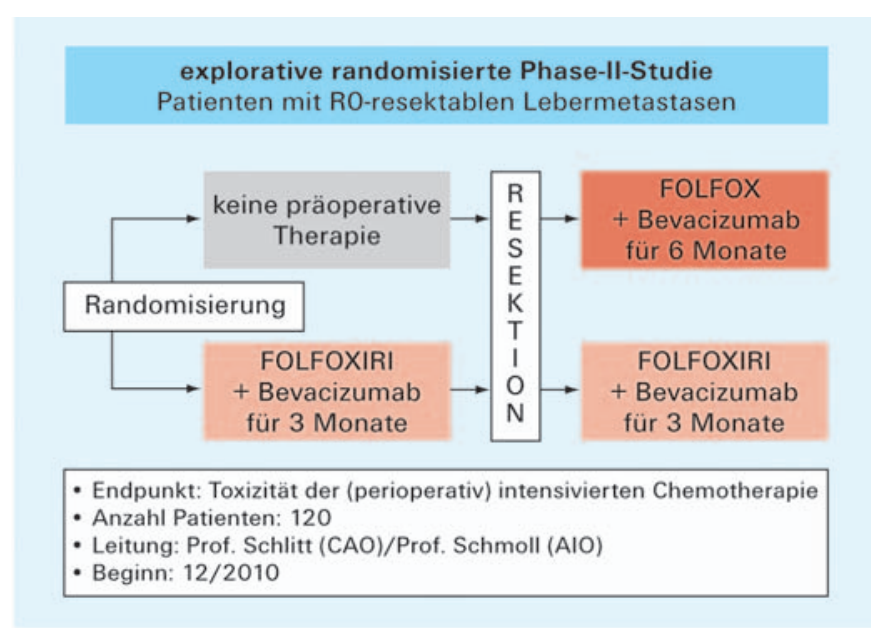

Abb. 11. AIO/CAO-Joint-Studie bei Patienten mit resektablen Lebermetastasen.

Bevacizumab. Primärer Studienendpunkt ist die Toxizität der perioperativ intensivierten Chemotherapie (Abb. 11).

In der «Panter»-Studie, die von Prof. Neuhaus et al. geleitet wird, werden insgesamt 270 Patienten mit sicher resektablen kolorektalen Lebermetastasen nach dem Fong-Score [75] stratifiziert und anschließend randomisiert. KRAS-WildtypPatienten erhalten entweder prä- und postoperativ FOLFOX plus Cetuximab oder nur postoperativ FOLFOX plus Cetuximab. Patienten mit KRAS-mutierten Tumoren erhalten FOLFOX. Primärer Studienendpunkt ist die perioperative Morbidität (Abb. 12).

\section{Vorgehen bei technisch zunächst irresektablen Lebermetastasen}

Bei Patienten mit irresektablen (aber potenziell resektablen) Lebermetastasen - mit der Schwierigkeit der Zuordnung zu dieser Gruppe beim Fehlen von klaren und verbindlichen Kriterien - ist eine präoperative, möglichst intensive systemische Therapie indiziert, um ein «Downsizing» und damit eine sekundäre Resektion zu ermöglichen.

\section{Cetuximab-haltige Therapie}

Patienten mit KRAS-Wildtyp-Tumoren und auf die Leber beschränkten Metastasen («liver-limited disease») können mit einer Cetuximab/Chemotherapie-Kombination hohe Ansprechraten (im Sinne einer metrischen Verkleinerung der Metastasen, wie nach RECIST) erreichen. So wurde in der CRYSTAL-Studie bei dieser Subgruppe unter der Kombination Cetuximab/FOLFIRI eine Ansprechrate von 77\% erzielt [80]. In der CELIM-Studie erhielten die insgesamt 106 Patienten entweder Cetuximab/FOLFOX oder Cetuximab/FOLFIRI. Die Ansprechraten lagen bei 68 bzw. 57\%. Dies führte zu einer R0-Resektionsrate von 38 bzw. 30\% [48]. Irritierend
Panter-Studie

270 Patienten mit sicher resektablen kolorektalen Lebermetastasen - KRAS-Wildtyp (WT) und mutiert (mt) (stratifiziert nach dem Fong-Score)

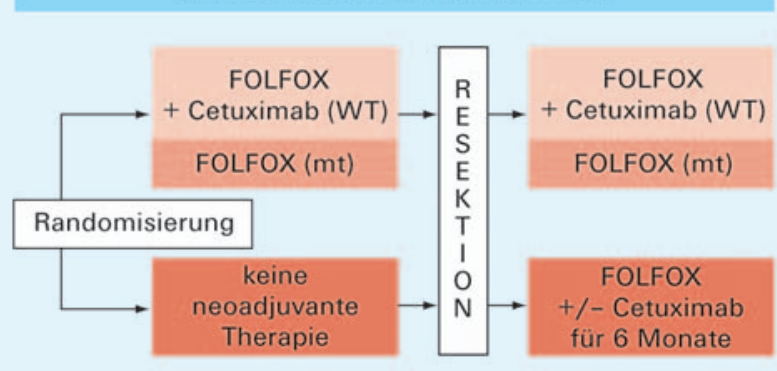

- primärer Studienendpunkt: perioperative Morbidität

Abb. 12. Panter-Studie.

ist allerdings, dass sich zwischen KRAS-Wildtyp-Tumoren und KRAS-mutierten Tumoren kein Unterschied zeigte; auBerdem fehlt eine Cetuximab-freie Vergleichsgruppe, sodass der tatsächliche Einfluss von Cetuximab auf das Ergebnis schwer abschätzbar ist.

\section{Bevacizumab-haltige Therapie}

Die mit Bevacizumab/Chemotherapie-Kombinationen erzielten Ansprechraten bleiben hinter den mit Cetuximab erzielten in der Regel zurück. So wurden in Phase-III-Studien Ansprechraten zwischen (in der NO16966-Studie) 38\% und (in der HORIZON-III-Studie) 47,3\% erzielt [54, 60, 61]. Allerdings betrug die Rate der kurativen Leberoperationen bei den Patienten, bei denen die Leber das einzige von Metastasen befallene Organ war, in der Doppelblindstudie NO16966 17,1\% (36/210) im Bevacizumab-Arm versus 12,6\% (26/207) im Vergleichsarm, obwohl der Arm mit Bevacizumab keine höhere RECIST-Ansprechrate aufwies und obwohl das Erzielen von Resektabilität kein erklärtes Studienziel war (eine geplante größere Operation stellte damals sogar ein Ausschlusskriterium dar) [61]. Das 2-JahresÜberleben der jeweils R0-resezierten Patienten betrug $92,3 \%$ in der Bevacizumab-Gruppe versus $79,0 \%$ in der Gruppe, die nur chemotherapiert worden war - eine Verbesserung um absolute 13,3\% [81]. Diese retrospektive Analyse, die allerdings prospektiv überprüft werden muss, stützt die Hypothese, dass unter einer Bevacizumab-haltigen Therapie tumorbiologische Veränderungen auftreten, die sich nicht durch die Größenabnahme nach RECIST abbilden lassen $[82,83]$.

Interessant ist auch eine Pilotstudie zum neoadjuvanten Einsatz von Bevacizumab plus XELOX bei potenziell resektablen Patienten, in der eine Gesamtansprechrate von $73 \%$ und eine Tumorkontrollrate von $94 \%$ erreicht wurden - darunter 9\% pathologische Vollremissionen [84]. Das 
Gesamtüberleben der resezierten Patienten

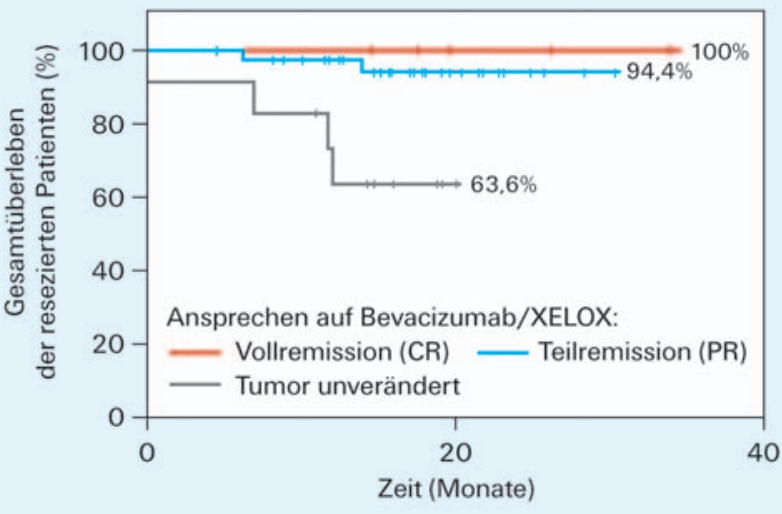

Abb. 13. Pilotstudie zum neoadjuvanten Einsatz von Bevacizumab plus XELOX bei potenziell resektablen Patienten (modifiziert nach [85]).

3-Jahres-Überleben der resezierten Patienten betrug 100\%, wenn zuvor eine Vollremission erreicht worden war. Bei den Patienten mit partieller Remission und Resektion konnte ein OS von 94,4\% erreicht werden, bei den Patienten mit «stable disease» und Resektion von 63,6\% [85] (Abb. 13).

\section{Dreifach-Chemotherapie}

Langzeitdaten der G.O.N.O.-Gruppe zur Dreifach-Chemotherapiekombination FOLFOXIRI (5-FU/FS/Oxaliplatin/Irinotecan) bei insgesamt 196 initial nicht resektablen, unselektionierten Patienten zeigen eine Ansprechrate von 70\%, eine R0-Resektionsrate von 19\% nach 5,5-monatiger systemischer Therapie und ein 5-Jahres-OS der resezierten Patienten von $42 \%$. Die Verträglichkeit der Therapie war gut, d.h. es gab keine perioperative Mortalität und die beobachtete Morbidität ließ sich gut handhaben [86].

\section{Maximal intensive Therapie}

Die Vierfach-Therapie FOLFOXIRI plus Bevacizumab führte in einer Phase-II-Studie der G.O.N.O.-Gruppe zu einer Ansprechrate von $80 \%$ (davon $20 \%$ pathologische Vollremissionen) und einer R0-Resektionsrate von 40\% - ohne perioperative Mortalität [47]. Aufgrund dieser vielversprechenden Ergebnisse plant die AIO derzeit eine neue Phase-II-Studie, in deren Rahmen insgesamt 240 Patienten randomisiert entweder FOLFOX plus Bevacizumab oder die maximal intensive Therapie FOLFOXIRI plus Bevacizumab erhalten sollen. Dabei geht es nicht nur um das Erreichen von Resektabilität, sondern auch um lange PFS-Zeiten bei den nicht resektablen Patienten. Deshalb wird nach 6-monatiger Induktion auf eine Erhaltungstherapie mit Bevacizumab plus 5-FU oder Capecitabin umgestellt.

Auch Cetuximab wurde im Rahmen mehrerer kleiner Pilotprojekte mit FOLFOXIRI kombiniert [87-89]. Bei Patienten mit auf die Leber beschränkten Metastasen wurden
Ansprechraten zwischen 75 und $82 \%$ erreicht - und in einer Studie [87] eine R0-Resektionsrate von $63 \%$.

\section{Neue Studien}

Basierend auf diesen Ergebnissen wurde jetzt die CELIM-2Studie initiiert. Im Rahmen der Studie werden Patienten mit nicht resektablen Lebermetastasen zunächst auf KRAS und BRAF getestet. Handelt es sich um KRAS- und BRAF-Wildtyp-Patienten, wird randomisiert entweder mit FOLFOX/ Cetuximab oder mit FOLFOXIRI/Cetuximab behandelt. Handelt es sich um Patienten mit KRAS-Mutationen, wird randomisiert entweder FOLFOXIRI oder FOLFOXIRI/ Bevacizumab gegeben. Primärer Studienendpunkt ist die Resektabilitätsrate, sekundärer Studienendpunkt das DFS.

Eine zweite Studie, «New Bos», wird von der EORTC (European Organisation for Research and Treatment of Cancer) durchgeführt. In dieser Studie sollen 300 KRAS-WildtypPatienten mit zunächst nicht resektablen Lebermetastasen randomisiert entweder FOLFOX oder FOLFOX plus Bevacizumab oder FOLFOX plus Panitumumab erhalten. Die systemische Therapie erfolgt über jeweils 3 Monate prä- und postoperativ. Primärer Studienendpunkt ist das pathohistologische Ansprechen, und es geht nicht allein darum, die einzelnen Studienarme miteinander zu vergleichen, sondern in erster Linie darum zu prüfen, ob eine Korrelation zwischen dieser Art des Ansprechens und dem DFS in den drei Studienarmen besteht.

\section{Fazit}

Welche präoperative Therapie für Patienten mit zunächst nicht resektablen Lebermetastasen langfristig die «beste» ist, lässt sich derzeit nicht klar beantworten. Deshalb wurden mehrere neue Studien initiiert. Erst durch Langzeitergebnisse, die neben Ansprechraten und R0-Resektionsraten auch reproduzierbare DFS- und OS-Zeiten liefern, wird sich das optimale Vorgehen klären lassen.

\section{Weitere innovative Substanzen für die Therapie des metastasierten kolorektalen Karzinoms: Neue Formen der klinischen Evaluation sind notwendig Verantwortlicher Autor: Dirk Arnold, Hamburg}

Die Inhibition zahlreicher Signalwege, die Interaktion von Tumor und Tumorenvironment bzw. Stroma (einschließlich der Angiogenese) sowie der Einsatz von Stammzellen sind therapeutische Ziele jenseits der bereits verfügbaren Mechanismen, die bei kolorektalen Karzinomen derzeit mit hohem Aufwand untersucht werden. So werden derzeit knapp 40 Inhibitoren gegen verschiedene Signalwege (zumeist gegen die BRAF/MEK-, PI3K/AKT/mTOR-, EGFR/HER-, IGF/ IGFR-Pathways alleine oder in Kombination) in klinischen Studien geprüft (PI3K = Phosphatidylinositol 3-Kinase, $\operatorname{IGF}(\mathrm{R})=$ Insulin-artiger Wachstumsfaktor(rezeptor)). Auch die Hemmung der angiogenen Pathways durch anti-VEGF- 
Abb. 14. Neues Studienkonzept für die klinische Prüfung von Onkologika (nach [90]).

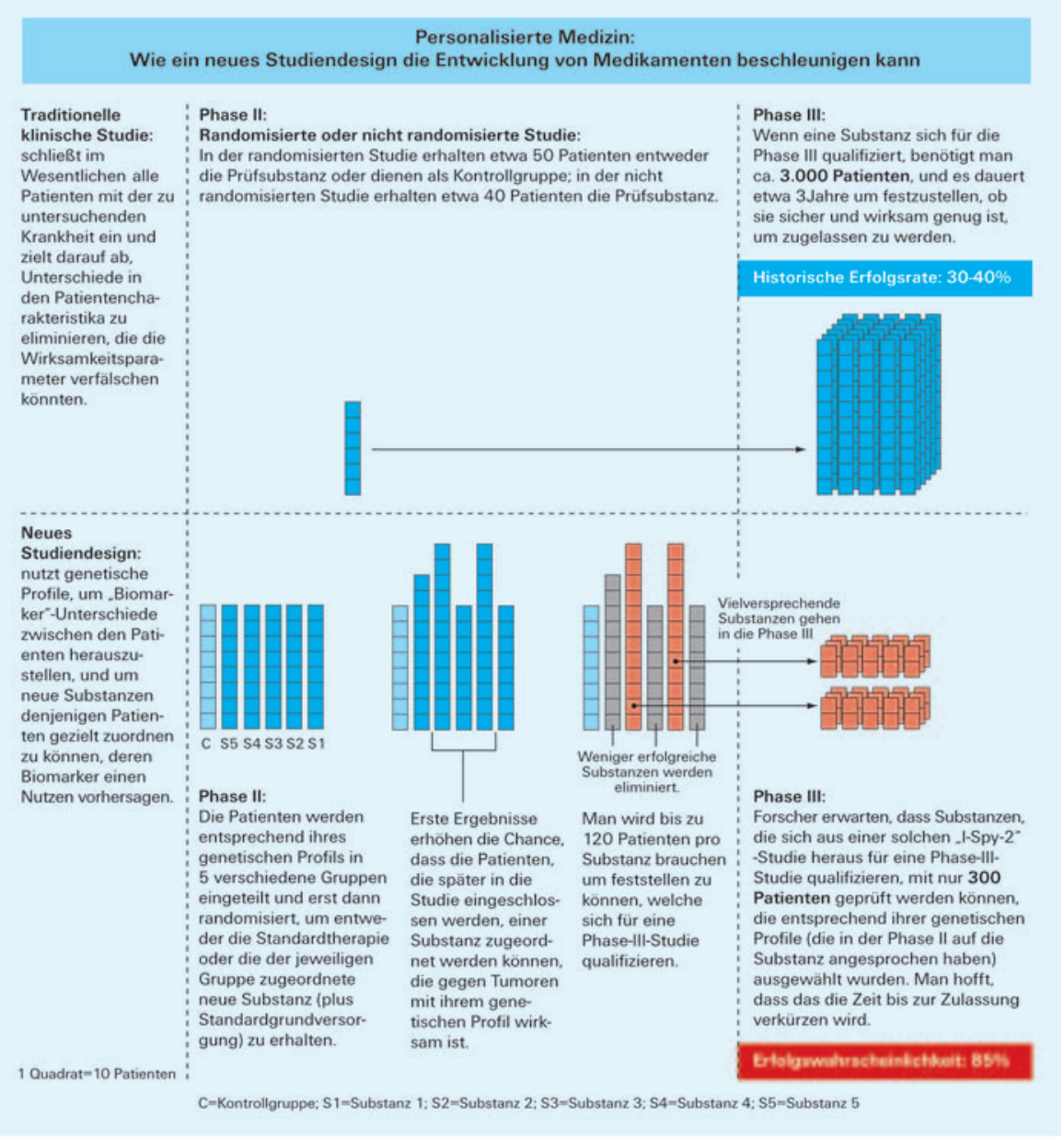

Moleküle, VEGFR-, Angiopoietin- und Integrin-Inhibitoren wird weiterentwickelt. Andere Wirkmechanismen, die in klinischen Studien untersucht werden, sind die Poly-(ADPRibose)-Polymerase (PARP)-, MET-, und Src-Inhibition und viele andere.

Trotz dieser Vielzahl von neuen Angriffspunkten ist die Euphorie der vergangenen Jahre etwas gebremst: Denn schon bei den jetzt in der Klinik befindlichen neuen Substanzen liegt die «Erfolgsrate» des klaren Nutzens bei max. 20\%; zahlreiche neue Ansätze der letzten Jahre wie die «Multitarget»Tyrosinkinase-Inhibitoren sind gescheitert. Zudem hat sich ein gewisser «Entwicklungsstillstand» eingestellt: Das PFS in der Erstlinie liegt bei maximal 12 Monaten, die Ansprechrate bei höchstens $60-70 \%$, ein OS von 2,5 Jahren wird nicht überschritten.

Auch ein methodischer Stillstand ist festzustellen: Der traditionelle Ansatz «Chemotherapie plus/minus neue Substanz» lässt in unselektionierten Studienpopulationen nur geringe Effekte erwarten. Deshalb sind - auch in Anbetracht der fast unendlichen Patientenzahl, die zur Prüfung aller neuer Mechanismen theoretisch benötigt würde - neue Studienkonzepte gefragt, in denen die Patientengruppen identifiziert werden, die von einer bestimmten neuen Substanz (mehr) profitieren könnten. Bei diesen «Plattform»-Studien wird ein molekulares Profil der Patienten zunächst hinsichtlich weniger Parameter (wie KRAS, BRAF, Ligandenkonzentration, aber z.B. auch VEGFR oder VEGF-Level) festgestellt. Die so gebildeten Untergruppen erhalten dann im Rahmen von Phase-I/II-Studien jeweils eine bestimmte Prüfsubstanz, die beim jeweiligen «Biomarker-Profil» am ehesten einen Nutzen verspricht. Die Substanzen, die in ihren Subgruppen eine vielversprechende Wirkung zeigen, gehen dann in die Phase III, wo sie wiederum nur in der jeweiligen Subgruppe geprüft werden. Man geht davon aus, dass für solche Phase-III-Studien mit nach genetischen Profilen ausgewählten Patienten nur jeweils 300 Teilnehmer benötigt werden - statt der üblichen 2000-3000 Teilnehmer in den traditionellen Phase-III-Studien - und dass hierdurch ein starker, auch das OS verbessernder Effekt nachweisbar ist. Darüber hinaus könnten sich Entwicklungs- und Zulassungszeiträume durch dieses Vorgehen verkürzen lassen; ganz abgesehen von der Erfolgsrate, die auf mindestens 70-80\% geschätzt wird. Erste Ansätze in dieser Richtung werden derzeit schon klinisch umgesetzt [90] (Abb. 14); auch die AIO plant die Einführung bzw. Beteiligung an einer solchen Studienplattform. 
Rektumkarzinom: Standards in der adjuvanten Therapie und Rolle der alleinigen Chemotherapie vor Operation Verantwortlicher Autor: Dirk Arnold, Hamburg

Bei Patienten mit Rektumkarzinom des UICC-Stadiums II/III ist die primäre neoadjuvante Radiochemotherapie (RCT) mit infusionalem 5-FU etabliert, denn sie verbessert die lokale Tumorkontrolle. Nach wie vor stellt aber die hohe Fernmetastasierungsrate das hauptsächliche Problem dar [91-93].

\section{Rolle der adjuvanten Chemotherapie nach neoadjuvanter Behandlung}

Die adjuvante 5-FU-basierte Chemotherapie war obligater Bestandteil der CAO/ARO/AIO-94-Studie [93] und der FFCD-9203-Studie [91] nach erfolgter präoperativer Radio(chemo)therapie. Aussagen über den Stellenwert einer postoperativen Chemotherapie können durch diese Studien also nicht gemacht werden. Die vierarmige EORTC-22921-Studie [92] hingegen randomisierte (mit einem $2 \times 2$ faktoriellen Design) zwischen einer postoperativen Chemotherapie und ausschließlicher postoperativer Beobachtung, nach präoperativer Radiotherapie oder RCT. Die postoperative Chemotherapie mit 5-FU/FS führte zwar nicht zu einer statistisch signifikanten Verbesserung des OS (67\% vs. $63 \%, \mathrm{p}=0,1187)$; der Überlebensvorteil betrug zum Zeitpunkt der Auswertung jedoch $4 \%$ absolut - und $6 \%$ absolut für das PFS (58\% vs. $52 \%, \mathrm{p}=0,1327)$. Außerdem separierten die Kurven nach 5 Jahren (für das OS) bzw. 2 Jahren (für das PFS) deutlich voneinander; die Langzeitdaten werden für 2012 erwartet.

Auch in der QUASAR-Studie [29] zeigte die adjuvante Therapie mit 5-FU beim Rektumkarzinom im Stadium II einen Nutzen, der tendenziell sogar größer war als beim Kolonkarzinom. Allerdings war in dieser Studie keine neoadjuvante Vortherapie erfolgt.

Eine Subgruppenanalyse der EORTC-22921-Studie kam zu dem Ergebnis, dass insbesondere Patienten mit Ansprechen auf die präoperative Therapie, im Sinne einer «DownKategorisierung» des Tumors von initial ypT3-4 auf ypT0-2, signifikant von der postoperativen Chemotherapie profitierten [94]. Das heißt, dass die Gruppe mit der besseren Prognose auch den größten Nutzen von der Chemotherapie erfahren würde. Allerdings wurde in einer weiteren, 1 Jahr später publizierten Subgruppen-Analyse deutlich, dass diese Beobachtung nur für die Patienten gilt, die präoperativ lediglich bestrahlt (ohne Chemotherapie) worden waren [95].

Eine weitere Studie aus Italien, die 2010 auf dem European Society for Therapeutic Radiology and Oncology (ESTRO)Kongress in Barcelona vorgestellt wurde, hat bei 655 Patienten die Frage nach dem Nutzen einer adjuvanten Chemotherapie nach neoadjuvanter RCT, mit 5-FU versus Kontrolle, ebenfalls geprüft. Auch hier zeigte sich in allen Subgruppen kein Vorteil für eine adjuvante Therapie mit 5-FU [96].

Zusammenfassend spricht damit die derzeitige formale Evidenz eher gegen die adjuvante Chemotherapie, und man wird sich, nach einer genauen Prüfung der neuen Studiendaten, fragen müssen, ob man die derzeitigen Empfehlungen in der S3-Leitlinie [9] weiterhin aufrechterhalten kann; diese befürwortet die adjuvante Chemotherapie mit 5-FU nach neoadjuvanter RCT, unabhängig vom Tumorstadium. Allerdings kann «pro» eine adjuvante Therapie die hohe Metastasierungsrate und das Fehlen jeglicher Therapie mit Oxaliplatin angeführt werden. In der Diskussion im Gremium zeigte sich, dass als pragmatischer Ansatz - zumindest bei Patienten mit mutmaßlich schlechter Prognose (große Tumoren, Lymphknotenpositivität, kein/kaum Ansprechen auf die neoadjuvante RCT) - eine adjuvante Therapie mit 5-FU/Oxaliplatin oder Capecitabin/Oxaliplatin erwogen wird.

\section{Bedeutung der pathologischen Vollremission}

Das pathohistologische Ansprechen, insbesondere die pathohistologische komplette Remission (pCR), stellt einen gut untersuchten frühen Surrogat-Endpunkt für die RCT des Rektumkarzinoms dar: Zahlreiche Studien haben gezeigt, dass das Auftreten einer pCR mit einer sehr geringen Lokalrezidivrate korreliert. Eine im letzten Jahr publizierte Metaanalyse hat zudem unterstrichen, dass die durch eine RCT erzielte pCR darüber hinaus auch mit einem signifikant längeren fernmetastasenfreien Überleben und OS einhergeht [97].

Interessanterweise zeigen einige neuere Beobachtungen, dass dies nicht für alle Schemata zu gelten scheint, z.B. zuletzt die kürzlich auf dem ASCO GI vorgestellte EXPERT-C-Studie [98]: In dieser randomisierten europäischen Phase-II-Studie hatten KRAS-Wildtyp-Patienten mit lokal fortgeschrittenem Rektumkarzinom zunächst eine Induktionschemotherapie mit Capecitabin/Oxaliplatin plus/minus Cetuximab erhalten. Im Anschluss daran erfolgte die Capecitabin-modulierte RCT. Postoperativ wurde erneut Capecitabin/Oxaliplatin plus/minus Cetuximab gegeben. Die pCR-Rate, der primäre Studienendpunkt, konnte durch die zusätzliche CetuximabGabe nicht verbessert werden (pCR 11\% vs. 7\%; $p=0,714$ ). Das OS als sekundärer Endpunkt wurde durch die zusätzliche Cetuximab-Gabe aber signifikant verlängert (3-Jahres-OS $96 \%$ vs. $81 \%$; $H R=0,27 ; p=0,035)$ (Abb. 15).

Angesichts dieses frappierenden Ergebnisses ist die Zuverlässigkeit des «Biomarkers» pCR zu hinterfragen. Die Ursachen hierfür wurden in der Expertenrunde ausführlich diskutiert; die wahrscheinlichste Hypothese ist, dass der «systemische» Effekt mit der daraus resultierenden Prognoseverbesserung den lokalen Effekt weit überwiegt, sodass sich die (geringeren) «Lokaleffekte» nicht (mehr) in eine Prognoseverbesserung umsetzen. In jedem Fall sollten weitere Studien den frühen Endpunkt pCR nur noch als sekundären Endpunkt einsetzen.

\section{Ausschließliche präoperative Chemotherapie (ohne RCT)}

Die Daten bisheriger Studien zeigen, dass eine adjuvante Chemotherapie nach einer vorausgegangenen präoperativen $\mathrm{RCT}$ häufig gar nicht, nicht zeitgerecht oder nur in unzurei- 


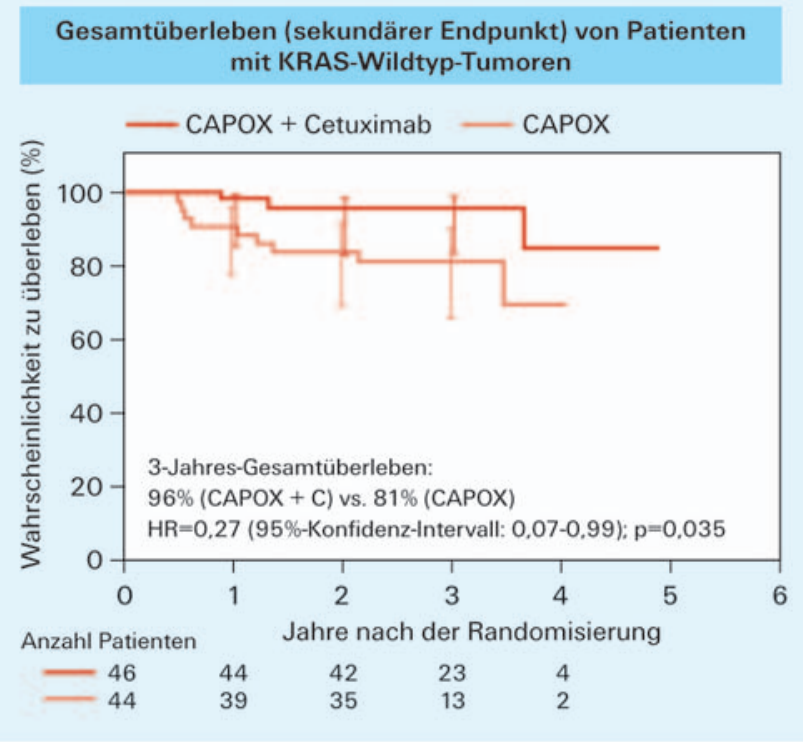

Abb. 15. EXPERT-C-Studie: randomisierte Phase-II-Studie bei Patienten mit lokal fortgeschrittenem Rektumkarzinom, Capecitabin/Oxaliplatin plus/minus Cetuximab (modifiziert nach [98]).

chender Dosisintensität durchführbar ist [99, 100]. Deshalb verfolgen neuere Studien den Ansatz, die systemische Chemotherapie vorzuziehen und - im Sinne einer Induktionschemotherapie - vor der neoadjuvanten RCT zu verabreichen [101].

Ein weiterer experimenteller Ansatz besteht darin, bei ausgewählten Patienten mit hoher Wahrscheinlichkeit für eine vollständige Tumorresektion (zirkumferenzieller Resektionsrand (CRM) negativ) und guter Prognose nur eine präoperative Induktionschemotherapie durchzuführen und auf die RCT ganz zu verzichten.

Dieses Vorgehen wurde im Rahmen einer Pilotstudie von einer Forschergruppe des Memorial Sloan-Kettering Cancer Centers näher untersucht [102]. Insgesamt 31 Patienten mit einem Rektumkarzinom im Stadium II/III (aber ohne T4-Tumor) erhielten 6 Zyklen FOLFOX. Während der ersten 4 Zyklen wurde zusätzlich Bevacizumab verabreicht. Dann erfolgte eine Re-Evaluierung mittels bildgebender Verfahren und endorektalem Ultraschall. Patienten mit bildgebendem Ansprechen wurden sofort operiert; nur Patienten, die auf die systemische Therapie nicht angesprochen hatten (Tumorprogression oder auch «stable disease»), sollten eine präoperative 5-FU-gestützte RCT erhalten. Eine solche «Salvage»-RCT war (postoperativ) auch für Patienten vorgesehen, bei denen durch die Resektion kein R0-Status erzielt werden konnte. Allerdings wurde bei allen Patienten (bis auf 2, die wegen kardiovaskulärer Nebenwirkungen aus der Studie ausschieden, aber dennoch R0-reseziert werden konnten) eine Tumorregression beobachtet. Die pCR-Rate lag bei $27 \%$. Sämtliche 29 Patienten konnten auch R0-reseziert werden, sodass bei keinem Patienten eine prä- oder postoperative RCT erfor-

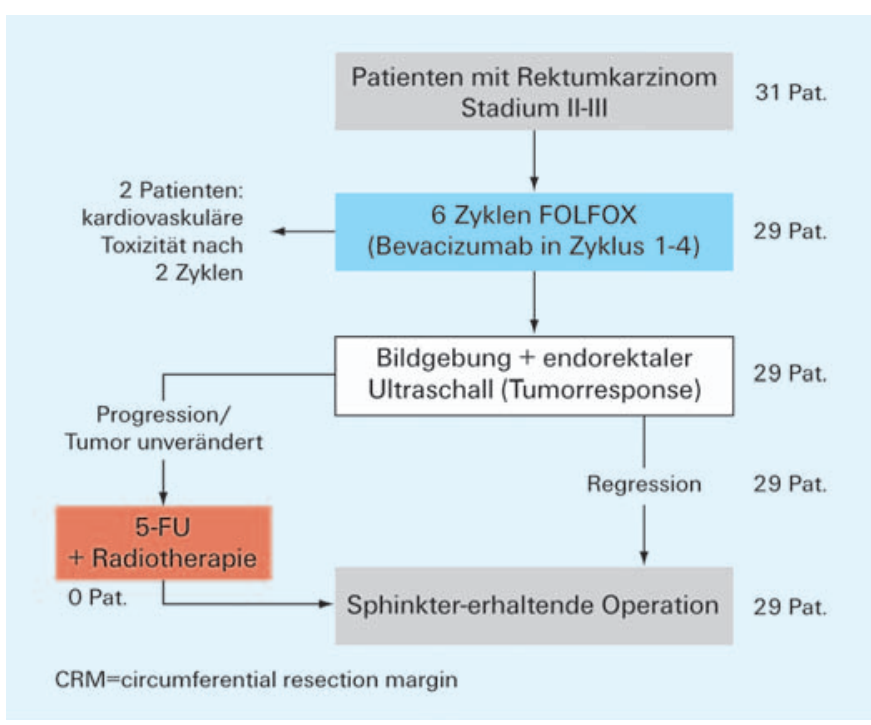

Abb. 16. Neoadjuvante Chemotherapie (ohne RCT) bei CRM-negativem T3-Rektumkarzinom (modifiziert nach [101]).

derlich wurde. Eine postoperative Chemotherapie war zwar allgemein empfohlen, aber dem behandelnden Arzt zur Entscheidung überlassen (Abb. 16).

Angesichts dieser vielversprechenden Ergebnisse wird jetzt eine US-Intergroup-Phase-III-Studie geplant, in der dafür geeignete Patienten präoperativ randomisiert entweder eine RCT oder 6 Zyklen FOLFOX erhalten. Postoperativ wird in beiden Studienarmen FOLFOX gegeben. Bei fehlendem Ansprechen oder Nicht-R0-Resektion erfolgt eine RCT.

\section{Fazit}

Eine adjuvante Chemotherapie beim Rektumkarzinom nach präoperativer RCT ist weiterhin nicht durch prospektive randomisierte Studien belegt, kann aber nach der Meinung der S3-Leitlinie - und auch des Expertengremiums - aufgrund der schlechten «Spontanprognose» von Patienten mit fortgeschrittenem Rektumkarzinom weiterhin erwogen werden. Wird behandelt, kann 5-FU oder Capecitabin verabreicht werden, bei Erwägung von Oxaliplatin analog 5-FU/Oxaliplatin bzw. Capecitabin/Oxaliplatin. Ein interessanter Ansatz ist, bei dafür geeigneten Patienten nur eine systemische Chemotherapie präoperativ durchzuführen und auf die RCT zu verzichten.

\section{Induktionschemotherapie vor neoadjuvanter RCT beim Rektumkarzinom \\ Verantwortlicher Autor: Thomas Höhler, Recklinghausen}

Der Vorteil einer Induktionschemotherapie vor der neoadjuvanten RCT besteht darin, dass die vorgezogene systemische Therapie zu einem früheren Zeitpunkt im Krankheitsverlauf 


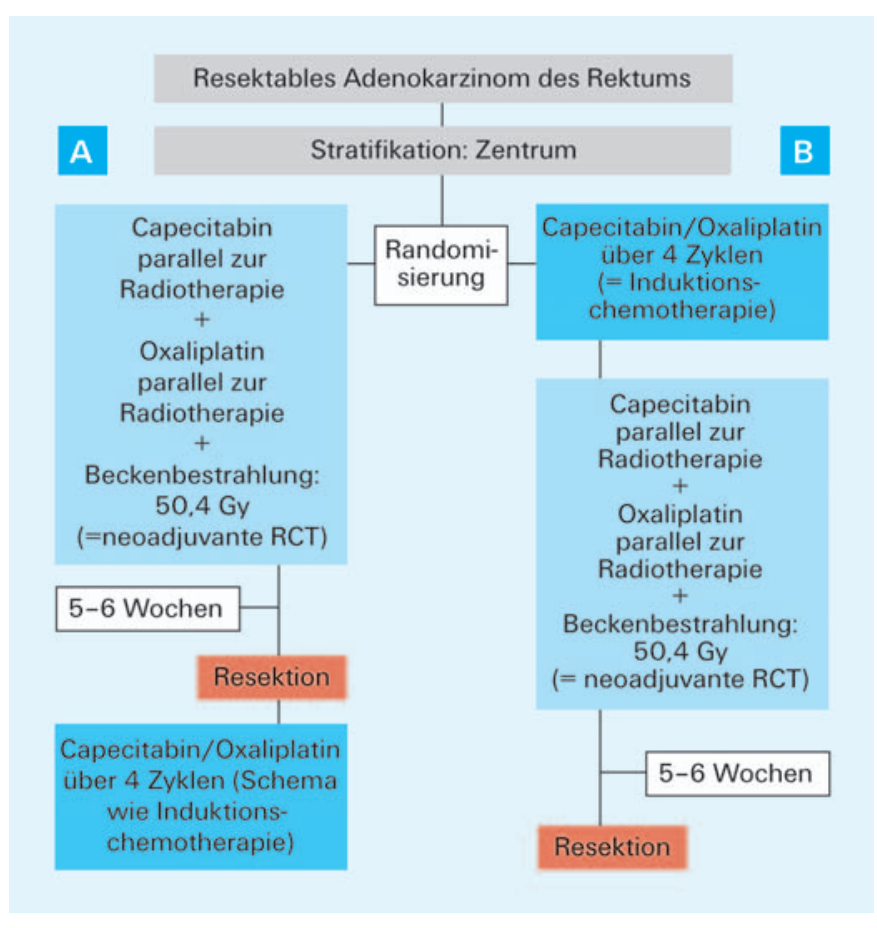

Abb. 17. Induktionschemotherapie vor neoadjuvanter RCT (modifiziert nach 104]).

erfolgt, als dies bei einer adjuvanten Therapie der Fall wäre. Die Chemotherapie ist zu diesem Zeitpunkt besser verträglich und kann in höherer Dosisintensität gegeben werden als die adjuvante Chemotherapie. Zudem kann man durch den sequenziellen Einsatz von systemischer Chemotherapie und RCT eine zusätzliche Tumorregression erwarten. Potenzielle Nachteile sind eine Verzögerung der Operation und die Selektion strahlenresistenter Tumorzellklone.

Die erste Studie zur Induktionschemotherapie beim lokal fortgeschrittenen Rektumkarzinom, die EXPERT-Studie, wurde bereits im Jahr 2006 veröffentlicht [103]. In dieser Studie, Vorläufer-Studie zur oben bereits erwähnten EXPERTC-Studie [98], erhielten 77 Rektumkarzinom-Patienten mit schlechter Prognose zunächst eine neoadjuvante Chemotherapie bestehend aus 4 Zyklen Capecitabin plus Oxaliplatin. Dann folgte eine Capecitabin-basierte RCT. Postoperativ wurden erneut 4 Zyklen Capecitabin/Oxaliplatin gegeben. Somit handelt es sich bei dem Studienprotokoll um eine Intensivierung der systemischen Therapie durch die zusätzliche neoadjuvante Gabe, nicht um das Vorziehen einer adjuvanten Chemotherapie in die Neoadjuvanz.

Die Ansprechrate nach Abschluss der neoadjuvanten Chemotherapie betrug $88 \%$ und konnte durch die anschließende RCT auf $97 \%$ gesteigert werden. Zudem konnten $24 \%$ pathologische Vollremissionen (der primäre Endpunkt) erzielt werden. Alle Patienten außer einem wurden R0-reseziert.

Die Studie wurde, nach einer Protokoll-Ergänzung zum Ausschluss von Patienten mit ernsten kardialen Problemen in der jüngsten Krankheitsgeschichte, weiter fortgesetzt und um- fasste letztlich 105 Patienten. Nach einer medianen Nachbeobachtungszeit von fast 5 Jahren wurde bei diesem Hochrisikokollektiv ein 3-Jahres-PFS von $68 \%$ und ein 3-JahresOS von $83 \%$ dokumentiert [104].

$\mathrm{Ob}$ das alleinige Vorziehen der systemischen Therapie in die Neoadjuvanz von Nutzen ist, wurde im Rahmen einer randomisierten Phase-II-Studie untersucht. Die Patienten erhielten im Prüfarm initial 4 Zyklen Capecitabin/Oxaliplatin, gefolgt von einer Capecitabin- und Oxaliplatin-basierten RCT. Postoperativ wurde nicht chemotherapiert. Dagegen wurde im Standardarm primär die RCT durchgeführt, und die 4 Zyklen Capecitabin/Oxaliplatin wurden postoperativ verabreicht [101] (Abb. 17). Die pCR, der primäre Endpunkt, betrug 13,5\% unter der Standardtherapie versus 14,3\% im Prüfarm mit der vorgezogenen systemischen Therapie. Darüber hinaus war die chemotherapeutische Dosisdichte im Prüfarm signifikant höher und die Toxizität niedriger, sodass eine randomisierte Phase-III-Studie zur definitiven Testung der Induktionsstrategie empfehlenswert erscheint.

\section{Fazit}

Die Nachbeobachtungszeiten in den bisher vorliegenden Phase-II-Studien sind noch zu kurz, Daten zur Lokalrezidivrate und zur Fernmetastasierungsrate liegen noch nicht vor. Das Konzept der Induktionschemotherapie - sowohl im Sinne einer Intensivierung der systemischen Therapie bei Risikopatienten als auch im Sinne eines Vorziehens der adjuvanten Therapie - erscheint aber attraktiv und sollte in Phase-IIIStudien geprüft werden.

\section{Klinische Vollremission nach RCT \\ beim Rektumkarzinom - wie weiter behandeln? \\ Verantwortlicher Autor: Hauke Lang, Mainz}

Der Begriff der «klinisch kompletten Remission» (cCR) ist nicht einheitlich definiert [105, 106], und die klinische Vollremission korreliert auch nicht mit der pathohistologischen Vollremission. So fand sich in einer Untersuchung mit $488 \mathrm{~Pa}-$ tienten, davon 93 Patienten mit cCR, nur in $25 \%$ der Fälle auch eine pCR [107]. Liegt nach der RCT tatsächlich eine pCR, also ein ypT0-Tumor vor, so sind bei 5\% der Patienten dennoch positive Lymphknoten vorhanden [105].

Therapeutisch ist bei cCR nach RCT sowohl ein radikalchirurgisches Vorgehen (totale mesorektale Exzision) als auch ein Abwarten, allerdings mit regelmäßiger Kontrolle des Befundes in kurzen Abständen, denkbar. Mit Letzterem wurde in einer Serie von 71 Patienten eine Lokalrezidivrate von $3 \%$ und eine Fernmetastasierungsrate von $4 \%$ erreicht $[108,109]$.

Eine dritte Möglichkeit ist die transanale endoskopische Mikrochirurgie, die auch in Mainz durchgeführt wird und die laut einer Übersichtsarbeit [105] bei ypT0-Tumoren zu sehr guten Ergebnissen mit einer durchschnittlichen Lokalrezidiv- 
rate von $1 \%$ und einer Fernmetastasierungsrate von $4 \%$ führt. Damit bietet sich diese Methode der lokalen Exzision als Staging-Methode an, um zu prüfen, ob tatsächlich ein ypT0Tumor vorliegt, und sie ist in diesem Fall dann auch die geeignete Therapie. Mit dem radikalchirurgischen Vorgehen werden keine besseren Ergebnisse erzielt [105].

Letzteres scheint auch eine aktuelle koreanische Arbeit zu bestätigen. Unter 333 Patienten mit ypT0-Tumoren, die sämtlich nachoperiert (283 Rektumresektionen, 50 Extirpationen) und $\mathrm{zu} 86 \%$ auch postoperativ bestrahlt wurden, befanden sich 9\% Lymphknoten-positive. Deren Langzeitergebnis war deutlich schlechter mit einem signifikant kürzeren 5-JahresOS als das der N0-Patienten [110]. Ob diese ypT0 Lymphknoten-positiven Patienten aber von einem radikalen Vorgehen tatsächlich profitieren, ist offen.

\section{Rektumkarzinom: Molekulare Prädiktoren der} Therapieantwort - kommt die Individualisierung? Verantwortliche Autoren: Torsten Liersch, Göttingen, Claus Rödel, Frankfurt

Das Ansprechen eines lokal fortgeschrittenen Rektumkarzinoms (cUICC-Stadien II, III) auf eine präoperative (neoadjuvante) 5-FU-basierte RCT ist sehr heterogen und reicht von der pCR bis zur Therapieresistenz. Angesichts der klinischen Forderung, eine an das «individuelle» Rezidivrisiko angepasste multimodale Therapiestrategie zu entwickeln, sind in den vergangenen 5 Jahren Fortschritte in der genomischen und proteomischen Analyse von zellulären Signaltransduktionswegen erzielt worden. Dabei zeigte sich, dass ein so komplexer Phänotyp wie «Tumorresponse» nicht vom Expressionslevel eines einzelnen Gens oder mehrerer Gene und Proteine abhängt. Methoden wie die Microarray-Technologie eröffneten die Möglichkeit, durch simultane Bestimmung der Expressionslevel von Zehntausenden von Genen die Komplexität genetischer Signaltransduktionswege und ihre Vernetzung zu entschlüsseln. Unter Einsatz dieser Technologien wird sich zukünftig nach vorheriger studiengebundener ReValidierung der bisher ermittelten Responseparameter die seit langem angestrebte personalisierte genomische Medizin verwirklichen lassen, in der Patienten auf Basis der individuellen Tumorbiologie und des genetischen Tumorprofils onkologisch «maßgeschneidert» behandelt werden können [111].

Gegenwärtig ist unter den postoperativ bestimmbaren klinikopathologischen Parametern bei Patienten mit einem initialen cUICC-II/III Rektumkarzinom und einer nach RCT nachweisbaren pCR oder partiellen Remission (PR) des Primarius der residuelle Lymphknotenstatus der wichtigste prognostische Marker. Er scheint sich für eine weitere individuelle Risikostratifizierung zu eignen [112]. Unter der Voraussetzung einer umfassenden, standardisierten histopathologischen Aufarbeitung des Rektumresektates (nach TME-Chirurgie) haben Patienten mit einem ypN0-Status (mindestens 12 meso- rektale Lymphknoten wurden untersucht!) nach neoadjuvanter RCT ein signifikant besseres tumorfreies Überleben als Patienten mit verbliebenen Lymphknotenmetastasen (ypN1/2-Status) [112].

Bei Lymphknoten-negativen Patienten (ypN0) wurden über die standardisierte Aufarbeitung des mesorektalen Kompartiments nur in 0,3\% der Fälle okkulte Mikrometastasen entdeckt, sodass hier keine Rationale für ein zusätzliches Screening besteht [113].

Bezüglich KRAS und BRAF hat sich gezeigt, dass in prätherapeutischen Biopsien von lokal fortgeschrittenen Rektumkarzinomen in $48 \%$ KRAS-Mutationen vorliegen, wohingegen in nur $2 \%$ BRAF-Mutationen gefunden wurden. Der KRAS-Status korrelierte weder mit dem Ansprechen auf die RCT noch mit dem OS. Lediglich bei G12V-Mutationen wurde, verglichen mit G13D-Mutationen, signifikant häufiger eine RCT-induzierte Tumorregression beobachtet, allerdings sind weitere Untersuchungen an größeren Patientenkollektiven erforderlich [114]. Da bei Rektumkarzinomen mit KRASMutationen bestimmte Gene, darunter DUSP4, eine MAPKinase-Phosphatase, und SMYD3, eine Histon-Methyltransferase, überexprimiert werden, besteht hier ein potenzieller Ansatzpunkt zur Entwicklung neuer, zielgerichteter Therapeutika, mit deren Hilfe die Resistenz der KRAS-mutierten Karzinome gegenüber EGFR-Antikörpern möglicherweise überwunden werden könnte [115].

Der eingangs bereits erwähnte Ansatz, aus prätherapeutischen Tumorproben genetische Response-Signaturen zu entwickeln, zeigt erste Erfolge. In einem Versuch konnte mithilfe des «Genexpression-Klassifizierers» bei $81 \%$ der Proben die richtige Prognose zugeordnet werden [116]. Interessant sind auch ganz aktuelle Daten, wonach eine niedrige ThymidylatSynthase-Expression beim lokal fortgeschrittenen Rektumkarzinom eine schlechte Prognose bedeuten kann [117] (Abb. 18). Zudem konnte kürzlich gezeigt werden, dass, wenn es mithilfe der präoperativen RCT nicht gelingt, eine Herabregulierung von Survivin, eines Apoptose-Inhibitors, zu induzieren, bei den betroffenen Patienten mit einer erhöhten Fernmetastasierungsrate und einem signifikant verkürzten OS gerechnet werden muss [118].

Mithilfe einer Kombination der genannten und weiterer Biomarker bzw. klinikopathologischer Faktoren dürfte es demnächst möglich sein, eine valide Rezidivrisiko-Stratifizierung nach erfolgter neoadjuvanter RCT durchzuführen und daran die Intensität der weiteren Therapie auszurichten.

\section{$5 \times 5$ Gy versus RCT beim Rektumkarzinom - Auswirkung auf die Lebensqualität Verantwortlicher Autor: Rainer Fietkau, Erlangen}

Lebensqualität ist ein multifaktorielles Geschehen. Für Patienten mit Rektumkarzinom bedeutet dies vor allem eine geringe chronische und akzeptable akute Toxizität der Thera- 
Abb. 18. Thymidylat-Synthase (TS) - Zielstruktur von 5-FU. Eine niedrige ThymidylatSynthase-Expression bedeutet eine schlechte Prognose (modifiziert nach [117]).

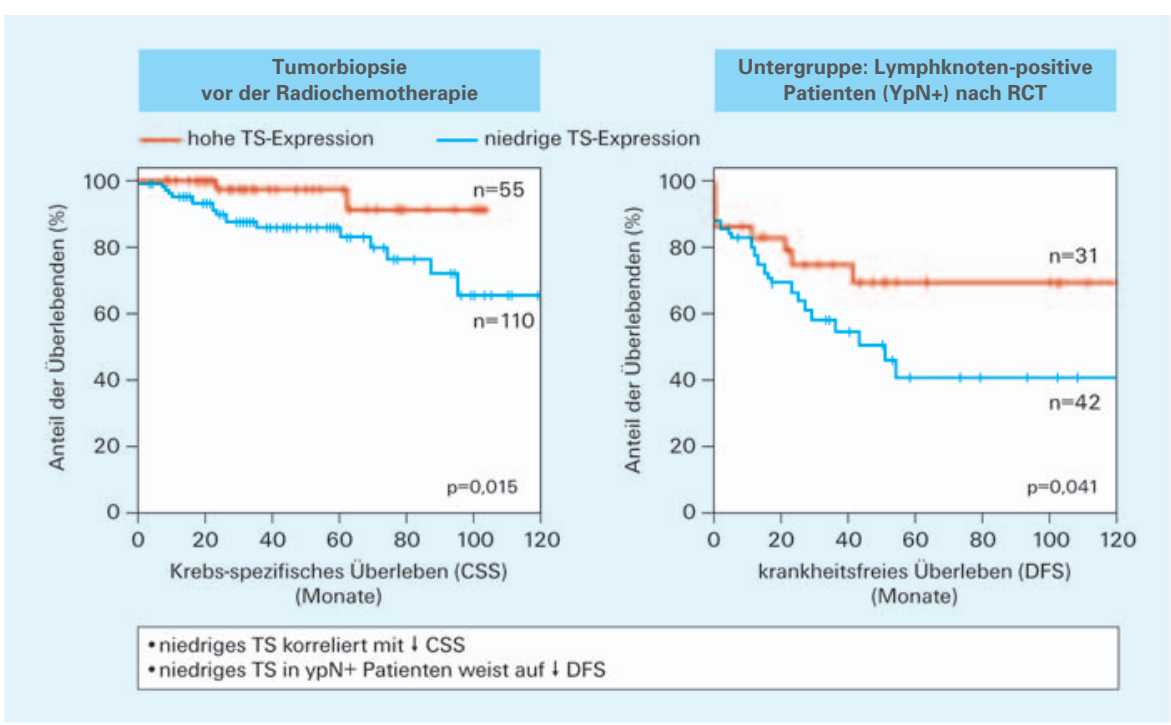

pie, Erhalt des Sphinkters und der Sphinkterfunktion sowie Aufrechterhaltung der sexuellen Funktion. Die Studien der letzten Jahre haben gezeigt, dass die RCT eventuell Vorteile gegenüber der $5 \times 5$ Gy-Kurzzeitbestrahlung aufweist. So war im Langzeitverlauf nach einer $5 \times 5$ Gy-Therapie signifikant häufiger ein neues Stoma erforderlich, oder das vorhandene Stoma konnte nicht entfernt werden $[119,120]$. In einer niederländischen Studie mit $5 \times 5$ Gy waren z.B. im Rahmen einer multivariaten Analyse bei Männern die Radiotherapie und ein temporäres oder permanentes Stoma signifikante Faktoren für eine reduzierte sexuelle Funktion 2 Jahre nach der Behandlung, für die erektile Dysfunktion z.B. ein exzessiver Blutverlust oder eine Anastomoseninsuffizienz. Bei Frauen waren die Radiotherapie und ein temporäres oder permanentes Stoma signifikante Faktoren für eine reduzierte sexuelle Funktion. Die «overall quality of life» war bei den zusätzlich bestrahlten Patienten im Vergleich zu den operierten Patienten aber nicht unterschiedlich [121]. Eine aktuelle australische Studie [122], in der $5 \times 5$ Gy mit der RCT verglichen wurde, zeigte keine signifikanten Unterschiede bezüglich der «späten Toxizität» und auch ein vergleichbares 5-Jahres-Überleben.

Insgesamt wird die Sphinkterfunktion bei Anwendung von $5 \times 5$ Gy in allen Studien negativ beeinflusst, wohingegen die Daten bei einer Langzeit-RCT nicht eindeutig sind [123].

\section{Responsebeurteilung durch PET/CT beim Rektum- und Kolonkarzinom}

Verantwortlicher Autor: Markus Luster, UIm

Seit einiger Zeit findet bei den bildgebenden Verfahren ein Paradigmenwechsel statt. Der Trend geht weg von der ausschließlich morphologisch-physikalischen Darstellung einer
Struktur und hin zur zusätzlichen Detektion spezifischer molekularer Signaturen bzw. bestimmter funktioneller Parameter. Surrogat-Biomarker wie die Magnetresonanz (MR)Spektroskopie oder die Positronenemissionstomographie (PET)/CT mit (neuen) radioaktiv markierten Tracern bieten die Möglichkeit, ein Therapieansprechen frühzeitig zu erfassen und infolgedessen das Behandlungsregime entsprechend zu modulieren.

Die integrierte anatomisch-metabolische Bildgebung mit Fluordesoxyglukose (FDG)-PET/CT gilt heute als ein etabliertes Verfahren [124]. In den USA ist das Monitoring der Therapieantwort durch PET bei vielen Indikationen Standard und wird von den großen Versicherern wie Medicare erstattet. Wie die Nationale PET-Registry zeigt, wurde der Therapieplan infolge des PET-Ergebnisses in 50\% der Fälle geändert, d.h. es wurde entweder zu einer anderen Therapie übergegangen oder die Dosis oder die Dauer der bisherigen Therapie wurde modifiziert [125]. In Deutschland ist das nuklearmedizinische Verfahren zum Therapie-Monitoring jedoch bisher nicht zugelassen.

Das Prinzip der Therapieresponse-Beurteilung durch PET/ CT besteht darin, dass bei einem weiterhin «positiven» PETScan z.B. nach 2 Therapiezyklen davon ausgegangen wird, dass die eingesetzte Therapie pro Zeiteinheit nicht genügend Tumorzellen eliminiert, also nicht stark genug wirksam ist, um innerhalb eines vertretbaren Zeitraums zum Erfolg zu führen. Umgekehrt impliziert ein negativer Scan nach 2 Therapiezyklen das Gegenteil [126, 127] (Abb. 19).

Neben dem Staging von Kolonkarzinom-Hochrisikopatienten, der Detektion von lokalen und systemischen Rezidiven und der Evaluierung einer potenziell resektablen, begrenzten Metastasierung eignet sich die FDG-PET/CT auch zum Monitoring nach lokal-ablativer Therapie von Lebermetastasen [128]. 
Abb. 19. Therapieresponse-Beurteilung durch PET/CT (modifiziert nach [127]).

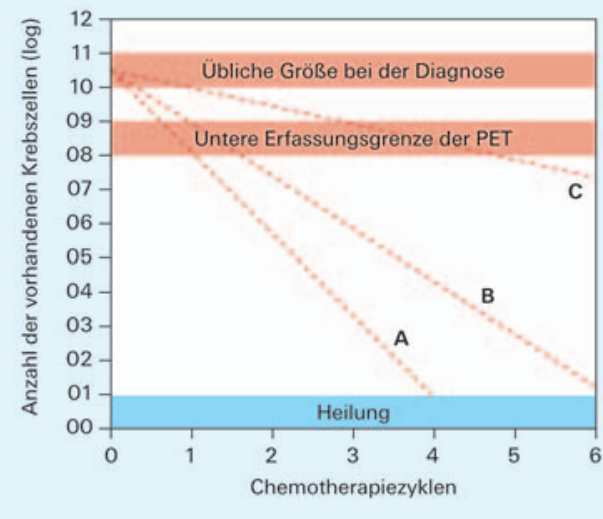

Ein positiver PET-Scan nach 2 Zyklen Chemotherapie lässt vermuten, dass weniger als 1 oder 2 logs (Logarithmus-Stufen) Tumorzellen eliminiert wurden. Es ist unwahrscheinlich, dass die 10 oder 11 logs, die für eine Heilung benötigt werden, sich durch 8 Zyklen eines Standardschemas eliminieren lassen werden.

Ein negativer PET-Scan nach 2 Zyklen Chemotherapie impliziert das Gegenteil. Die Rate der Tumorzellabtötung bei diesem Tumor reicht aus, um Heilung zu bewirken Tumor reicht aus, um Heilung zu bewirk
oder zumindest eine länger anhaltende Remission.

\section{Fortgeschrittenes Magenkarzinom: AVAGAST-Studie und neue Therapieoptionen \\ Verantwortlicher Autor: Thomas Höhler, Recklinghausen}

Das Magenkarzinom ist weltweit der am vierthäufigsten diagnostizierte Krebs - und bei Männern die am zweithäufigsten zum Tode führende Tumorerkrankung. Da die Erstsymptome unspezifisch sind, wird die Diagnose meist im Spätstadium gestellt. Mit einer medianen Überlebenszeit von etwa 10-11 Monaten unter Chemotherapie hat das fortgeschrittene Magenkarzinom eine schlechte Prognose. Im letzten Jahr wurden 2 neue Studien zu dieser Karzinomentität vorgestellt.

An der AVAGAST-Studie [129] nahmen insgesamt 774 Patienten mit einem nicht vorbehandelten, lokal fortgeschrittenen oder metastasierten Karzinom des Magens oder des gastroösophagealen Übergangs teil. Sie erhielten randomisiert und doppelblind entweder Capecitabin/Cisplatin plus Bevacizumab oder Capecitabin/Cisplatin plus Plazebo (Abb. 20). Cisplatin wurde über maximal 6 Zyklen gegeben, Capecitabin und Bevacizumab bzw. Plazebo bis zur Krankheitsprogression. An der Studie nahmen insgesamt 93 Zentren aus 17 Ländern teil.

Die Patienten waren zu zwei Drittel Männer, im Median 58 bzw. 59 Jahre alt (Spanne: 22-82 Jahre) und wiesen zu 95\% einen Eastern Cooperative Oncology Group (ECOG)-PS von 0 oder 1 auf. Knapp die Hälfte der Patienten (49\%) wurde in Asien rekrutiert, 32\% in Europa, 19\% in Nord- und Südamerika. Die Bevacizumab-haltige Therapie war sehr gut verträglich; Toxizitäten des World Health Organization (WHO)Grades 3-5 waren unter Bevacizumab nicht häufiger als unter Plazebo. Lediglich Hypertonie wurde deutlich häufiger beobachtet $(6 \%$ vs. $<1 \%)$.

Das OS, der primäre Endpunkt, wurde im Gesamtkollektiv von 10,1 Monaten unter der alleinigen Chemotherapie auf 12,1 Monate unter Chemotherapie plus Bevacizumab verlängert. Dieser Unterschied war nicht signifikant ( $p=0,1002$; HR $=0,87 ; 95 \%-C I=0,73-1,03)$. Damit ist die Studie negativ. Das

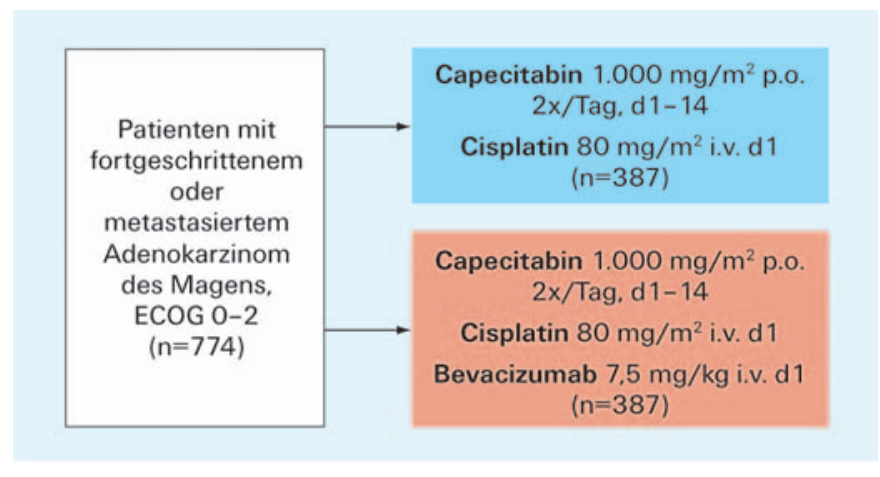

Abb. 20. AVAGAST-Studie: Bevacizumab beim Magenkarzinom (modifiziert nach [129]).

PFS betrug 5,3 Monate unter der alleinigen Chemotherapie versus 6,7 Monate unter Chemotherapie plus Bevacizumab. Dieser Unterschied war signifikant mit $\mathrm{p}=0,0037$ ( $\mathrm{HR}=0,80$; $95 \%-C I=0,68-0,93)$. Auch bezüglich der Ansprechrate zeigte sich ein signifikanter Unterschied. Es sprachen $37 \%$ der Chemotherapierten, aber $46 \%$ der mit Chemotherapie plus Bevacizumab Behandelten auf die Therapie an. Dieser Unterschied von $9 \%$ war signifikant mit $\mathrm{p}=0,0315$.

\section{Auffällige regionale Unterschiede}

Interessant sind die regionalen Unterschiede in dieser Studie. Besonders stark profitierten Patienten aus Nord- und Südamerika von der zusätzlichen Bevacizumab-Gabe, während sich bei asiatischen Patienten der geringste Nutzen zeigte. Europäische Patienten lagen dazwischen (Tab. 3).

Die potenziellen Ursachen für diese regionalen Unterschiede sind nur zum Teil erkennbar. Auffällig ist, dass in Panamerika, dem Kontinent mit dem größten Überlebensgewinn durch die Bevacizumab-Gabe, nur in $21 \%$ der Fälle eine Zweitlinientherapie gegeben wurde, wohingegen in Asien $66 \%$ der Patienten eine Zweitlinientherapie erhielten. Europa lag mit $31 \%$ Zweitlinientherapien dazwischen. Deutliche Unterschiede bestanden bezüglich der Tumorlokalisation und 
Tab. 3. AVAGASTStudie: regionale Unterschiede beim Ansprechen

\begin{tabular}{lllllll}
\hline Region & $\begin{array}{l}\text { Capecitabin/Cisplatin } \\
\text { +Plazebo, Median, } \\
\text { Monate }\end{array}$ & $\begin{array}{l}\text { Capecitabin/Cisplatin } \\
\text { + Bevacizumab, } \\
\text { Median, Monate }\end{array}$ & $\begin{array}{l}\text { Differenz, } \\
\text { Monate }\end{array}$ & HR & 95\%-CI \\
\hline OS & Asien & 12,1 & 13,9 & 1,8 & 0,97 & $0,75-1,25$ \\
& Europa & 8,6 & 11,1 & 2,5 & 0,85 & $0,63-1,14$ \\
PFS & Amerika & 6,8 & 11,5 & 4,7 & 0,63 & $0,43-0,94$ \\
& Asien & 5,6 & 6,7 & 1,1 & 0,92 & $0,74-1,14$ \\
& Europa & 4,4 & 6,9 & 2,5 & 0,71 & $0,54-0,93$ \\
& Amerika & 4,4 & 5,9 & 1,5 & 0,65 & $0,46-0,93$ \\
\hline
\end{tabular}

Modifiziert nach [129].

Abb. 21. ToGA-Studie: Das Ansprechen auf Trastuzumab korreliert mit der RezeptorÜberexpression (modifiziert nach [131]).

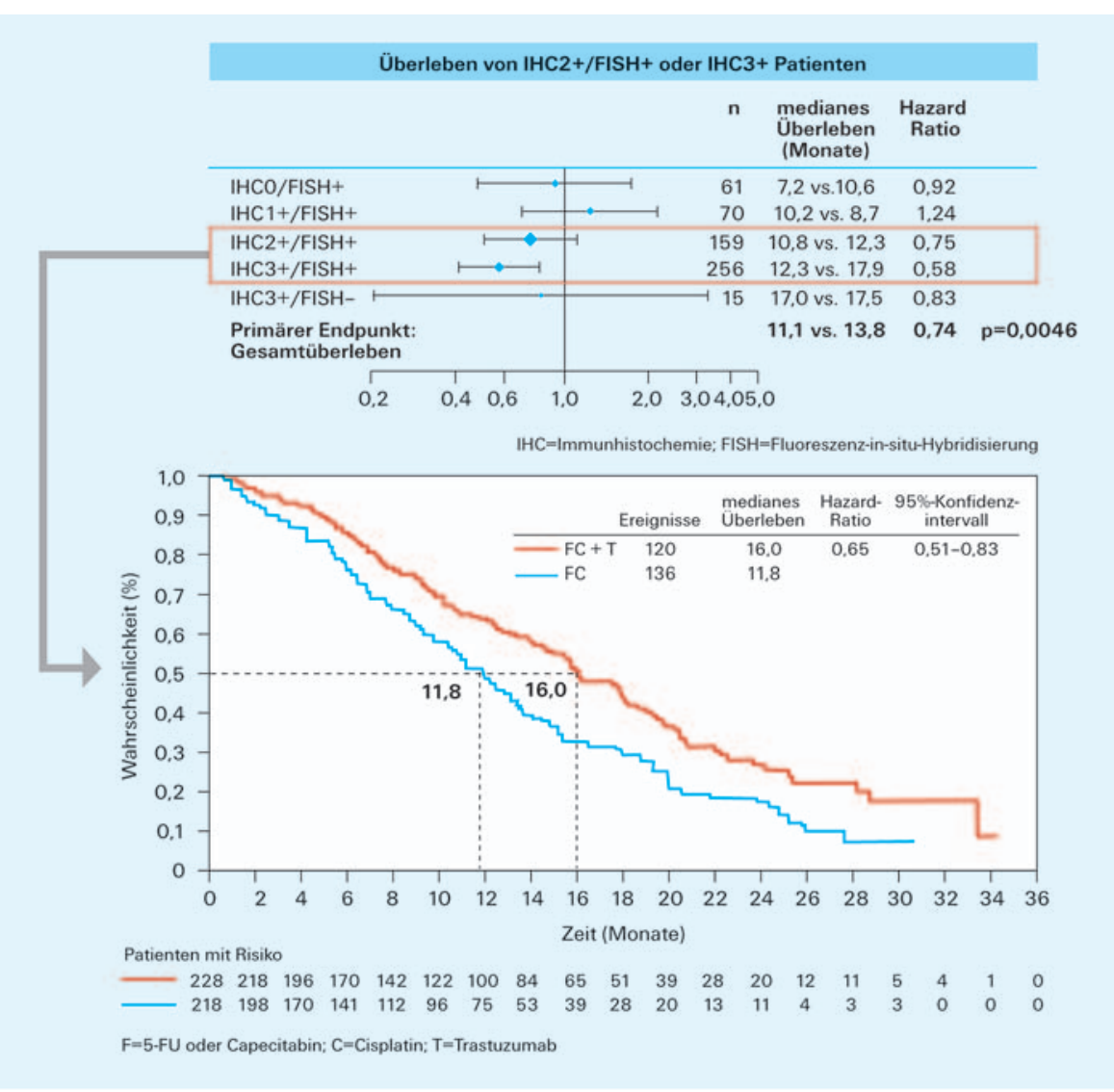

-ausbreitung. Bei Asiaten lagen nur selten Karzinome des gastroösophagealen Übergangs vor (nur 6\% vs. 16\% in Amerika), und die Tumoren hatten sehr viel seltener in die Leber metastasiert (bei $27 \%$ vs. $42 \%$ in Amerika).

Möglicherweise wäre die Studie positiv ausgefallen, wenn man sich auf europäische und amerikanische Patienten beschränkt hätte. $\mathrm{Ob}$ die Studie noch einmal, dann ohne asiatische Patienten, durchgeführt wird, ist derzeit offen.

\section{Cetuximab beim gastroösophagealen Karzinom und Ösophaguskarzinom}

Im Rahmen einer 3-armigen randomisierten Phase-II-Studie (CALGB 80403) erhielten insgesamt 245 Patienten mit metastasiertem Ösophaguskarzinom oder Karzinom des gastroöso- phagealen Übergangs Cetuximab plus in jedem Therapiearm eine andere Chemotherapie [130]. Das mediane PFS und OS war mit 6,7 bzw. 12,4 Monaten unter FOLFOX/Cetuximab am längsten, und auch die Verträglichkeit dieses Regimes war am besten, sodass sich eine Phase-III-Studie mit FOLFOX/ Cetuximab im Prüfarm anbieten würde.

\section{Status quo der HER2-Diagnostik beim Magenkarzinom Verantwortlicher Autor: Josef Rüschoff, Kassel}

Der monoklonale Antikörper Trastuzumab ist gegen den humanen EGFR (HER2) gerichtet und seit über einem Jahr zur Therapie des metastasierten Magenkarzinoms zugelassen. 
Basis für die Zulassung waren die Ergebnisse der Phase-IIIStudie ToGA [131]. In dieser randomisierten, multizentrischen Studie zeigten Patienten, deren Tumor entweder in der immunhistochemischen Untersuchung dreifach positiv (IHC $3+)$ und in der Fluoreszenz-in-situ-Hybridisierung positiv $(\mathrm{FISH}+)$, oder mit IHC $2+$ und FISH+ bewertet wurde, ein hervorragendes Ansprechen und wiesen ein medianes OS von 16,0 Monaten auf - versus 11,8 Monate, wenn kein Trastuzumab gegeben wurde $(\mathrm{HR}=0,65)($ Abb. 21).

Angesichts dieser Daten wurde Trastuzumab (Herceptin $\left.{ }^{\circledR}\right)$ in Kombination mit Cisplatin plus einem oralen Fluoropyrimidin oder infusionalem 5-FU zugelassen zur Erstbehandlung von Patienten mit metastasiertem Magenkarzinom, «deren Tumore eine HER2-Überexpression aufweisen, definiert durch IHC 2+ und ein bestätigendes FISH+-Ergebnis, oder durch IHC $3+$, ermittelt durch ein genaues und validiertes Testverfahren» [132]. Daraus ergibt sich der in der Abbildung 21 ausgeführte Testalgorithmus (Abb. 22).

\section{HER2-Testung beim Magenkarzinom}

Die neue S3-Leitlinie zum Magenkarzinom sagt klar, dass «vor dem Einsatz einer palliativen medikamentösen Tumortherapie der HER2-Status als positiver prädiktiver Faktor für eine Therapie mit Trastuzumab bestimmt werden sollte. Die histopathologische Bestimmung am Tumorgewebe soll qualitätsgesichert durchgeführt werden» [133].

Gegenüber der HER2-Testung beim Brustkrebs müssen einige Besonderheiten beachtet werden. Denn das Magenkarzinom ist im Vergleich zum Brustkrebs ein sehr heterogen wachsender Tumor und weist in der Regel eine inkomplette Membranfärbung im HercepTest auf. Eine solche inkomplette Membranfärbung würde beim Brustkrebs zu der Beurteilung «IHC-negativ» führen. Würde man beim Magenkarzinom die gleichen Scoring-Kriterien anlegen wie beim Brustkrebs, so würde dies zu etwa 50\% falsch negativen Ergebnissen führen, d.h. man würde etwa die Hälfte der Patienten, die von Trastuzumab profitieren könnten, nicht finden.

Unter Beachtung des modifizierten Scoring-Systems für die Immunhistochemie wurden für ToGA 3807 Patienten mit dem HercepTest gescreent. Insgesamt 23\% der Patienten wurden als IHC $2+$ oder 3+ bewertet [134].

Wichtig für die Bewertung ist, dass Resektate anders beurteilt werden müssen als Biopsate. Ein Resektat ist dann IHC 3+, wenn eine starke Membranfärbung in mindestens $10 \%$ der Tumorzellen gegeben ist. Dabei spielt es keine Rolle, ob die Membranfärbung komplett oder nur basolateral oder lateral vorhanden ist. Ein Biopsat ist IHC 3+, wenn in einer Gruppe von mindestens 5 Tumorzellen eine starke Membranfärbung vorliegt, die Beurteilung ist also hier unabhängig vom Prozentsatz der gefärbten Zellen. Nach aktuellen Daten ist die Konkordanz zwischen Biopsie und Resektat, diese Art der Beurteilung vorausgesetzt, hoch; sie liegt - in Abhängigkeit von der Biopsiezahl - zwischen 75 und $95 \%$.
EMA (European Medicines Agency; Evaluation of Medicines for Human Use) vom 26.01.2010: .Herceptin ist nur bei Patienten mit metastasiertem Magenkarzinom anzuwenden, deren Timove eine HER2-Öberexpression, definiert durch IHC2+ und ein bestätigendes FISH+-Ergebnis, oder durch IHC3+, aufweisen, ermittelt durch ein genaues und validiertes Testverfahren."

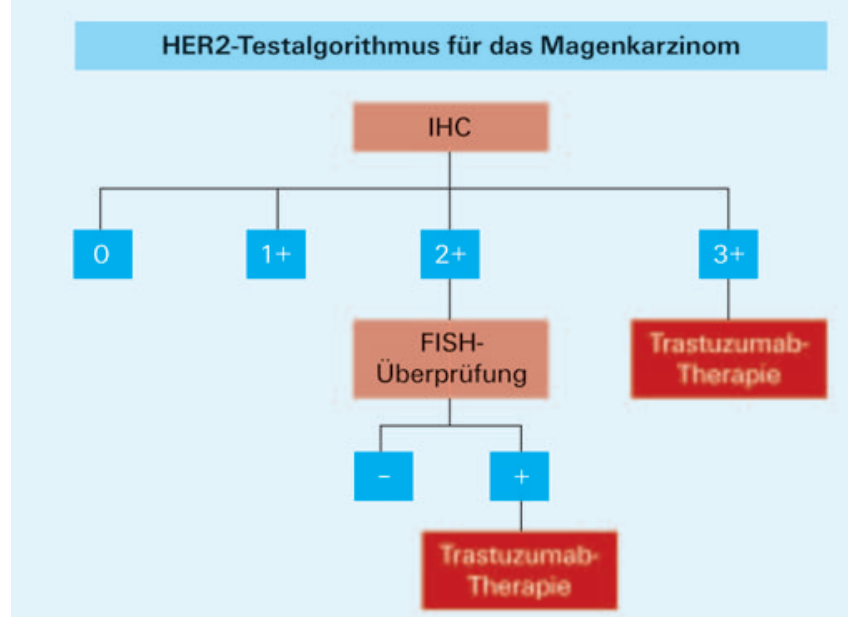

IHC=Immunhistochemie; FISH=Fluoreszenz-in-situ-Hybridisierung

Abb. 22. HER2-Testalgorithmus beim Magenkarzinom.

Die starke Membranfärbung (IHC 3+) ist mit dem Mikroskop schon bei schwacher (2,5-5-facher) Vergrößerung erkennbar («sogenannte Objektivregel»). Ein IHC-Score von $2+$ wird vergeben, wenn die Membranfärbung schwach bis mittelgradig ausgeprägt ist. Für den Nachweis dieser mittelgradigen Färbung wird eine 10-20-fache Vergrößerung benötigt. Der HER2-Status bei diesen Patienten ist grenzwertig und muss, laut der aktuellen European Medicines Agency (EMA)-Zulassung, mit dem FISH-Test überprüft werden. Ein IHC-Score von 1+ wird dann vergeben, wenn eine sehr schwache Membranfärbung nur bei starker (40-facher) Vergrößerung erkennbar ist. Ein IHC-Score von 0 bedeutet, dass keinerlei Membranfärbung vorhanden ist oder dass weniger als $10 \%$ der Tumorzellen im Resektat bzw. weniger als $5 \mathrm{Tu}$ morzellen im Biopsat eingefärbt sind [135].

Neben dem in der ToGA-Studie angewandten HercepTest und FISH wurden inzwischen 2 weitere Testplattformen entwickelt (4B5 (Anti-HER2-Antikörper) und Hellfeld-Doppelin-situ-Hybridisierung (BDISH)), die mit einem anderen Antikörper arbeiten, eine andere In-situ-Hybridisierungstechnik anwenden und die HER2-positiven Fälle klarer kenntlich machen. Zudem ist die Übereinstimmung zwischen IHC-Befund und (F)ISH bei der Verwendung dieser neuen Techniken wesentlich besser.

\section{Ergebnisse des 1. Ringversuchs 2010}

Der 1. Ringversuch der Qualitätssicherungs-Initiative Pathologie (QuIP) umfasste insgesamt 101 Teilnehmer. Nur 62,9\% 
der Teilnehmer bestanden den IHC-Test. Hauptfehlerquellen waren ganz überwiegend eine insgesamt zu schwache Färbung und die Tendenz, diese Färbung überhöht zu bewerten. Als Ursache kommen eine zu niedrige Antikörper-Konzentration, Probleme mit der Spezifität der verwendeten Antikörper und eine zu kurze Inkubationszeit in Betracht. Von der Food and Drug Administration (FDA) sind nur der HercepTest und der monoklonale Antikörper 4B5 anerkannt. Alle Teilnehmer, die den 4B5 verwendeten, bestanden den Test. Alle Teilnehmer, die «no name»-Testplattformen verwendeten, fielen durch.

Aktuell wird ein neuer Ringversuch angeboten (www.ringversuch.de).

\section{Fazit}

Das IHC-Scoring-System für das Magenkarzinom ist anders als das beim Mammakarzinom. Fortbildungen für Pathologen und Ringversuche weisen in das neue Scoring-System ein.

\section{Umsetzung der S3-Leitlinie Magenkarzinom Verantwortlicher Autor: Karsten Ridwelski, Magdeburg}

Die neu erstellte S3-Leitlinie zur «Diagnostik und Therapie des Adenokarzinoms des Magens und ösophagogastralen Übergangs» wurde auf dem Deutschen Krebskongress am 24. Februar 2010 in Berlin vorgestellt, ist aber bis heute nicht voll publiziert. Zur palliativen Therapie führt die S3-Leitlinie aus, dass «Patienten in gutem Allgemeinzustand eine systemische Chemotherapie zum frühestmöglichen Zeitpunkt angeboten werden soll. ... Alter stellt keine Kontraindikation dar ... Bei Tumoren ohne HER2-Überexpression ist eine systemische Platin/Fluoropyrimidin-haltige Kombinationstherapie indiziert.» Liegt HER2-Positivität vor (definiert als IHC 3+ oder IHC 2+/FISH+, entsprechend der EMEAZulassung) gilt: «Aufgrund eines nachgewiesenen Überlebensvorteils besteht eine Indikation für den Einsatz von Trastuzumab in Kombination mit Cisplatin plus 5-FU oder Capecitabin.»

Die Veröffentlichung und Umsetzung der neuen S3-Leitlinie erscheint dringend erforderlich, denn die Behandlungsrealität weicht in vielen Bereichen deutlich von der wissenschaftlichen Evidenz ab. Dies zeigt die Qualitätssicherungsstudie Magenkarzinom, in die im Jahr 2009685 Patienten eingebracht wurden. Beispielsweise erfolgte eine neoadjuvante Chemotherapie vor der Magen(teil)resektion nur bei 22,5\% der Patienten. Alle anderen Patienten erhielten keinerlei präoperative Behandlung. Dabei heißt es in der S3Leitlinie: «Bei Kategorien uT3 und resektabel uT4 soll/sollte eine präoperative Chemotherapie durchgeführt und postoperativ fortgesetzt werden.»

\section{Update perioperative Therapie des Magenkarzinoms Verantwortlicher Autor: Wolfram Trudo Knoefel, Düsseldorf}

Die EORTC-Studie 40954 zur perioperativen Therapie des Magenkarzinoms wurde Ende letzten Jahres publiziert [136]. Leider musste die Studie wegen unzureichender Rekrutierung nach der Aufnahme von nur 144 Patienten vorzeitig beendet werden. In der Studie war randomisiert entweder präoperativ chemotherapiert oder nur chirurgisch behandelt worden. Durch die präoperative Chemotherapie konnte die R0Resektionsrate signifikant von 66,7 auf $81,9 \%$ erhöht werden ( $\mathrm{p}=0,036)$. Auch die Anzahl der Lymphknoten-negativen Patienten wurde signifikant verbessert (von 61,4 auf 76,5\%; $\mathrm{p}=0,018$ ). Ein signifikanter Überlebensvorteil konnte aber nicht erreicht werden, was jedoch auf die niedrige statistische Aussagekraft (weniger Patienten als geplant) zurückzuführen sein mag. Weitere Kritikpunkte an der Studie sind der Einschluss von Stadium-IV-Patienten und die hohe Rate an gastroösophagealen Tumoren.

Insgesamt scheint die neue Studie jedoch die wissenschaftliche Evidenz aus der MAGIC-Studie [137] und anderen zu bestätigen, wonach die perioperative Therapie positive Effekte zeigt. Die Nachfolgestudie MAGIC II (UK NCRI ST03) prüft derzeit die perioperative Therapie mit ECX (Epirubicin, Cisplatin, Capecitabin) versus ECX plus Bevacizumab.

\section{Fortschritt beim metastasierten Pankreaskarzinom Verantwortlicher Autor: Helmut Oettle, Friedrichshafen}

Die Kombination Gemcitabin plus Erlotinib ist seit der Veröffentlichung der PA.3-Studie und der AViTA-Studie ein akzeptierter Standard beim metastasierten Pankreaskarzinom. Patienten, die unter der Therapie ein Exanthem entwickeln, profitieren von der Behandlung [138, 139].

Eine weitere Phase-III-Studie zur Kombination Gemcitabin/Erlotinib wurde auf dem letztjährigen ASCO-Meeting vorgestellt [140]. In dieser Studie der AIO erhielten die Patienten randomisiert entweder Gemcitabin/Erlotinib als FirstLine-Therapie, gefolgt von Capecitabin ab dem Zeitpunkt des Therapieversagens, oder es wurde mit Capecitabin/Erlotinib begonnen, gefolgt von einer Gemcitabin-Monotherapie ab dem Zeitpunkt des Therapieversagens. Beide Therapieabfolgen waren letztlich gleichermaßen wirksam mit einem medianen OS von 6,9 versus 6,6 Monaten. Die Erstlinientherapie mit Gemcitabin/Erlotinib war jedoch signifikant besser wirksam (Zeit bis zum Therapieversagen der Erstlinientherapie 3,4 Monate unter Gemcitabin/Erlotinib vs. 2,4 Monate unter Capecitabin/Erlotinib; HR =0,69; $\mathrm{p}=0,0036)$. Darüber hinaus machte auch diese Studie deutlich, dass es die Patienten mit Hauttoxizität sind, die von der zusätzlichen ErlotinibGabe profitieren. Das mediane OS von Patienten mit «rash» des Grades I-IV betrug 8,7 Monate - versus einem medianen 


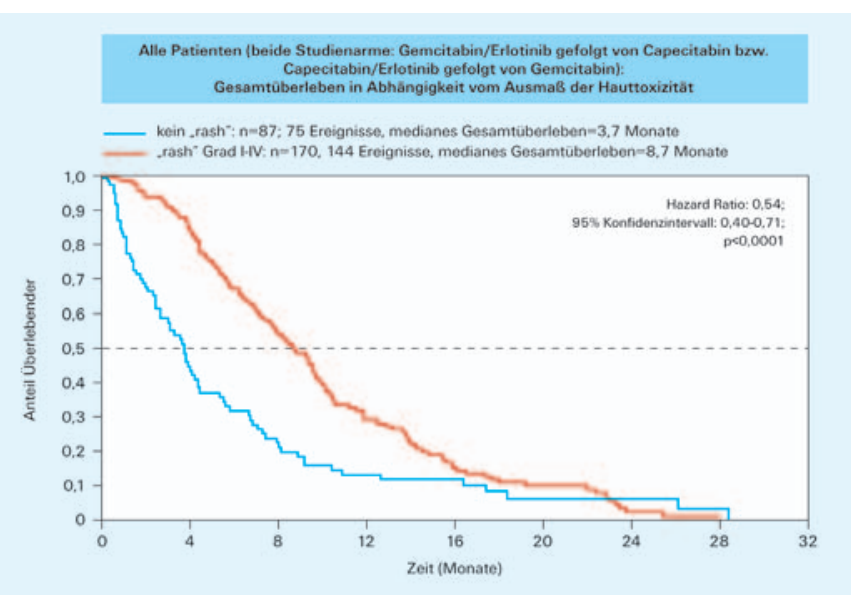

Abb. 23. Neue Phase-III-Studie zur Kombination Gemcitabin/Erlotinib in der First-Line-Therapie des fortgeschrittenen Pankreaskarzinoms: Assoziation zwischen Hauttoxizität und OS (modifiziert nach [140]).

OS von nur 3,7 Monaten bei den Patienten ohne «rash» (HR $=0,54 ; \mathrm{p}<0,0001)($ Abb. 23).

Ebenfalls auf dem ASCO-Meeting 2010 vorgestellt wurde die Phase-III-Studie PRODIGE 4/ACCORD 11 [141]. Insgesamt 342 Patienten erhielten als First-Line-Therapie randomisiert entweder das Vierfach-Schema FOLFIRINOX (infusionales 5-FU, FS, Irinotecan, Oxaliplatin) oder eine Gemcitabin-Monotherapie. Voraussetzungen für die Studienteilnahme waren metastasiertes Stadium, gute Organfunktionen, Bilirubin $<1,5 \times$ ULN (upper limit of normal) und ein PS von 0-1. Diese Studie zeigt beeindruckende Ergebnisse. So betrug die Ansprechrate 31,6\% unter FOLFIRINOX versus 9,4\% unter Gemcitabin $(\mathrm{p}=0,0001)$. Das mediane PFS lag bei 6,4 Monaten versus 3,3 Monaten $(\mathrm{HR}=0,47$; $<<0,0001)$. Der primäre Endpunkt, das mediane OS, betrug 11,1 Monate unter FOLFIRINOX versus 6,8 Monaten unter der Gemcitabin-Monotherapie (HR =0,57; $\mathrm{p}<0,0001)$ (Abb. 24). Damit begründet diese Studie einen neuen Meilenstein in der Therapie des metastasierten Adenokarzinoms des Pankreas.

Allerdings ist die Toxizität des FOLFIRINOX-Schemas nicht unerheblich und erfordert ein enges Monitoring. So trat eine Neutropenie des WHO-Grades $3 / 4$ bei $45,7 \%$ der FOLFIRINOX-Patienten auf, eine febrile Neutropenie des Schweregrades $3 / 4$ bei $5,4 \%$ (vs. $0,6 \%$ im Gemcitabin-Arm). $\mathrm{Zu}$ einer schweren Diarrhö kam es bei $12,7 \%$ der FOLFIRINOX-Patienten (vs. 1,2\% der Gemcitabin-Patienten). Neuropathie (WHO 3/4) wurde bei $9 \%$ versus $0 \%$ berichtet. Damit eignet sich das FOLFIRINOX-Schema vor allem für selektionierte Patienten in gutem Allgemeinzustand, wohingegen die Gemcitabin/Erlotinib-Kombination aufgrund ihrer besseren Verträglichkeit breiter einsetzbar ist. Ein direkter Vergleich gegenüber einer Therapie mit Gemcitabin/Erlotinib bei Patienten mit «rash» steht noch aus.

Nach Versagen einer Gemcitabin-Erstlinientherapie sind mit infusionalem 5-FU/FS plus Oxaliplatin (OFF-Schema) als

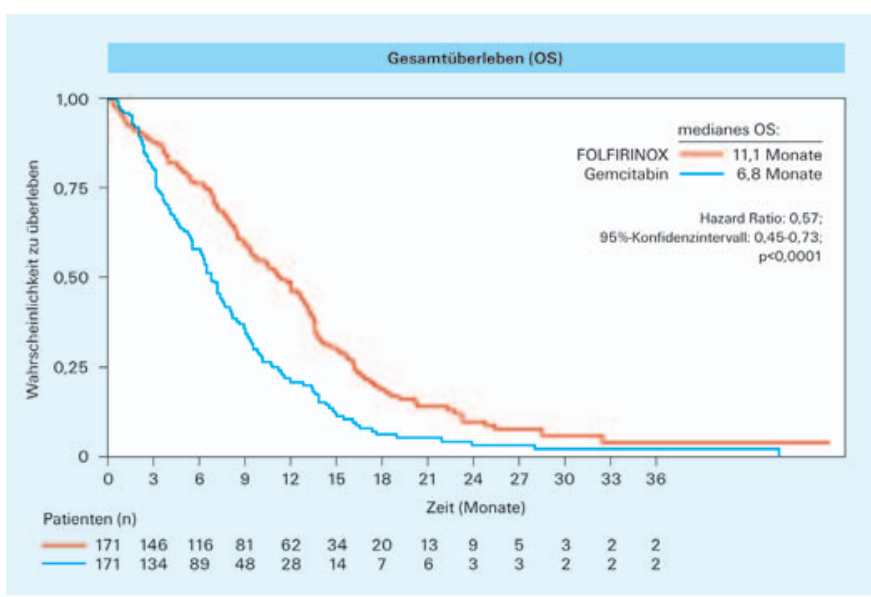

Abb. 24. Phase-III-Studie PRODIGE 4/ACCORD 11: FOLFIRINOX (infusionales 5-FU, FS, Irinotecan, Oxaliplatin) versus Gemcitabin beim fortgeschrittenen Pankreaskarzinom (modifiziert nach [141]).

Zweitlinientherapie gute Ergebnisse zu erzielen. In der Phase-III-Studie CONKO-003 konnte mit diesem Therapieregime ein OS in der Zweitlinie von 26 Wochen erzielt werden (vs. 13 Wochen unter alleiniger 5-FU/FS-Therapie; $\mathrm{p}=0,014)[142]$.

\section{Stadien-adaptierte Therapie des hepatozellulären Karzinoms \\ Verantwortlicher Autor: Stefan Kubicka, Hannover}

Aufgrund der eingeschränkten Behandlungsmöglichkeiten ist das hepatozelluläre Karzinom weltweit die am dritthäufigsten zum Tode führende Krebsart. Die Inzidenz nimmt in westlichen Industrienationen aufgrund der Verbreitung der Adipositas und Hepatitis-C-Virusinfektionen stark zu. Patienten mit Leberzirrhose weisen das höchste Risiko auf und sollten regelmäßig überwacht werden, um den Tumor in einem möglichst frühen Stadium zu diagnostizieren.

Findet sich ein technisch resektabler Tumor und ist die Leberfunktion normal, ist eine Leberteilresektion sinnvoll. Liegt ein Einzelknoten $\leq 5 \mathrm{~cm}$ vor oder handelt es sich um maximal 3 Knoten von je $\leq 3 \mathrm{~cm}$ Durchmesser, kann, je nach Leberfunktion, noch reseziert werden, oder es sollte bei zunehmender Leberschädigung eher eine Lebertransplantation (LTX) erfolgen, wenn hierfür keine Kontraindikationen vorliegen (Abb. 25). Bestehen Kontraindikationen für eine LTX, ist bei ansonsten gleichen Voraussetzungen wie bei der LTX eine Radiofrequenzablation (RFA) oder eine perkutane Ethanolinjektion (PEI) indiziert. Die RFA ist, verglichen mit der PEI, das überlegene Verfahren hinsichtlich der Lokalrezidivrate und hinsichtlich des OS. Die Nebenwirkungsrate unter der RFA wird, je nach Studie, als vergleichbar oder aber als etwas höher bezeichnet [143, 144]. 
Abb. 25. Stadien-adaptierte Therapie des hepatozellulären Karzinoms.

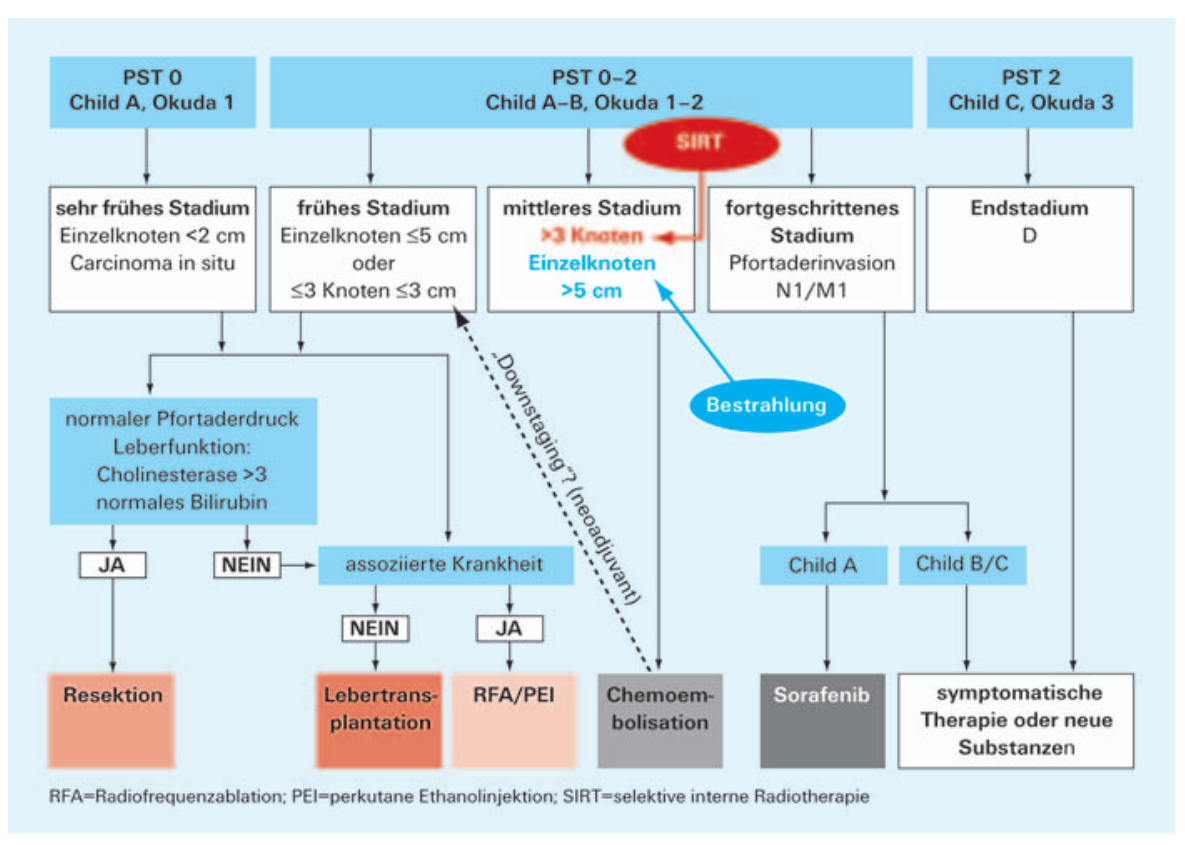

Hat der Patient mehr als 3 Knoten oder einen Einzelknoten $>5 \mathrm{~cm}$ Durchmesser, ist eine Chemoembolisation indiziert. Die Remissionsraten liegen hier bei $30-40 \%$, sodass sich das Verfahren auch zum «Downstaging» eignet mit der Möglichkeit, eine RFA anzuschließen [145]. Damit ist auch eine Heilung erreichbar. Die 3-Jahres-Überlebensrate nach RFA beträgt etwa $75 \%$ und entspricht damit etwa den Daten der Leberteilresektion.

Alternativ, vor allem bei Nichtansprechen auf die Chemoembolisation, kommt die selektive interne Radiotherapie (SIRT) infrage. Hierbei handelt es sich um ein aufwendiges Verfahren, denn zur Vorbereitung sind eine Test-Angiographie und eine Dosimetrie, insbesondere der Lunge, obligat. In einer Untersuchung der Daten von 463 Patienten zeigte sich, dass durch die Radioembolisation, verglichen mit der Chemoembolisation, zwar die Zeit bis zur Tumorprogression signifikant verlängert werden konnte (13,3 vs. 8,4 Monate; $\mathrm{p}=$ 0,046), das OS war aber nicht signifikant verschieden [146]. Vor diesem Hintergrund wird die SIRT für Standardpatienten nicht als primäres Verfahren empfohlen, sondern eher als «Salvage»-Therapie betrachtet. Die externe Bestrahlung wird in Deutschland nur selten angewendet, ist aber unter Voraussetzung einer modernen Therapieplanung ein sehr interessantes Verfahren vor allem für vereinzelte größere Tumorherde.

\section{Systemische Therapie}

Beim fortgeschrittenen Leberzellkarzinom mit Pfortaderbeteiligung und Lymphknotenbefall bzw. Fernmetastasen muss systemisch behandelt werden. Chemotherapien sind allerdings kaum wirksam. Am meisten verspricht man sich derzeit von der zielgerichteten Therapie, und das attraktivste Ziel ist der VEGF [147]. Der Multikinase-Inhibitor Sorafenib erwies sich in 2 randomisierten, Plazebo-kontrollierten Phase-III-
Studien als wirksam, d.h. das OS der Patienten wurde signifikant verlängert (in der SHARP-Studie von 7,9 auf 10,7 Monate $(\mathrm{HR}=0,69 ; \mathrm{p}<0,001)[148,149]$. Die Ansprechraten auf Sorafenib sind jedoch marginal (2\% in der SHARP-Studie, $3 \%$ in der asiatischen Studie), und auch die Zeit bis zur symptomatischen Tumorprogression konnte durch Sorafenib nicht verbessert werden $(\mathrm{HR}=1,08)$. Das bedeutet, dass ein klinisch-symptomatischer Benefit unter Sorafenib gegebenenfalls nicht erkennbar ist; die Patienten erfahren keine Verbesserung ihrer Lebensqualität. Dazu kommt die Toxizität der Therapie - vor allem Diarrhöen und ein Hand-FußSyndrom.

Weitere auf VEGF abzielende Substanzen werden derzeit klinisch geprüft. Eine mit Bevacizumab plus Erlotinib durchgeführte Phase-II-Studie erschien vielversprechend mit einer Gesamtansprechrate von $25 \%$ und einem medianen OS von 15,65 Monaten [150]. Der VEGF-Antikörper Bevacizumab ist darüber hinaus auch besser verträglich als der MultikinaseInhibitor Sorafenib, dessen Wirksamkeit im wesentlichen ebenfalls auf der Anti-VEGF-Wirkung beruht, der aufgrund der Hemmung weiterer Kinasen aber ein unvorteilhaftes Nebenwirkungsprofil aufweist. Trotz seiner Vorzüge wird Bevacizumab beim hepatozellulären Karzinom derzeit aber nicht weiterentwickelt und es wird keine Zulassung für diese Indikation angestrebt, was von der Expertenrunde ausdrücklich bedauert wurde.

Der Versuch, die Wirksamkeit von Sorafenib durch die Kombination mit Doxorubicin weiter zu verbessern, führte zwar in einer Phase-II-Stude zu einem OS von 13,7 Monaten [151] - allerdings kam es in der Studie bei 53\% der Patienten zu Neutropenien des Schweregrades 3/4 und bei 15\% zu einer schweren Fatigue, sodass diese Kombination aufgrund ihrer Toxizität zurückhaltend beurteilt werden sollte. 
Tab. 4. Stadiengerechte Therapie in interdisziplinärer Kooperation beim Ösophaguskarzinom (Barrett-Karzinom)

\author{
Niedriggradige Dysplasie \\ Hochgradige Dysplasie \\ T1a-Kategorie \\ T1b-Kategorie \\ T2-Kategorie \\ T3- oder N1-Kategorie \\ T4- oder M1-Kategorie
}

\author{
«Watch-and-Wait», endoskopisches Überwachungsprogramm \\ endoskopische Resektion, limitierte Resektion \\ limitierte Resektion, endoskopische Resektion \\ limitierte Resektion, gegebenenfalls transthorakale Ösophagektomie \\ transthorakale Ösophagektomie \\ multimodale Therapie im Rahmen von Studien mit Response-Evaluation \\ alleinige Chemotherapie mit gegebenenfalls lokaler Palliation \\ (Endoskopie oder Radiotherapie)
}

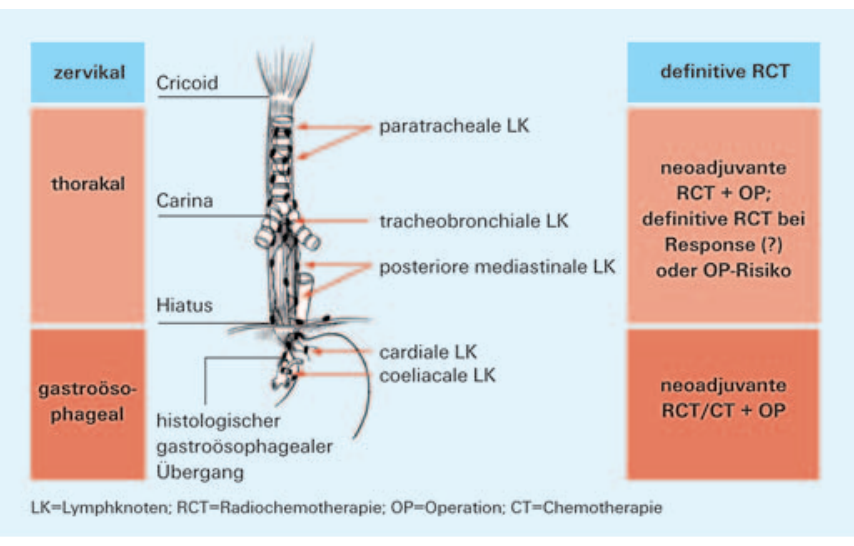

Abb. 26. Ösophaguskarzinom und Adenokarzinom des ösophagogastralen Übergangs - lokalisationsabhängige Therapie.

Bei Patienten mit einer Leberzirrhose im Stadium ChildPugh B sollte auch eine Sorafenib-Monotherapie aufgrund der erhöhten Lebertoxizität nur sehr zurückhaltend eingesetzt werden. In einer Studie mit 38 Child-B-Patienten wurde unter Sorafenib bei $40 \%$ ein erhöhtes Bilirubin, bei $18 \%$ ein Aszites und bei $11 \%$ eine Enzephalopathie beobachtet [152]. Das mediane OS der Child-B-Patienten betrug trotz der Therapie nur 14 Wochen.

\section{Vorgehen beim lokalisierten Ösophaguskarzinom Verantwortliche Autoren: Claus Rödel, Frankfurt, Wolfram Trudo Knoefel, Düsseldorf}

Bei einem fortgeschrittenen Karzinom im zervikalen Anteil des Ösophagus gilt die definitive RCT als Standard. In Fällen eines frühen Karzinoms kann aber die Resektion und Rekonstruktion mit einem freien Dünndarmtransplantat exzellente Langzeitergebnisse liefern.

Liegt das Karzinom thorakal, konkurrieren mehrere Vorgehensweisen miteinander. Eine Metaanalyse aus dem Jahr 2007 spricht bei fortgeschrittenen Tumoren (T3/T4 oder N+) für die neoadjuvante RCT gefolgt von der Operation [153]. Die Vorteile gegenüber der alleinigen Operation sind eine höhere R0-Resektionsrate, eine geringere Lokalrezidivrate und eine bessere 3-Jahres-Überlebensrate (Overall Response
$(\mathrm{OR})=0,66 ; \mathrm{p}=0,016)$ - allerdings (in älteren Studien) um den Preis einer tendenziell höheren operativen Mortalität $(\mathrm{OR}=1,72 ; \mathrm{p}=0,07)$ [154].

Auf dem letzten ASCO-Meeting wurde die Phase-III-Studie CROSS vorgestellt, in der Patienten mit überwiegend Stadium-IIIA-Tumoren (T3N0, T3N1) und überwiegend Adenokarzinomen (74\%) randomisiert entweder eine neoadjuvante Paclitaxel/Carboplatin-basierte RCT erhielten oder nur operiert wurden. Das mediane OS wurde durch die RCT signifikant verlängert (von 26 auf 49 Monate; $p=0,011$; HR $=0,67$ ). Die postoperative Mortalität war in beiden Therapiearmen vergleichbar [155]. Demgegenüber konnte in einer französischen Phase-III-Studie, die ebenfalls auf dem ASCO-Meeting 2010 präsentiert wurde, aber Patienten in früheren Krankheitsstadien (Stadium I, IIA, IIB) einschloss, kein Vorteil durch die neoadjuvante RCT festgestellt werden, weshalb die Studie abgebrochen wurde [156].

Die präoperative Chemotherapie (ohne Radiotherapie) bietet laut der Gebski-Metaanalyse ebenfalls einen Vorteil beim operablen Ösophaguskarzinom. Dieser ist jedoch nur beim Adenokarzinom signifikant [153].

Bei Patienten mit einem lokal fortgeschrittenen Plattenepithelkarzinom des Ösophagus wurde randomisiert eine Induktionschemotherapie plus RCT plus Operation mit der Induktionschemotherapie plus RCT ohne Operation verglichen. Das Ansprechen auf die Induktionschemotherapie war der einzige unabhängige prognostische Faktor für ein längeres OS. Die Operation verbesserte das lokale PFS vor allem bei den Non-Respondern, weshalb die Autoren die Hypothese formulierten, dass Patienten mit Tumorresponse nach Induktionschemotherapie nicht mehr notwendigerweise operiert werden müssen [157]. Allerdings zeigte sich eine höhere Lokalrezidivrate, wenn auf die Operation verzichtet wurde.

In Rahmen einer zweiten Studie, in der $89 \%$ der Patienten ein Plattenepithelkarzinom aufwiesen, wurden nach der RCT nur die Responder randomisiert, um entweder operiert $\mathrm{zu}$ werden oder eine fortgesetzte RCT zu erhalten. Es bestätigte sich, dass operierte und nicht operierte Patienten ein vergleichbares OS - bei einer höheren Lokalrezidivrate bei Verzicht auf die Operation - hatten [158].

Bei den Adenokarzinomen des gastroösophagealen Übergangs zeigt die Gebski-Metaanalyse sowohl für die neoadjuvante RCT wie auch für die neoadjuvante Chemotherapie 
eine im Vergleich zur alleinigen Operation signifikante Überlebensverbesserung [153]. Eine randomisierte Phase-III-Studie verglich den Nutzen von präoperativer RCT und präoperativer Chemotherapie bei lokal fortgeschrittenen Tumoren (uT3-4Nx) direkt, musste jedoch wegen unzureichender Rekrutierung vorzeitig geschlossen werden [159]. Die pathohistologischen Ergebnisse waren nach RCT signifikant besser, was sich trotz der geringen Patientenzahl in ein deutlich besseres OS übertrug (3-Jahres-Überleben 47,4\% vs. 27,7\%; p = 0,07; $\mathrm{HR}=0,67)$.

\section{Fazit und Ausblick}

Beim lokal fortgeschrittenen (T3,4; N+) Plattenepithelkarzinom des Ösophagus ist eine neoadjuvante RCT plus Operation indiziert. Bei gutem Ansprechen auf die RCT ist auch die definitive RCT möglich. Bei lokal fortgeschrittenen
Adenokarzinomen des gastroösophagealen Übergangs können sowohl die präoperative RCT wie auch die präoperative Chemotherapie zum Einsatz kommen (Abb. 26). Frühe Karzinome (T1-2N0) können ausschließlich operiert werden (Tab. 4).

Innovative Aspekte könnten sich künftig durch eine prätherapeutische Prädiktion des Ansprechens auf die neoadjuvante RCT oder Chemotherapie mittels MicroarrayAnalysen ergeben [160].

\section{Disclosure Statement}

The authors were speakers at the meeting and contributors to the publication «XI. Interdisziplinärer Expertenworkshop Gastrointestinale Tumore`, Schlossgut Oberambach, Münsing», sponsored by Roche Pharma AG.

\section{Literatur}

1 Andre $\mathrm{T}$ et al.; Multicenter International Study of Oxaliplatin/5-Fluorouracil/Leucovorin in the Adjuvant Treatment of Colon Cancer (MOSAIC) Investigators: Oxaliplatin, fluorouracil, and leucovorin as adjuvant treatment for colon cancer. $\mathrm{N}$ Engl J Med 2004:350:2343-2351.

2 Kuebler JP et al.: Oxaliplatin combined with weekly bolus fluorouracil and leucovorin as surgical adjuvant chemotherapy for stage II and III colon cancer: results from NSABP C-07. J Clin Oncol 2007;25:2198-2204.

$>3$ Haller DG et al.: NO16968: XELOXA. Adjuvant treatment with capecitabine and oxaliplatin (XELOX) in stage III colon cancer. Eur J Cancer Suppl 2009;7:4, abstr 5LBA.

$\checkmark 4$ Twelves $\mathrm{C}$ et al.: Capecitabine as adjuvant treatment for stage III colon cancer. N Engl J Med 2005;352:2696-2704.

$\checkmark 5$ André $\mathrm{T}$ et al.: Semimonthly versus monthly regimen of fluorouracil and leucovorin administered for 24 or 36 weeks as adjuvant therapy in stage II and III colon cancer: results of a randomized trial. J Clin Oncol 2003;21:2896-2903.

6 Lumley T: Network meta-analysis for indirect treatment comparisons. Stat Med 2002;21:23132324

7 Cassidy J, Schmoll H-J, Chu E, et al.: Comparative clinical efficacy of adjuvant chemotherapy regimens in randomized controlled trials of early-stage colon cancer: systematic review and meta-analysis. ASCO GI 2011, abstr 498.

-8 Schmoll H-J et al.: Phase III trial of capecitabine plus oxaliplatin as adjuvant therapy for stage III colon cancer: a planned safety analysis in 1,864 patients. J Clin Oncol 2007;25:102-109.

$\checkmark 9$ Schmiegel W et al.: S3-Leitlinie «Kolorektales Karzinom»-Aktualisierung 2008. Z Gastroenterol 2008;46:799-840.

10 Schmiegel W et al.: Colorectal carcinoma: the management of polyps, (neo)adjuvant therapy, and the treatment of metastases. Dtsch Arztebl Int 2009; 106:843-848.

11 McCleary $\mathrm{J}$ et al.: Impact of older age on the efficacy of newer adjuvant therapies in $>12500$ patients (pts) with stage II/III colon cancer: Findings from the ACCENT database. J Clin Oncol 2009; 27(suppl):15s, abstr 4010.
2 André $\mathrm{T}$ et al.: Improved overall survival with oxaliplatin, fluorouracil, and leucovorin as adjuvant treatment in stage II or III colon cancer in the MOSAIC trial. J Clin Oncol 2009;27:3109-3116.

13 Van Cutsem E et al.: Randomized phase III trial comparing biweekly infusional fluorouracil/leucovorin alone or with irinotecan in the adjuvant treatment of stage III colon cancer: PETACC-3. J Clin Oncol 2009;27:3117-3125.

14 Saltz LB et al.: Irinotecan fluorouracil plus leucovorin is not superior to fluorouracil plus leucovorin alone as adjuvant treatment for stage III colon cancer: results of CALGB 89803. J Clin Oncol 2007; 25:3456-3461.

15 Lembersky BC et al.: Oral uracil and tegafur plus leucovorin compared with intravenous fluorouracil and leucovorin in stage II and III carcinoma of the colon: results from National Surgical Adjuvant Breast and Bowel Project Protocol C-06. J Clin Oncol 2006;24:2059-2064.

16 Twelves C et al.: Capecitabine versus 5-FU/LV in stage III colon cancer: Updated 5-year efficacy data from X-ACT trial and preliminary analysis of relationship between hand-foot syndrome (HFS) and efficacy. ASCO GI 2008, abstr 274.

17 Haller DG et al.: Efficacy findings from a randomized phase III trial of capecitabine plus oxaliplatin versus bolus 5-FU/LV for stage III colon cancer (NO16968): No impact of age on disease-free survival (DFS). ASCO GI 2010, abstr 284.

18 Cassidy $\mathrm{J}$ et al.: Review of completed and ongoing trials of capecitabine-based adjuvant therapy in patients with early-stage colon cancer. ASCO GI 2011, abstr 495.

19 Ychou $\mathrm{M}$ et al.: A phase III randomized trial of LV5FU2 + CPT-11 vs. LV5FU2 alone in adjuvant high risk colon cancer (FNCLCC Accord02/ FFCD9802). ASCO 2005, abstr 3502.

20 Alberts SR et al.: Adjuvant mFOLFOX6 with or without cetuxiumab ( $\mathrm{Cmab})$ in KRAS wild-type (WT) patients (pts) with resected stage III colon cancer (CC): Results from NCCTG Intergroup Phase III Trial N0147. ASCO 2010, abstr CRA 3507.
21 Goldberg RM et al.: Adjuvant mFOLFOX6 plus or minus cetuximab ( $\mathrm{Cmab})$ in patients (pts) with KRAS mutant $(\mathrm{m})$ resected stage III colon cancer (CC): NCCTG Intergroup Phase III Trial N0147. ASCO 2010, abstr 3508.

22 Huang J et al.: Adjuvant FOLFIRI with or without cetuximab in patients with resected stage III colon cancer: NCCTG Intergroup phase III trial N0147. ASCO GI 2011, abstr 363.

23 Wolmark $\mathrm{N}$ et al.: A phase III trial comparing mFOLFOX6 to mFOLFOX6 plus bevacizumab in stage II or III carcinoma of the colon: Results of NSABP Protocol C-08. J Clin Oncol 200927 (suppl):18s, abstr LBA4.

24 De Gramont A et al.: AVANT: Results from a randomized, three-arm multinational phase III study to investigate bevacizumab with either XELOX or FOLFOX4 versus FOLFOX4 alone as adjuvant treatment for colon cancer. ASCO GI 2011, abstr 362.

25 Biagi JJ et al.: The impact of time to adjuvant chemotherapy on survival in colorectal cancer: A systematic review and meta-analysis. ASCO GI 2011, abstr 364.

26 Salazar R et al.: Gene expression signature to improve prognosis prediction of stage II and III colorectal cancer. J Clin Oncol 2011;29:17-24.

27 Rosenberg $\mathrm{R}$ et al.: Independent validation of a prognostic genomic profile (ColoPrint) for stage II colon cancer patients. ASCO GI 2011, abstr 358.

28 Kerr D et al.: A quantitative multigene RT-PCR assay for prediction of recurrence in stage II colon cancer: Selection of the genes in four large studies and results of the independent, prospectively designed QUASAR validation study. J Clin Oncol 2009;27(suppl):15s, abstr 4000.

29 Quasar Collaborative Group: Adjuvant chemotherapy versus observation in patients with colorectal cancer: a randomised study. Lancet 2007;370: 2020-2029.

30 Roth AD, Tejpar S, Yan P, et al.: Stage-specific prognostic value of molecular markers in colon cancer: Results of the translational study on the PETACC 3-EORTC 40993-SAKK 60-00 trial. J Clin Oncol 2009;27(suppl):15s, abstr 4002. 
31 Roth AD, Tejpar S, Delorenzi M, et al.: Prognostic role of KRAS and BRAF in stage II and III resected colon cancer: results of the translational study on the PETACC-3, EORTC 40993, SAKK 60-00 trial. J Clin Oncol 2010;28:466-474.

32 Popat S et al.: Systematic review of microsatellite instability and colorectal cancer prognosis. J Clin Oncol 2005;23:609-618.

33 Meropol NJ et al.: Use of a multigene prognostic assay for selection of adjuvant chemotherapy in patients with stage II colon cancer: Impact on qualityadjusted life expectancy and costs. ASCO GI 2011, abstr 491.

34 Ribic CM et al.: Tumor microsatellite-instability status as a predictor of benefit from fluorouracilbased adjuvant chemotherapy for colon cancer. N Engl J Med 2003;349:247-257.

35 Jover R et al.: The efficacy of adjuvant chemotherapy with 5-fluorouracil in colorectal cancer depends on the mismatch repair status. Eur J Cancer 2009;45:365-373.

36 Sargent DJ et al.: Confirmation of deficient mismatch repair (dMMR) as a predictive marker for lack of benefit from 5-FU based chemotherapy in stage II and III colon cancer (CC): A pooled molecular reanalysis of randomized chemotherapy trials. ASCO 2008, abstr 4008.

37 Tejpar S et al.: Microsatellite instability (MSI) in stage II and III colon cancer treated with 5FU-LV or 5FU-LV and irinotecan (PETACC 3-EORTC 40993-SAKK 60/00 trial). J Clin Oncol 2009;27 (suppl):15s, abstr 4001.

38 Pogue-Geile KL et al.: Use of a prognostic (prog) gene index and nodal status to identify a subset of stage II and III colon cancer patients (pts) who may not need oxaliplatin (ox)-containing adjuvant chemotherapy. J Clin Oncol 2010;28(suppl):15s, abstr 3516 .

39 Hohenberger W et al.: Standardized surgery for colonic cancer: complete mesocolic excision and central ligation - technical notes and outcome. Colorectal Dis 2009;11:354-364

40 West NP, Hohenberger W, et al.: Complete mesocolic excision with central vascular ligation produces an oncologically superior specimen compared with standard surgery for carcinoma of the colon. J Clin Oncol 2010;28:272-278.

41 West NP: Pathology grading of colon cancer surgical resection and its association with survival: a retrospective observational study. Lancet Oncol 2008; 9:857-865.

42 Koopman M et al.: Sequential versus combination chemotherapy with capecitabine, irinotecan, and oxaliplatin in advanced colorectal cancer (CAIRO): a phase III randomised controlled trial. Lancet 2007;370:135-142.

43 Seymour MT et al.: Different strategies of sequential and combination chemotherapy for patients with poor prognosis advanced colorectal cancer (MRC FOCUS): a randomised controlled trial. Lancet 2007;370:143-152.

44 Sargent DJ et al.: Pooled safety and efficacy analysis examining the effect of performance status on outcomes in nine first-line treatment trials using individual data from patients with metastatic colorectal cancer. J Clin Oncol 2009;27:1948-1955.

$\checkmark 45$ Souglakos J et al.: FOLFOXIRI (folinic acid, 5-fluorouracil, oxaliplatin and irinotecan) vs FOLFIRI (folinic acid, 5-fluorouracil and irinotecan) as first-line treatment in metastatic colorectal cancer (MCC): a multicentre randomised phase III trial from the Hellenic Oncology Research Group (HORG). Br J Cancer 2006;94:798-805.
46 Falcone A et al.; for the Gruppo Oncologico Nord Ovest: Phase III trial of infusional fluorouracil, leucovorin, oxaliplatin, and irinotecan (FOLFOXIRI) compared with infusional fluorouracil, leucovorin, and irinotecan (FOLFIRI) as first-line treatment for metastatic colorectal cancer. J Clin Oncol 2007; 25:1670-1676.

47 Masi G et al.: Bevacizumab with FOLFOXIRI (irinotecan, oxaliplatin, fluorouracil, and folinate) as first-line treatment for metastatic colorectal cancer: a phase 2 trial. Lancet Oncol 2010;11:845-852.

48 Folprecht $\mathrm{G}$ et al.: Tumour response and secondary resectability of colorectal liver metastases following neoadjuvant chemotherapy with cetuximab: the CELIM randomised phase 2 trial. Lancet Oncol 2010;11:38-47.

49 Van Cutsem E et al.: Cetuximab and chemotherapy as initial treatment for metastatic colorectal cancer. N Engl J Med 2009;360:1408-1417.

50 Bokemeyer C et al.: Fluorouracil, leucovorin, and oxaliplatin with and without cetuximab in the firstline treatment of metastatic colorectal cancer. J Clin Oncol 2009;27:663-671.

51 Maughan TS et al.: Oxaliplatin and fluoropyrimidine chemotherapy plus or minus cetuximab: The effect of infusional 5-FU or capecitabine on the outcomes of the MRC COIN trial in advanced colorectal cancer (ACRC). ASCO GI 2010, abstr 402.

52 Tveit $\mathrm{K}$ et al.: Randomized phase III study of 5-fluorouracil/folinate/oxaliplatin given continuously or intermittently with or without cetuximab, as first-line treatment of metastatic colorectal cancer: The NORDIC VII study (NCT00145314), by the Nordic Colorectal Cancer Biomodulation Group. ASCO GI 2011, abstr 365.

53 Kopetz S: Phase IB STUDY of the src inhibitor dasatinib with FOLFOX and cetuximab in refractory metastatic colorectal cancer. GI ESMO 2010, Ann Oncol 2010;21 (Suppl 6): vi11-vi19.

54 Hurwitz $\mathrm{H}$ et al.: Bevacizumab plus irinotecan, fluorouracil, and leucovorin for metastatic colorectal cancer. N Engl J Med 2004;350:2335-2342.

55 Fuchs CS, Marshall J, Mitchell E, et al.: Randomized, controlled trial of irinotecan plus infusional, bolus, or oral fluoropyrimidines in first-line treatment of metastatic colorectal cancer: Results from the BICC-C study. J Clin Oncol 2007;25:4779-4786.

56 Fuchs $\mathrm{C}$ et al.: Randomized, controlled trial of irinotecan plus infusional, bolus, or oral fluoropyrimidines in first-line treatment of metastatic colorectal cancer: updated results from the BICC-C study. J Clin Oncol 2008;26:689-690.

57 Hecht JR et al.: Interim results from PACCE: Irinotecan / bevacizumab +/- panitumumab as firstline treatment for metastatic colorectal cancer. ASCO GI 2008, abstr 279

58 Hecht JR et al.: An updated analysis of safety and efficacy of oxaliplatin (Ox)/bevacizumab (bev) +/panitumumab (pmab) for first-line treatment (tx) of metastatic colorectal cancer (mCRC) from a randomized, controlled trial (PACCE). ASCO GI 2008, abstr 273.

59 Punt CJ et al.: Randomized phase III study of capecitabine, oxaliplatin, and bevacizumab with or without cetuximab in advanced colorectal cancer (ACC), the CAIRO2 study of the Dutch Colorectal Cancer Group (DCCG). ASCO 2008, abstr LBA4011.

60 Schmoll H-J et al.: mFOLFOX6 + cediranib versus mFOLFOX6 + bevacizumab in previously untreated metastatic colorectal cancer: a randomized, double-blind, phase II/III study (HORIZON III). ESMO 2010, Ann Oncol 2010;21(suppl 8).
61 Saltz LB et al.: Bevacizumab in combination with oxaliplatin-based chemotherapy as first-line therapy in metastatic colorectal cancer: a randomized phase III study. J Clin Oncol 2008;26:2013-2019. Erratum in: J Clin Oncol 2008;26:3110.

62 Tebbutt NC et al.: International randomised phase III study of capecitabine (Cap), bevacizumab (Bev) and mitomycin $\mathrm{C}$ (MMC) in first line treatment of metastatic colorectal cancer (mCRC): final results of the AGITG MAX trial. ESMO 2009, abstr 6001.

63 Kabbinavar FF et al.: Combined analysis of efficacy: the addition of bevacizumab to fluorouracil/ leucovorin improves survival for patients with metastatic colorectal cancer. J Clin Oncol 2005;23: 3706-3712.

64 Eng $\mathrm{C}$ et al.: Impact on quality of life of adding cetuximab to irinotecan in patients who have failed prior oxaliplatin-based therapy: The EPIC trial. ASCO 2007, abstr 4003.

$65 \mathrm{Au} \mathrm{H}$ : Quality of life in patients with advanced colorectal cancer treated with cetuximab: Results of the NCIC CTG and AGITG CO.17 trial. ASCO 2007, abstr 4002.

66 Amado RG et al.: Wild-type KRAS is required for panitumumab efficacy in patients with metastatic colorectal cancer. J Clin Oncol 2008;26:1626-1634.

67 Peeters M et al.: Phase III study (20050181) of panitumumab (pmab) with FOLFIRI versus FOLFIRI alone as second-line treatment (tx) in patients (pts) with metastatic colorectal cancer (mCRC): Pooled safety results. J Clin Oncol 2008;26(suppl):abstr 4064

68 Adams R et al.: Intermittent versus continuous oxaliplatin-fluoropyrimidine (Ox-Fp) chemotherapy (CT) in first-line treatment of patients (pts) with advanced colorectal cancer (aCRC): Predictive factors $(\mathrm{PF})$, quality of life $(\mathrm{QL})$, and final efficacy results from the MRC COIN trial. ASCO 2010, abstr 3525.

69 Tabernero J et al.: Phase III study of first-line XELOX plus bevacizumab (BEV) for 6 cycles followed by XELOX plus BEV or single-agent (s/a) $\mathrm{BEV}$ as maintenance therapy in patients (pts) with metastatic colorectal cancer (mCRC): The MACRO trial. ASCO 2010, abstr 3501.

70 Murukesh N et al.: Biomarkers of angiogenesis and their role in the development of VEGF inhibitors. Br J Cancer 2010;102:8-18.

71 de Bazelaire $\mathrm{C}$ et al.: Magnetic resonance imagingmeasured blood flow change after antiangiogenic therapy with PTK787/ZK 222584 correlates with clinical outcome in metastatic renal cell carcinoma. Clin Cancer Res 2008;14:5548-5554.

72 Chun YS, Vauthey JN, et al.: Association of computed tomography morphologic criteria with pathologic response and survival in patients treated with bevacizumab for colorectal liver metastases. JAMA 2009;302:2338-2344.

73 Bokemeyer C et al.: Cetuximab with chemotherapy (CT) as first-line treatment for metastatic colorectal cancer (mCRC): Analysis of the CRYSTAL and OPUS studies according to KRAS and BRAF mutation status. ASCO 2010, abstr 3506.

74 Nordlinger B et al.: Combination of surgery and chemotherapy and the role of targeted agents in the treatment of patients with colorectal liver metastases: recommendations from an expert panel. Ann Oncol 2009;20:985-992.

75 Fong Y et al.: Clinical score for predicting recurrence after hepatic resection for metastatic colorectal cancer: analysis of 1001 consecutive cases. Ann Surg 1999;230:309-318, discussion 318-321. 
76 Nordlinger B, Sorbye H, Glimelius B et al.: Perioperative chemotherapy with FOLFOX4 and surgery versus surgery alone for resectable liver metastases from colorectal cancer (EORTC Intergroup trial 40983): a randomised controlled trial. Lancet 2008;371:1007-1016.

77 Portier G et al.: Multicenter randomized trial of adjuvant fluorouracil and folinic acid compared with surgery alone after resection of colorectal liver metastases: FFCD ACHBTH AURC 9002 trial. J Clin Oncol 2006;24:4976-4982.

78 Langer B et al.: Fluorouracil (FU) plus L-leucovorin $(\mathrm{L}-\mathrm{LV})$ versus observation after potentially curative resection of liver or lung metastases from colorectal cancer (CRC): results of the ENG (EORTC/NCIC CTG/GIVIO) randomized trial. Proc Am Soc Clin Oncol 2002;21:abstr 592.

79 Mitry E et al.: Adjuvant chemotherapy after potentially curative resection of metastases from colorectal cancer: a pooled analysis of two randomized trials. J Clin Oncol 2008;26:4906-4911.

80 Van Cutsem E et al.: Cetuximab plus FOLFIRI in the treatment of metastatic colorectal cancer (mCRC): The influence of KRAS and BRAF biomarkers on outcome: Updated data from the CRYSTAL trial. ASCO GI 2010, abstr 281.

81 Cassidy J et al.: Surgery with curative intent in patients treated with first-line chemotherapy (CT) + bevacizumab (BEV) for metastatic colorectal cancer (mCRC): First BEAT and NO16966. ASCO 2008, abstr 4022.

82 Ribero D et al.: Bevacizumab improves pathologic response and protects against hepatic injury in patients treated with oxaliplatin-based chemotherapy for colorectal liver metastases. Cancer 2007;110: 2761-2767.

83 Kishi Y et al.: Extended preoperative chemotherapy does not improve pathologic response and increases postoperative liver insufficiency after hepatic resection for colorectal liver metastases. Ann Surg Oncol 2010;17:2870-2876.

84 Grünberger B et al.: Bevacizumab, capecitabine, and oxaliplatin as neoadjuvant therapy for patients with potentially curable metastatic colorectal cancer. J Clin Oncol 2008;26:1830-1835.

85 Grünberger T et al.: Progression-free survival in a phase II study of perioperative bevacizumab plus XELOX in patients with potentially curable metastatic colorectal cancer. ASCO 2008, abstr 4073.

86 Masi G et al.: Long-term outcome of initially unresectable metastatic colorectal cancer patients treated with 5-fluorouracil/leucovorin, oxaliplatin, and irinotecan (FOLFOXIRI) followed by radical surgery of metastases. Ann Surg 2009;249:420-425.

87 Garufi C et al.: POCHER (preoperative chemotherapy for hepatic resection) with cetuximab (Cmab) plus CPT-11/5-fluorouracil (5-FU)/ leucovorin(FA)/oxaliplatin (L-OHP) (CPT-11FFL) in unresectable colorectal liver metastases (CLM). ASCO 2009, abstr e15020.

88 Ychou M et al.: Preliminary results of a multicentre phase II trial evaluating cetuximab in combination with FOLFIRINOX (LV5FU + irinotecan + oxaliplatin) as first line treatment of metastatic colorectal cancer (mCRC) patients. ASCO GI 2009, abstr 450.

89 Folprecht $\mathrm{G}$ et al.: Cetuximab and FOLFOXIRI: Dose-escalation study in previously untreated patients with metastatic colorectal cancer. ASCO GI 2010, abstr 480.

90 Berry D et al.: Personalized Medicine: How redesigning a clinical trial can speed drug development. Wall Street Journal, October 2010.
91 Gerard JP, Conroy T, Bonnetain F, et al.: Preoperative radiotherapy with or without concurrent fluorouracil and leucovorin in T3-4 rectal cancers: results of FFCD 9203. J Clin Oncol 2006;24:46204625

92 Bosset JF; for the EORTC Radiotherapy Group Trial 22921: Chemotherapy with preoperative radiotherapy in rectal cancer. N Engl J Med 2006; 355:1114-1123.

93 Sauer R et al.: Preoperative vs. postoperative chemoradiotherapy for rectal cancer. New Engl J Med 2004;351:1731-1740.

94 Collette L et al.: Patients with curative resection of cT3-4 rectal cancer after preoperative radiotherapy or radiochemotherapy: does anybody benefit from adjuvant fluorouracil-based chemotherapy? A trial of the European Organisation for Research and Treatment of Cancer Radiation Oncology Group. J Clin Oncol 2007;25:43794386.

95 Collette L et al.: Correspondence. J Clin Oncol 2008;26:508-509.

96 Cionini L et al.: Final results of a randomized trial on adjuvant chemotherapy after preoperative chemoradiation in rectal cancer. Radiother Oncol 2010;96(suppl 1):abstr 299.

97 Maas M et al.: Long-term outcome in patients with a pathological complete response after chemoradiation for rectal cancer: a pooled analysis of individual patient data. Lancet Oncol 2010; 11:835-844.

98 Dewdney A et al.: EXPERT-C: A randomized phase II European multicenter trial of neoadjuvant chemotherapy (capecitabine/oxaliplatin) and chemoradiation (CRT) with or without cetuximab followed by total mesorectal excision (TME) in patients with MRI-defined high-risk rectal cancer. ASCO GI 2011, abstr 360.

99 Rödel C et al.: Multicenter phase II trial of chemoradiation with oxaliplatin for rectal cancer. J Clin Oncol 2007;25:110-117.

100 Sebag-Montefiori DJ et al.: Three-year survival results of CORE (capecitabine, oxaliplatin, radiotherapy, and excision) study after postoperative chemotherapy in patients with locally advanced rectal adenocarcinoma. abstr 447

101 Fernández-Martos C et al.: Phase II, randomized study of concomitant chemoradiotherapy followed by surgery and adjuvant capecitabine plus oxaliplatin (CAPOX) compared with induction CAPOX followed by concomitant chemoradiotherapy and surgery in magnetic resonance imaging-defined, locally advanced rectal cancer: Grupo Cancer de Recto 3 study. J Clin Oncol 2010;28:859-865.

102 Schrag D et al.: Neoadjuvant FOLFOX-bev, without radiation, for locally advanced rectal cancer. ASCO 2010, abstr 3511.

103 Chau I et al.: Neoadjuvant capecitabine and oxaliplatin followed by synchronous chemoradiation and total mesorectal excision in magnetic resonance imaging-defined poor-risk rectal cancer. J Clin Oncol 2006;24:668-674.

104 Chua YJ et al.: Neoadjuvant capecitabine and oxaliplatin before chemoradiotherapy and total mesorectal excision in MRI-defined poor-risk rectal cancer: a phase 2 trial. Lancet Oncol 2010; 11:241-248.

105 Kundel Y et al.: Is local excision after complete pathological response to neoadjuvant chemoradiation for rectal cancer an acceptable treatment option? Dis Colon Rectum 2010;53:1624-1631.
106 Habr-Gama A et al.: Complete clinical response after neoadjuvant chemoradiation therapy for distal rectal cancer: characterization of clinical and endoscopic findings for standardization. Dis Colon Rectum 2010;53:1692-1698.

107 Hiotis SP et al.: Assessing the predictive value of clinical complete response to neoadjuvant therapy for rectal cancer: an analysis of 488 patients. J Am Coll Surg 2002;194:131-135, discussion 135136.

108 Habr-Gama A et al.: Operative versus nonoperative treatment for stage 0 distal rectal cancer following chemoradiation therapy: long-term results. Ann Surg 2004;240:711-717, discussion 717-718.

109 Habr-Gama A et al.: Assessment and management of the complete clinical response of rectal cancer to chemoradiotherapy. Colorectal Dis 2006;8(suppl 3):21-24.

110 Yeo SG et al.: Pathologic complete response of primary tumor following preoperative chemoradiotherapy for locally advanced rectal cancer: long-term outcomes and prognostic significance of pathologic nodal status (KROG 09-01). Ann Surg 2010;252:998-1004.

111 Liersch T et al.: Molekulare Marker zur Responseprädiktion beim lokal fortgeschrittenen Rektumkarzinom. Kommt die Individualisierung der Therapie? Der Onkologe 2010;16:779-788.

112 Sprenger T et al.: Stage II/III rectal cancer with intermediate response to preoperative radiochemotherapy: do we have indications for individual risk stratification? World J Surg Oncol 2010;8:27.

113 Sprenger T et al.: Preoperative chemoradiotherapy does not necessarily reduce lymph node retrieval in rectal cancer specimens - results from a prospective evaluation with extensive pathological work-up. J Gastrointest Surg 2010;14:96-103.

114 Gaedcke J et al.: KRAS and BRAF mutations in patients with rectal cancer treated with preoperative chemoradiotherapy. Radiother Oncol 2010; 94:76-81.

115 Gaedcke J et al.: Mutated KRAS results in overexpression of DUSP4, a MAP-kinase phosphatase, and SMYD3, a histone methyltransferase, in rectal carcinomas. Genes Chromosomes Cancer 2010;49:1024-1034.

116 Opitz L et al.: Impact of RNA degradation on gene expression profiling. BMC Med Genomics 2010;3:36.

117 Conradi LC et al.: Thymidylate synthase as a prognostic biomarker for locally advanced rectal cancer after multimodal treatment. Ann Surg Oncol 2011; DOI: 10.1245/S10434-011-1605-4

-118 Sprenger T et al.: Failure of down-regulation of Survivin following neoadjuvant radiochemotherapy in rectal cancer is associated with distant metastases and shortened survival. Clin Cancer Res 2011;17:1623-1631.

119 Bujko K et al.: Long-term results of a randomized trial comparing preoperative short-course radiotherapy with preoperative conventionally fractionated chemoradiation for rectal cancer. $\mathrm{Br} \mathrm{J}$ Surg 2006;93:1215-1223.

120 Fietkau R et al.: Letter to the editor. Br J Cancer 2007.

121 Lange MM et al.: Risk factors for sexual dysfunction after rectal cancer treatment. Eur J Cancer 2009;45:1578-1588 
122 Ngan S et al.: A randomized trial comparing local recurrence (LR) rates between short-course (SC) and long-course (LC) preoperative radiotherapy (RT) for clinical T3 rectal cancer: An intergroup trial (TROG, AGITG, CSSANZ, RACS). ASCO 2010, abstr 3509.

123 Pietsch AP et al.: Effect of neoadjuvant chemoradiation on postoperative fecal continence and anal sphincter function in rectal cancer patients. Int J Colorectal Dis 2007;22:1311-1317.

124 Chowdhury FU et al.: [18F]FDG PET/CT imaging of colorectal cancer: a pictorial review. Postgrad Med J 2010;86:174-182.

125 Hillner BE et al.: The impact of positron emission tomography (PET) on expected management during cancer treatment: findings of the National Oncologic PET Registry. Cancer 2009;115:410 418. Erratum in: Cancer 2009;115:1133.

126 Weber WA et al.: Monitoring cancer treatment with PET/CT: does it make a difference? J Nucl Med 2007;48(suppl 1):36S-44S.

127 Wahl RL et al.: From RECIST to PERCIST: Evolving considerations for PET response criteria in solid tumors. J Nucl Med 2009;50(suppl 1): 122S-150S.

128 Joosten $\mathrm{J}$ et al.: Cryosurgery and radiofrequency ablation for unresectable colorectal liver metastases. Eur J Surg Oncol 2005;31:1152-1159.

129 Kang YK et al.: AVAGAST: A randomized, double-blind, placebo-controlled, phase III study of first-line capecitabine and cisplatin plus bevacizumab or placebo in patients with advanced gastric cancer (AGC). ASCO 2010, abstr LBA4007.

130 Enzinger PC et al.: CALGB 80403/ECOG 1206: A randomized phase II study of three standard chemotherapy regimens (ECF, IC, FOLFOX) plus cetuximab in metastatic esophageal and GE junction cancer. ASCO 2010, abstr 4006.

131 Bang Y-J et al.: Trastuzumab in combination with chemotherapy versus chemotherapy alone for treatment of HER2-positive advanced gastric or gastro-oesophageal junction cancer (ToGA): a phase 3, open-label, randomised controlled trial Lancet 2010;376:687-697.

132 European Medicines Agency vom 28.1.2010.

133 S3-Leitlinie Magenkarzinom, vorgestellt auf dem Deutschen Krebskongress, Berlin, 24. Februar 2010.

134 Bang Y et al.: Pathological features of advanced gastric cancer (GC): Relationship to human epidermal growth factor receptor 2 (HER2) positivity in the global screening programme of the ToGA trial. J Clin Oncol 2009;27(suppl):15s, abstr 4556.

135 Rüschoff J et al.: HER2 diagnostics in gastric cancer - Guideline validation and development of standardized immunohistochemical testing. Virchows Arch 2010;457:299-307.
136 Schuhmacher C et al.: Neoadjuvant chemotherapy compared with surgery alone for locally advanced cancer of the stomach and cardia: European Organisation for Research and Treatment of Cancer randomized trial 40954. J Clin Oncol 2010;28:5210-5218.

137 Cunningham D et al.: Perioperative chemotherapy versus surgery alone for resectable gastroesophageal cancer. N Engl J Med 2006;355:11-20.

138 Moore MJ et al.: Erlotinib plus gemcitabine compared with gemcitabine alone in patients with advanced pancreatic cancer: a phase III trial of the National Cancer Institute of Canada Clinical Trials Group. J Clin Oncol 2007;25:1960-1966.

139 Van Cutsem E et al.: Rash as a marker for the efficacy of gemcitabine plus erlotinib-based therapy in pancreatic cancer: Results from the AViTA study. ASCO GI 2009, abstr 117.

140 Boeck SH et al.: Gemcitabine plus erlotinib (GE) followed by capecitabine $(\mathrm{C})$ versus capecitabine plus erlotinib (CE) followed by gemcitabine $(\mathrm{G})$ in advanced pancreatic cancer (APC): A randomized, cross-over phase III trial of the Arbeitsgemeinschaft Internistische Onkologie (AIO). ASCO 2010, abstr LBA4011.

141 Conroy $\mathrm{T}$ et al.: Randomized phase III trial comparing FOLFIRINOX (F: 5FU/leucovorin [LV], irinotecan $[\mathrm{I}]$, and oxaliplatin $[\mathrm{O}]$ ) versus gemcitabine $(\mathrm{G})$ as first-line treatment for metastatic pancreatic adenocarcinoma (MPA): Preplanned interim analysis results of the PRODIGE 4/ACCORD 11 trial. ASCO 2010, abstr 4010.

142 Pelzer $U$ et al.: A randomized trial in patients with gemcitabine refractory pancreatic cancer. Final results of the CONKO 003 study. ASCO 2008, abstr 4508.

143 Lin SM et al.: Randomised controlled trial comparing percutaneous radiofrequency thermal ablation, percutaneous ethanol injection, and percutaneous acetic acid injection to treat hepatocellular carcinoma of $3 \mathrm{~cm}$ or less. Gut 2005;54:1151-1156.

144 Shiina S et al.: A randomized controlled trial of radiofrequency ablation with ethanol injection for small hepatocellular carcinoma. Gastroenterology 2005;129:122-130.

145 Llovet JM et al.: Hepatocellular carcinoma. Lancet 2003;362:1907-1917.

146 Salem R et al.: Radioembolization results in longer time-to-progression and reduced toxicity compared with chemoembolization in patients with hepatocellular carcinoma. Gastroenterology 2011;140:497-507.

147 Zender L, Kubicka S: Molecular pathogenesis and targeted therapy of hepatocellular carcinoma. Onkologie 2008;31:550-555.

148 Llovet JM et al; SHARP Investigators Study Group: Sorafenib in advanced hepatocellular carcinoma. N Engl J Med 2008;359:378-390.
149 Cheng AL et al.: Efficacy and safety of sorafenib in patients in the Asia-Pacific region with advanced hepatocellular carcinoma: a phase III randomised, double-blind, placebo-controlled trial. Lancet Oncol 2009;10:25-34.

150 Thomas MB et al.: Phase II trial of the combination of bevacizumab and erlotinib in patients who have advanced hepatocellular carcinoma. J Clin Oncol 2009;27:843-850.

151 Abou-Alfa GK et al.: Final results from a phase II (PhII), randomized, double-blind study of sorafenib plus doxorubicin $(\mathrm{S}+\mathrm{D})$ versus placebo plus doxorubicin $(\mathrm{P}+\mathrm{D})$ in patients (pts) with advanced hepatocellular carcinoma (AHCC). ASCO GI 2008, abstr 128.

152 Abou-Alfa GK et al.: Is sorafenib (S) safe and effective in patients (pts) with hepatocellular carcinoma (HCC) and Child-Pugh B (CPB) cirrhosis? ASCO 2008, abstr 4518

153 Gebski V et al.: Survival benefits from neoadjuvant chemoradiotherapy or chemotherapy in oesophageal carcinoma: a meta-analysis. Lancet Oncol 2007;8:226-234.

154 Urschel JD et al.: A meta-analysis of randomized controlled trials that compared neoadjuvant chemoradiation and surgery to surgery alone for resectable esophageal cancer. Am J Surg 2003; 185:538-543.

155 Gaast AV et al.: Effect of preoperative concurrent chemoradiotherapy on survival of patients with resectable esophageal or esophagogastric junction cancer: Results from a multicenter randomized phase III study. ASCO 2010, abstr 4004.

156 Mariette C et al.: Surgery alone vs. chemoradiotherapy followed by surgery for localized esophageal cancer: analysis of a randomized controlled phase III trial. FFCD 9901. ASCO 2010, abstr 4005.

157 Stahl M et al.: Chemoradiation with and without surgery in patients with locally advanced squamous cell carcinoma of the esophagus. J Clin Oncol 2005;23:2310-2317.

158 Bedenne L et al.: Chemoradiation followed by surgery compared with chemoradiation alone in squamous cancer of the esophagus: FFCD 9102. J Clin Oncol 2007;25:1160-1168.

159 Stahl M et al.: Phase III comparison of preoperative chemotherapy compared with chemoradiotherapy in patients with locally advanced adenocarcinoma of the esophagogastric junction. J Clin Oncol 2009;27:851-856

160 Schauer M et al.: Microarray-based response prediction in esophageal adenocarcinoma. Clin Cancer Res 2010;16:330-337. 